\author{
TO THE
}

\title{
OFFICE OF MANAGEMENT AND BUDGET
}

\author{
ON THE
}

IMPLEMENTATION OF OMB CIRCULAR A-119

AND P.L. 104-113

\author{
COVERING THE PERIOD:
}

OCTOBER 1, 1998 THROUGH SEPTEMBER 30, 1999

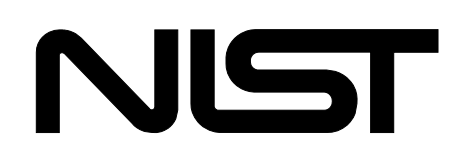

United States Department of Commerce

National Ins titute of Standards and Technology

Technology Services

Office of Standards Services

Gaithersburg, Maryland 20899-2100 


\section{ANNUAL REPORT TO THE OFFICE OF MANAGEMENT AND BUDGET (OMB) ON THE \\ IMPLEMENTATION OF OMB CIRCULAR A-119 AND P.L. 104-113 \\ Table of Contents}

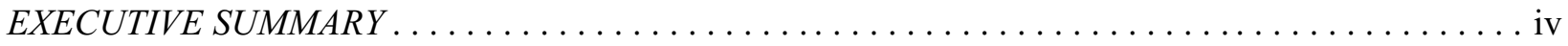

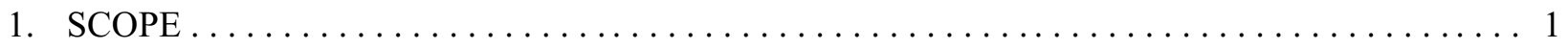

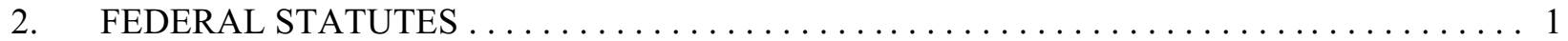

$2.1 \quad$ National Technology Transfer and Advancement Act (NTTAA) $\ldots \ldots \ldots \ldots \ldots \ldots \ldots \ldots$

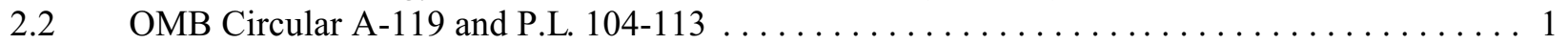

2.2.1 Agencies use of voluntary consensus standards versus government-unique standards . . . . . 1

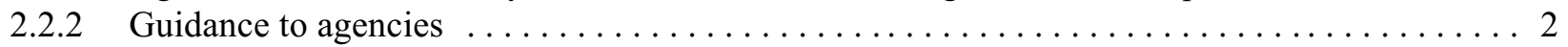

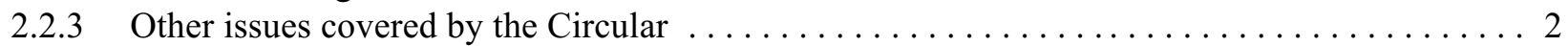

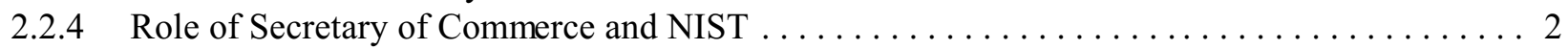

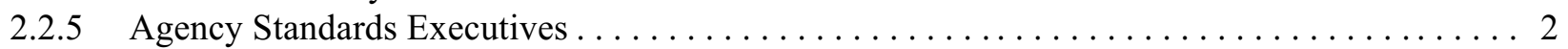

3. INTERAGENCY COMMITTEE ON STANDARDS POLICY (ICSP) $\ldots \ldots \ldots \ldots \ldots \ldots \ldots 2$

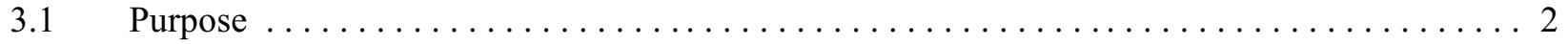

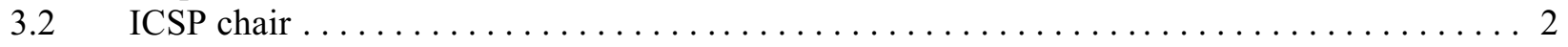

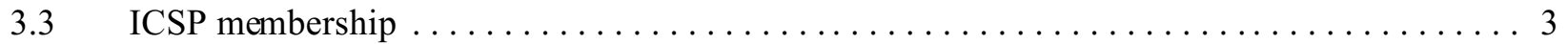

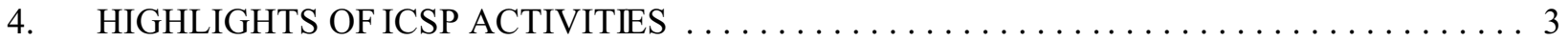

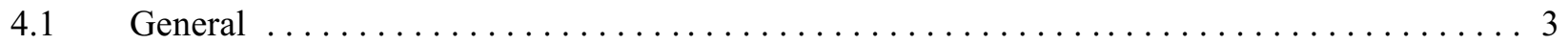

4.2 Interaction with private sector standards organizations $\ldots \ldots \ldots \ldots \ldots \ldots \ldots \ldots \ldots$

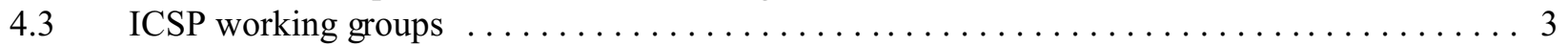

5. HIGHLIGHTS OF FEDERAL AGENCY ACTIVITIES $\ldots \ldots \ldots \ldots \ldots \ldots \ldots \ldots \ldots \ldots$

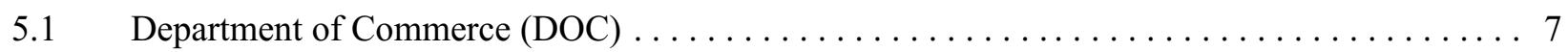

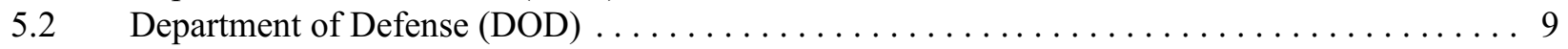

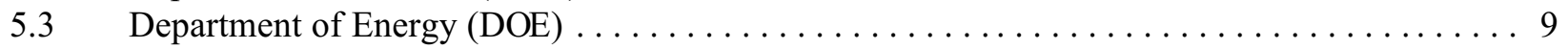

5.4 Department of Health and Human Services (HHS),

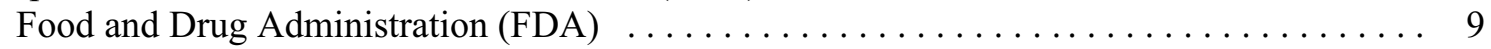

5.5 Consumer Product Safety Commission (CPSC) $\ldots \ldots \ldots \ldots \ldots \ldots \ldots \ldots \ldots \ldots \ldots$

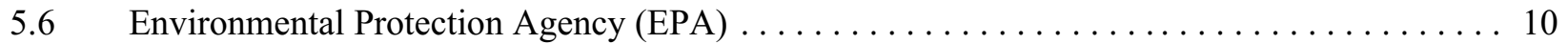

$5.7 \quad$ Federal Communications Commission (FCC) $\ldots \ldots \ldots \ldots \ldots \ldots \ldots \ldots \ldots \ldots \ldots \ldots$

$5.8 \quad$ Federal Emergency Management Agency (FEMA) $\ldots \ldots \ldots \ldots \ldots \ldots \ldots \ldots \ldots \ldots \ldots$

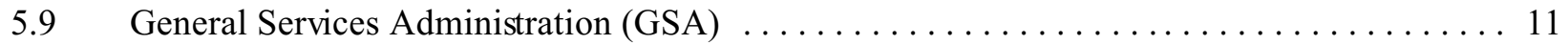

5.10 National Aeronautics and Space Adminis tration (NASA) $\ldots \ldots \ldots \ldots \ldots \ldots \ldots \ldots \ldots \ldots$

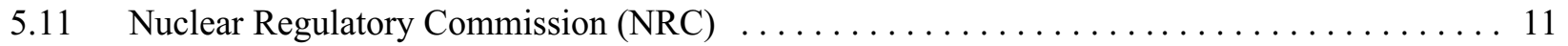

6. AGENCY USE OF GOVERNMENT-UNIQUE STANDARDS IN LIEU OF

VOLUNTARY CONSENSUS STANDARDS $\ldots \ldots \ldots \ldots \ldots \ldots \ldots \ldots \ldots \ldots \ldots \ldots$

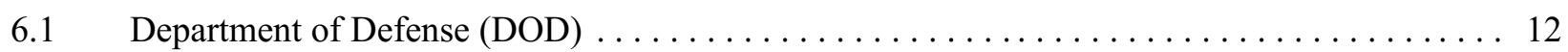

6.2 National Aeronautics and Space Adminis tration (NASA) $\ldots \ldots \ldots \ldots \ldots \ldots \ldots \ldots \ldots \ldots$

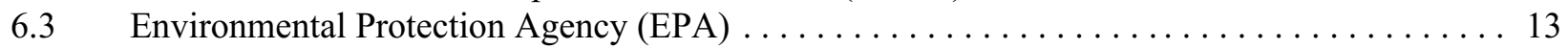

$6.4 \quad$ Federal Emergency Management Agency (FEMA) $\ldots \ldots \ldots \ldots \ldots \ldots \ldots \ldots \ldots \ldots \ldots$ 


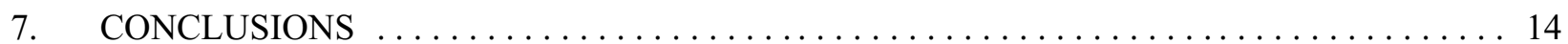

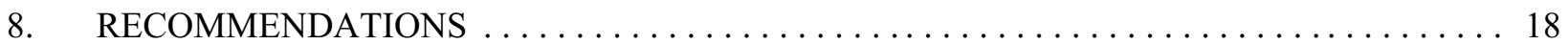

APPENDIX A: CABINET DEPARTMENT REPORTS $\ldots \ldots \ldots \ldots \ldots \ldots \ldots \ldots \ldots \ldots \ldots \ldots \ldots$ A-1

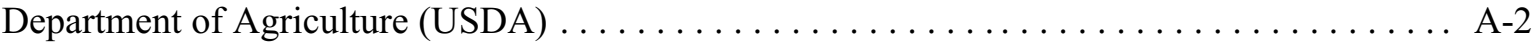

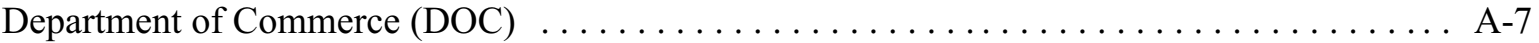

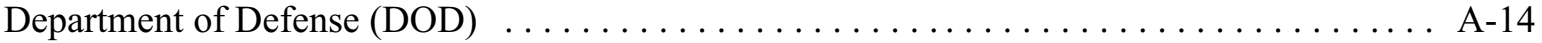

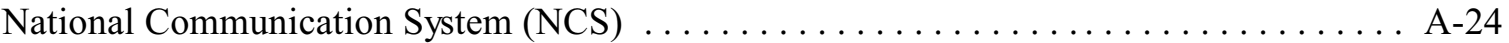

Department of Education (DOED) $\ldots \ldots \ldots \ldots \ldots \ldots \ldots \ldots \ldots \ldots \ldots \ldots \ldots \ldots \ldots \ldots \ldots \ldots$

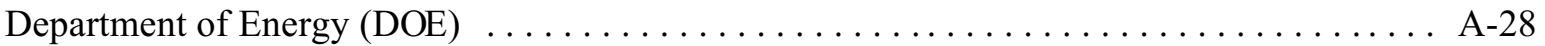

Department of Health and Human Services (HHS)

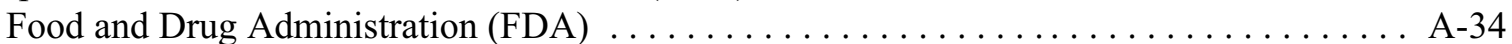

Department of Housing and Urban Development (HUD) $\ldots \ldots \ldots \ldots \ldots \ldots \ldots \ldots$ A $\ldots \ldots \ldots$

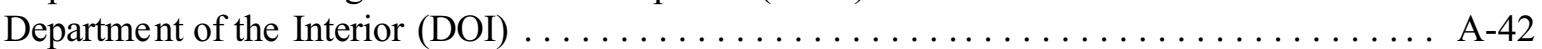

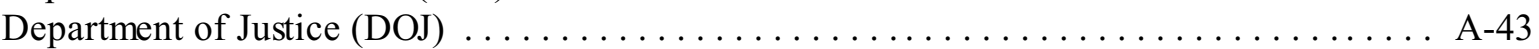

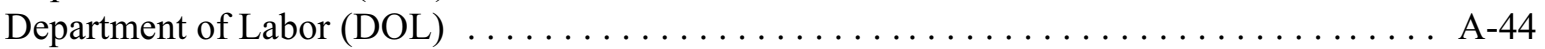

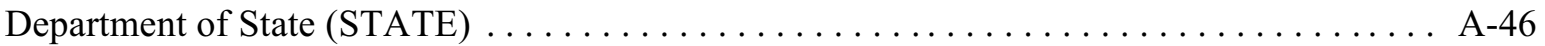

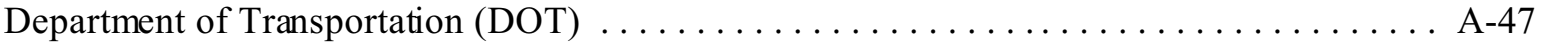

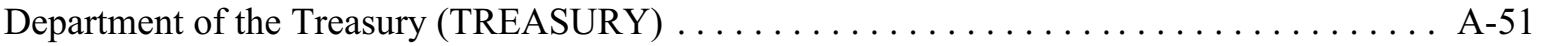

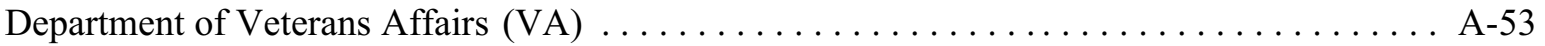

APPENDIX B: OTHER AGENCY AND COMMISSION REPORTS $\ldots \ldots \ldots \ldots \ldots \ldots \ldots \ldots$ B-1

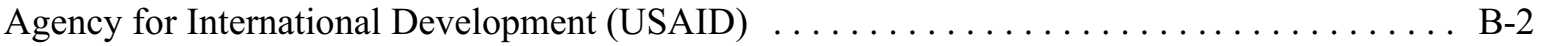

Consumer Product Safety Commission (CPSC) $\ldots \ldots \ldots \ldots \ldots \ldots \ldots \ldots \ldots \ldots \ldots \ldots \ldots \ldots \ldots$

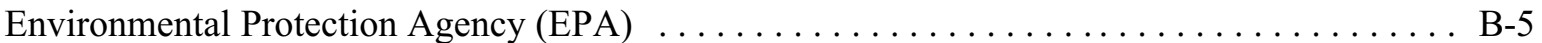

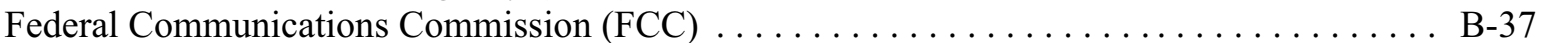

Federal Emergency Management Agency (FEMA) . . . . . . . . . . . . . . . . . . B-39

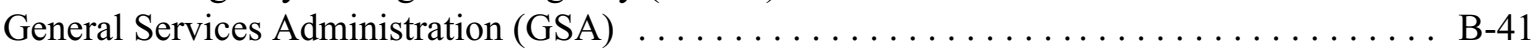

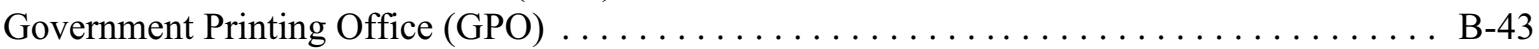

National Aeronautics and Space Adminis tration (NASA) $\ldots \ldots \ldots \ldots \ldots \ldots \ldots \ldots \ldots \ldots \ldots$

National Archives and Records Administration (NARA) $\ldots \ldots \ldots \ldots \ldots \ldots \ldots \ldots \ldots \ldots$. $\ldots \ldots$

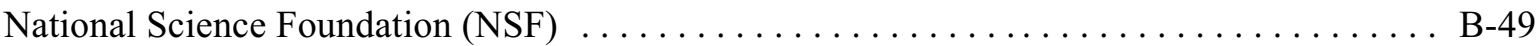

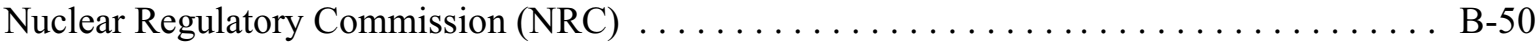

APPENDIX C: CHARTER OF THE INTERAGENCY COMMITTEE ON STANDARDS

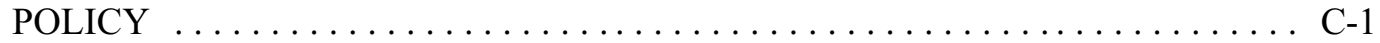

APPENDIX D: MEMBERSHIP OF THE INTERAGENCY COMMITTEE ON STANDARDS

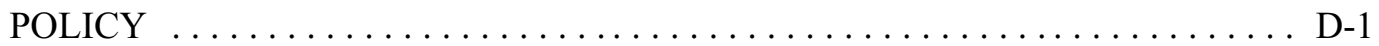

APPENDIX E: LIST OF NIST PUBLICATIONS RELATED TO P.L. $104-113 \ldots \ldots \ldots \ldots \ldots \ldots$ E-1 


\section{EXECUTIVE SUMMARY}

Office of Management and Budget (OMB) Circular A-119 1 , Federal Participation in the Development and Use of Voluntary Consensus Standards and in Conformity Assessment Activities, requires the National Institute of Standards and Technology (NIST) to report annually to OMB on the progress that Federal agencies have made toward using voluntary standards rather than agency-unique standards, as well as on NIST efforts in coordinating agencies use of voluntary standards and participation in standardization activities, and to provide summaries of the status of individual agency use of standards and participation and interaction with private sector voluntary standards bodies.

Public Law (P.L.) 104-113, the National Technology Transfer and Advancement Act (NTTAA), and OMB Circular A-119 require Federal agencies to use voluntary standards to the extent practicable, and to report when they have developed agency-specific standards in lieu of voluntary consensus standards. The present report addresses the development of agency-unique standards, the extent and nature of participation by Federal agencies in the development of voluntary standards, their use of voluntary standards, and an evaluation of the effectiveness of the policies promulgated in the Circular.

This report covers fiscal year (FY) 1999, from October 1, 1998, through September 30, 1999.

NIST relies on the Interagency Committee on Standards Policy (ICSP) as the primary means of fulfilling NIST s responsibilities for coordinating Federal standards-related activities. This report describes NIST s coordination activities with special emphasis on implementing the NTTAA. It also includes information on the activities of the ICSP and its working groups, an overview of standards policy coordination, individual agencies reports on NTTAA implementation efforts, and future courses of action.

On September 28 1999, NIST, who chairs the ICSP, requested that each agency provide information on the status of its implementation of both the OMB Circular A-119 and the NTTAA. The Circular and the NTTAA require that each agency collect specific information regarding the status of its implementation activities: agency use of government-unique standards in lieu of voluntary consensus standards, the use of voluntary consensus standards, the number of voluntary standards substituted for government-unique standards, and the number of individual agency participants in voluntary standards bodies. This information is summarized by agency in Table 1 on page 15 of the report. Totals for all Federal agencies are shown in the following table:

${ }^{1}$ OMB issued a revised Circular A-119 on February 19, 1998. 


\begin{tabular}{|c|c|c|c|c|c|c|}
\hline \multicolumn{7}{|c|}{$\begin{array}{l}\text { Fiscal Year (FY) } 1999 \text { Statistics on Federal Agencies Participation in Development of } \\
\text { and Adoption of Voluntary Consensus Standards }{ }^{1}\end{array}$} \\
\hline \multicolumn{2}{|c|}{$\begin{array}{l}\text { Number of } \\
\text { Voluntary } \\
\text { Consensus } \\
\text { Standards Bodies in } \\
\text { which Agencies } \\
\text { Reported } \\
\text { Participation }\end{array}$} & \multicolumn{2}{|c|}{$\begin{array}{l}\text { Number of Agencies } \\
\text { Employees } \\
\text { Participating in } \\
\text { Voluntary Consensus } \\
\text { Standards Bodies }\end{array}$} & \multirow[t]{2}{*}{$\begin{array}{l}\text { Number of } \\
\text { additional } \\
\text { Voluntary } \\
\text { Consensus } \\
\text { Standards } \\
\text { used in } \\
\text { FY } 1999\end{array}$} & \multirow{2}{*}{$\begin{array}{l}\text { Number of } \\
\text { Voluntary } \\
\text { Consensus } \\
\text { Standards } \\
\text { substituted in } \\
\text { FY } 1999 \text { for } \\
\text { Government- } \\
\text { Unique } \\
\text { Standards }\end{array}$} & \multirow{2}{*}{$\begin{array}{l}\text { Number of } \\
\text { Government- } \\
\text { Unique } \\
\text { Standards } \\
\text { Used in Lieu } \\
\text { of Voluntary } \\
\text { Consensus } \\
\text { Standards in } \\
\text { FY } 1999\end{array}$} \\
\hline $\begin{array}{c}\text { FY } \\
1999\end{array}$ & $\begin{array}{l}\text { Change } \\
\text { from } \\
\text { FY } 1998\end{array}$ & FY 1999 & $\begin{array}{l}\text { Change } \\
\text { from } \\
\text { FY } 1998\end{array}$ & & & \\
\hline 823 & -41 & 2,832 & -378 & 2,669 & 542 & 88 \\
\hline
\end{tabular}

1 Not reflected in the chart are the total number of voluntary consensus standards adopted by Federal agencies and those in the process of being adopted. For example, DOD reported that their total number of adopted voluntary consensus standards was 8,618 for FY 1999, DOE reported that their total was 1,306 for FY 1999.

In addition to adoption of voluntary consensus standards, Federal regulatory agencies, such as EPA, have developed procedures for alerting the public about proposed regulations. The EPA has developed wording for inclusion in its notices of proposed rulemaking to draw attention to Federal opportunities for using voluntary consensus standards. Such notices allow standards developing organizations (SDOs) the opportunity to alert Federal agencies of standards and standards activities of potential interest. Federal procurement agencies, such as DOD and NASA, have developed procedures for alerting proposers about opportunities for use of voluntary standards on procurement actions.

Agencies have also instituted procedures for identifying existing standards when proposing new regulations or in procurement activities. During FY 1999, DOD continued to move Mil-Specs into the private sector. Some agencies, notably the HHS, have convened agency-wide workshops with other agencies, and invited key stakeholders to educate their standards personnel. Finally, private sector SDOs instituted briefing sessions with Federal agencies to address the issue of references to out-of-date standards in regulations.

The decline in agency participation in standards committee activities first noted in the FYs 1997 and 1998 reports has continued. (See charts 2 and 3 on page 17 of the report). In the recommendations section of this report, a number of possible reasons for this decline are listed. 
Included in Appendices A and B of this report are the reports sent to NIST from the 14 Cabinet Departments and 12 other agencies and commissions. They are provided, with minimal or no editing and reformatting. Copies of the ICSP Charter, the FY 1999 ICSP membership list, and a list of NIST publications related to P.L. 104-113 are provided in Appendices C, D, and E, respectively. 


\section{Annual Report to the Office of Management and Budget on Implementation of OMB Circular A-119}

\section{SCOPE}

This report describes the progress that Federal agencies have made in the use of voluntary consensus standards and participation in standardization activities. It also highlights some examples of agencies interactions with private-sector voluntary consensus standards bodies, agencies use of government-unique standards, and the activities of the Interagency Committee on Standards Policy (ICSP). It discusses National Institute of Standards and Technology s (NIST s) efforts in coordinating Federal agencies standards-related activities, including interactions with key private sector organizations. This report covers fiscal year (FY) 1999 from October 1, 1998, through September 30, 1999.

Appendices A and B provide copies of the reports that NIST received from Cabinet Departments, other agencies, and commissions. Appendices C, D, and E, respectively, provide copies of the ICSP Charter, ICSP membership, and a list of NIST publications related to Public Law (P.L.) 104-113.

\section{FEDERAL STATUTES}

2.1 National Technology Transfer and Advancement Act (NTTAA) - P.L. 104-113, the NTTAA of 1995, codified ex isting policies of the Office of Management and Budget (OMB) Circular A-119, established reporting requirements, and authorized NIST to coordinate standards conformity assessment activities of Federal agencies, and with the private sector.

2.2 OMB Circular A-119 and P.L. 104-113 - On February 19, 1998, OMB is sued the newlyrevised Circular A-119, Federal Participation in the Development and Use of Voluntary Consensus Standards and in Conformity Assessment Activities, to replace the Circular dated October 20, 1993. The purpose was to make the terminology of the Circular consistent with P.L. 104-113, to issue guidance to agencies on making their reports to OMB, to direct the Secretary of Commerce to issue policy guidance for conformity assessment, and to make changes for clarity.

\subsubsection{Agencies use of voluntary consensus standards versus government-unique} standards - Consistent with section 12(d) of the NTTAA, the Circular directs agencies to use voluntary consensus standards in lieu of government-unique standards except where inconsistent with law or otherwise impractical. It also provides guidance for agencies participating in voluntary consensus standards bodies and describes procedures for satisfying the reporting requirements of the NTTAA. The policies in the Circular are intended to minimize reliance by agencies on government-unique standards. These policies do not create the basis for 
discrimination in agency procurement or regulatory activities among standards developed in the private sector, whether or not they are developed by voluntary consensus standards bodies.

2.2.2 Guidance to agencies - Consistent with section 12(b) of the NTTAA, the Circular directs the Secretary of Commerce to issue guidance to agencies on ways to coordinate their conformity assessment activities. The goal of this guidance is to reduce unnecessary duplication and complexity in Federal conformity assessment activities. Draft guidance was prepared and circulated within the ICSP for comment, with particular attention paid to meeting regulatory agency concerns. The draft guidance will be published in 2000 for additional public comment.

2.2.3 Other issues covered by the Circular - The Circular also describes policies regarding Federal use of standards and Federal participation in voluntary consensus standards bodies. It covers the use of standards in regulations and provides procedures for managing and reporting on agency use of standards in procurement and regulations. It also covers reporting requirements including how an agency is to report on its development and use of standards. The Circular also specifies the responsibilities of the Secretary of Commerce and NIST, agency heads, and Agency Standards Executives.

2.2.4 Role of Secretary of Commerce and NIST - The NTTAA and the Circular assign several policy coordination and implementation tasks to the Secretary of Commerce and specifically to NIST. NIST is responsible for chairing the ICSP and submitting an annual report to $\mathrm{OMB}$ on agency implementation activities. Compiling this report requires the full cooperation and assistance of all departments and agencies.

2.2.5 Agency Standards Executives - The revised Circular clarifies the role of Agency Standards Executives, particularly regarding agency-wide compliance with the NTTAA s legal requirements. The Standards Executive is responsible for coordinating agency-wide standardsrelated activities, coordinating the implementation of the Circular, and serving on the ICSP.

\section{INTERAGENCY COMMITTEE ON STANDARDS POLICY (ICSP)}

3.1 Purpose - The ICSP was established in 1968 to encourage coordination and liaison among Federal agencies on matters related to standards. In 1992, the Secretary of Commerce reconstituted the ICSP to provide the required "interagency consultative mechanism to advise the Secretary and agency heads in implementing the policy." In October 1997, the Secretary of Commerce approved a new Charter, which included requirements of the NTTAA. A copy of the new Charter is provided as Appendix C.

3.2. ICSP chair - The Director of the NIST Office of Standards Services chairs the ICSP on behalf of the NIST Director and the Secretary of Commerce. The ICSP is the primary vehicle for 
coordinating Federal activities under the NTTAA and the OMB Circular. NIST develops very few agency-unique standards for either procurement or regulation purposes, but plays a major role in standards-related technical and policy-related activities as directed by both the Circular and the NTTAA.

3.3 ICSP membership - The ICSP is currently composed of representatives of the 14 Federal Cabinet Departments, 12 other Federal agencies and commissions, and several offices in the Executive Office of the President. The composition of the ICSP is shown in figure 1 on page 6 . The ICSP membership is provided as Appendix D.

\section{HIGHLIGHTS OF ICSP ACTIVITIES}

4.1 General - The ICSP met five times in FY 1999. The meetings focused on such topics as the NTTAA, agency implementation of the OMB Circular A-119, the proposed conformity assessment guidance, and the annual report to OMB. There were presentations and discussions on implementing the NTTAA, various agency standards-related policy issues, and the proposed guidance on Federal conformity assessment activities. ICSP members heard presentations from NIST regarding the National Cooperation for Laboratory Accreditation (NACLA) activities, the National Voluntary Conformity Assessment Systems Evaluation (NVCASE) Program, Strategic Management of Standards activities at NIST, and a new NIST Standards Policy document.

At the March 1999 meeting, the Committee invited Mr. James H. Turner, Senior Staff Member for Technology and Counsel, House Committee on Science, U.S. House of Representatives, to give his perspective on the NTTAA.

4.2 Interaction with private sector standards organizations - Representatives from several private sector standards developing organizations (SDOs) gave presentations on topics of interest. The speakers represented such organizations as Underwriters Laboratories and the American Society of Mechanical Engineers.

4.3 ICSP working groups - During 1999, a variety of ICSP activities were carried out by the ICSP s working groups shown in figure 1 on page 6.

Their activities are described as follows:

Regulatory Agencies Working Group (RAWG) - The ICSP s RAWG, chaired by CPSC, helps to develop and implement standards policies of interest to regulatory entities of the Federal Government. Membership includes representatives from CPSC, DOE, EPA, FCC, FDA, FERC, HUD, NIST, NRC, OSHA, and USDA. The RAWG reports to the ICSP and serves as a forum for interagency information exchange and discussion of issues of mutual interest to regulatory agencies. During 1999, the RAWG focused on issues and activities related to: (1) implementation of OMB Circular A-119 entitled, "Federal Participation in the Development and Use of Voluntary Standards;" 
(2) conformity assessment; (3) a national standards strategy; (4) on-line standards development; (5) accreditation of standards developers using "essential requirements;" and (6) referencing voluntary standards in Federal Regulations.

Working Group on Strategic Standards Management - During 1999, the ICSP s Standards Management Working Group, chaired by DOE, examined options for a second Federal Technical Standards Workshop during FY 2000. The effort to coordinate the Workshop among Federal agencies will continue in FY 2000, and will focus on Federal standards management processes and coordination with SDOs.

Working Group on Directory Databases - The ICSP working group on Directory Databases, chaired by NIST, met once in 1999 to review and discuss the final report and guidelines for developing databases of standards committee participants, review current activities of working group members, and to assess the need for technical assistance, and future activities. Ten agencies were represented. The final report and guidelines were adopted as presented. It was decided that web-based systems are the preferred method for developing, maintaining, and disseminating information on committee participation. Four agencies--NIST, DOD, DOE, and NASA--have their information available on the Web. The NIST Webmaster provided the group with information on how agencies may be able to link individual databases without creating one main database, allowing agencies to maintain their own information. The group agreed to invite technical representatives to the next meeting to provide guidance on developing databases and on creating web links.

\section{Working Group on Quality Management (International Organization for} Standardization (ISO) 9000) - NIST provided material on the proposed revisions to the ISO 9000 standards to the ICSP. NIST also responded to requests for assistance/ information from individual agencies on this topic. However, there were no meetings of this working group in FY 1999. To determine if there is a continuing need for this working group, ICSP members were asked to nominate representatives within their agencies who might be interested in serving on the committee. No names were received. This working group will remain inactive until the ICSP determines that there is a need for its reactivation, but NIST will continue to share information related to the revisions of ISO 9000 with ICSP members.

Interagency Working Group on Environmental Management Systems (EMS) (ISO 14000) - The Interagency Working Group on EMS/ISO 14000, co-chaired by EPA and DOE, met several times in FY 1999 to discuss items of mutual interest related to ISO 14000. Recently, the group began drafting a fact sheet on Environmental Management Systems and ISO 14000 in the Government. This document is slated for completion in FY 2000. 
Procurement Agencies Working Group - This working group, chaired by DOD, did not meet in FY 1999 since no issues specifically related to procurement were identified. This working group will be reactivated should issues arise in this area in the future.

Working Group on Federal Agency Participation - This working group, chaired by DOD, did not meet in FY 1999. Last year, the working group surveyed SDOs about the reported decline in government participation, but the survey did not yield significant results. The working group had hoped to determine whether participation had, in fact, declined, and that the decreasing numbers were not just a result of inaccurate reporting. The working group would have liked to compare government decline in participation with changes in other sectors. While the limited data collected confirmed substantial decline in government participation, and showed that it exceeded the decline from other sectors, the sample size was considered too small to be representative. Some SDOs, while not having exact numbers to report, did say that they had actually seen some increases in government participation.

Working group members and the ICSP remain concerned about declining participation-even fewer participants this year than last--and will request a discussion topic at a future ICSP meeting.

Laboratory Accreditation Work Group - This working group, chaired by NIST, did not meet in FY 1999. Its primary functions are now being addressed by the National Cooperation for Laboratory Accreditation (NACLA). This group will be subsumed into the Federal Coordination Group of NACLA during FY 2000.

Standards Working Group of the CIO and of ICSP - This Working Group s goal is to develop a unified government voice on standards and technology requirements. The Standards Working Group of the Enterprise Interoperability and Emerging Information Technology Committee of the Federal CIO Council provides a forum for Federal agencies to identify and define their common requirements so that they may be transmitted to the appropriate voluntary standards development committees or consortia for action. The intent of the working group, chaired by NIST, is to improve the bargaining power of Federal agencies within voluntary standards committees through coordinated requirement statements. In FY 2000, NIST intends to create an e-mail reflector for supporting the work of the Standards Working Group, and a web-based requirements tracking database, which includes capability for web-based submission of proposed requirements. The group first met in December 1998 at NIST, with participants from the DISA Center for Standards, HHS, DOE, DOED, DOI, DTIC, VA, EPA, NARA, NIH, Treasury, NRC, USDA, HUD, FAA, DOD-ASD, and Center for Disease Control. The group met a second time to provide briefings on topics requested by working group members, including an overview of the voluntary standards community and a short introduction to software con formance tes ting. 
(Figure 1 not available) 


\section{HIGHLIGHTS OF AGENCY ACTIVITIES}

5.1 Department of Commerce (DOC) - Within DOC, NIST has responsibility for the primary activities for implementation of P.L. 104-113 and OMB Circular A-119. During FY 1999, NIST conducted a number of activities to strengthen coordination between agencies and the private sector. Among these were:

NIST published two editions of Special Publication (SP) 739, Directory of Federal Government Certification and Related Programs. The document contains information on Federal Government procurement and regulatory conformity assessment programs that might affect products and services. Entries include the purpose of each requirement, whether mandatory or voluntary, and methods used to ensure compliance. Sources of documentation, reciprocity arrangements, enforcement approaches, and other items are listed. SP 739 contains information on many new Federal programs and the document s scope has been expanded to include other related types of Federal programs that have an impact on the marketplace. The document is available on the Internet at $<$ http://ts.nist.gov/ts/htdocs/210/216/216.htm>.

NIST cosponsored a major national workshop on conformity assessment issues with the American National Standards Institute (ANSI) and the American Council of Independent Laboratories on February 9, 1999. This meeting concluded that: (1) the U.S. conformity assessment system is very complex and all parties need to work together to simplify it, and (2) both the Federal Government and the private sector need to harmonize their conformity assessment activities to reduce duplication and complexity. One outcome of the meeting was the formation of a public/private sector organization known as the Conformity Assessment Network.

In March 1999, NIST s Office of Standards Services (OSS) and five private sector organizations cosponsored a one-week workshop on Electrical Safety Systems for the Americas. This successful partnership among NIST, the National Electrical Manufacturers Association, the National Fire Protection Association, Underwriters Laboratories, Intertek Testing Services, and the International Code Council, established an international forum for identifying and discussing issues related to building codes, product certification, installation, and enforcement practices in the Americas.

Representatives of the European Commission and Canada, in conjunction with the Food and Drug Administration (FDA) and NIST s OSS, held a workshop on April 12-14, 1999, for U.S. and Canadian entities desiring to be designated as Conformity Assessment Bodies (CABs) for medical devices under the U.S.-European Union (EU) and Canada-EU Mutual Recognition Agreements (MRAs). The workshop covered the overall requirements of the European Directive for Medical Devices and the specific requirements for entities to be designated as $\mathrm{CABs}$. 
The European Commission, in conjunction with the Federal Communications Commission (FCC) and OSS, held a workshop on April 26-27, 1999, for U.S. and Canadian entities desiring to be CABs for telecommunications and electromagnetic compatibility (EMC) under the U.S.-EU and Canada-EU MRAs. The seminar, conducted by staffs of the European Commission, FCC, and NIST, covered the European Directives for Telecommunications and $\mathrm{EMC}$ and the specific requirements for entities to be designated as CABs.

OSS hosted a seminar in May 1999 for representatives of the International Organization for Standardization Committee on Consumer Policy (COPOLCO) from 23 countries to introduce them to consumer-related U.S. Government regulatory and standards activities. NIST welcomed the group and gave them an overview of NIST s program activities. Speakers from the Environmental Protection Agency (EPA), Consumer Product Safety Commission, Department of Agriculture, and FDA described their regulatory activities and their work with consumers to ensure that regulations reflect consumer needs. The seminar, coordinated with ANSI and FDA, was part of a week-long program for COPOLCO members.

NIST Internal Report (IR) 6363, TBT Agreement Activities of the National Institute of Standards and Technology 1998, published in August 1999, describes the role of NIST s National Center for Standards and Certification Information (NCSCI) in support of the World Trade Organization (WTO) Agreement on Technical Barriers to Trade (TBT). Under the U.S. Trade Agreements Act of 1979 and its amendments, NCSCI is responsible for operating the U.S. WTO TBT inquiry point for information on standards, technical regulations, and conformity assessment procedures that might significantly affect trade.

OSS s Standards Assistance and Management Information (SAMI) project published the Directory of DOC Staff Memberships on Outside Standards Committees in January 1999. This annual directory contains two indexes: (1) DOC staff committee participants and (2) committee sponsors. The directory can be viewed electronically on the SAMI Web site (<http://www.nist.gov/sami $>$ ).

NIST officials from OSS participated in the annual Standards Engineering Society Conference, Standards Strategies in a Competitive World, on August 16-17, 1999, in Toronto, Canada.

Based on a request by the Conformity Assessment Network, NIST launched a new Web site (<http://ts.nist.gov/ca $>$ ) in September 1999, featuring conformity assessment issues, programs, and procedures. This site is a one-stop shopping Web site for conformity assessment information. The site contains the 1999 edition of NIST s Directory of Federal Government Certification and Related Programs.

Dr. Belinda Collins, Director of NIST OSS, took office as the International Laboratory Accreditation Cooperation (ILAC) Chair at the annual ILAC meeting in Sydney, 
Australia, in October 1999. The ILAC members represent laboratory accreditation bodies in some 50 countries, plus three major regional organizations. ILAC aims to achieve globally-accepted criteria for the recognition of the competence of accreditation bodies, and the development of regional and world-wide mutual recognition arrangements based on the needs of laboratories and their clients, and the importance of comprehensive audits and periodic proficiency testing.

5.2 Department of Defense (DOD) - One major thrust of the Department s Military Specifications (MilSpecs) Reform initiative was the emphasis on replacing military-unique documents with voluntary consensus standards wherever there was a dual-use application. As a result of this initiative, DOD carefully reviewed all of its 40,000 MilSpecs and standards and identified documents with potential for becoming voluntary standards.

Also, the Department has put into place a very stringent system to review every new requirement for a military-unique document to determine if a voluntary consensus document would be more appropriate. At a minimum, new documents and revisions to existing documents must be approved by a DOD senior executive. In addition, DOD activities are directed to review all available sources to locate an appropriate voluntary consensus standard rather than create a military-unique document. Further, its five-year review process identifies documents that did not have a voluntary consensus standard counterpart at one time, but for which an appropriate document may now have been created.

5.3 Department of Energy (DOE) - DOE continues to take a pro-active approach to standards and standards management even as its mission changes in response to the conclusion of the Cold War and shrinking Congressional appropriations. Within DOE, a number of programs and facilities have shifted their focus from production, research, and/or development to environmental remediation and restoration. DOE will literally be breaking new ground in these areas. In the face of a changing mission and a reduced work force, DOE continues to actively use and support the development of voluntary consensus standards to meet its needs. DOE is also continuing its initiative to better define candidate DOE technical standards for conversion to voluntary consensus standards.

\subsection{Department of Health and Human Services (HHS), Food and Drug Administration}

(FDA) - In November 1999, FDA conducted HHS-wide training on the requirements of OMB Circular A-119. The training was designed for regulation writers and employees involved in standards development and management activities. HHS is increasingly becoming involved in the development and use of voluntary consensus standards. Additional HHS-wide training and coordination activities are planned. 
5.5 Consumer Product Safety Commission (CPSC) - At CPSC, the Voluntary Standards Coordinator establishes agency views and decisions on standards issues using Commission responses to staff briefing packages and recommendations. These views are reflected in the Commission's Operating Plan and Budget.

5.6 Environmental Protection Agency (EPA) - In FY 1999, EPA promulgated 617 final rules, of which 207 (33.5 percent) referenced the NTTAA. In addition, the Agency published a variety of proposed rules, many of which also addressed compliance with the NTTAA. The total number of final and proposed rules that contained reference to the NTTAA was 326. This number reflects an increase of more than 300 percent over the 1998 report. This increase reflects both the Agency s successful implementation of the NTTAA and the OMB Circular and the publication of the interim Rule Writer s Guide last year.

In FY 1999, 10 final rules and 6 proposed rules adopted (or proposed for adoption) more than 45 voluntary consensus standards. Within 10 final rules, EPA found 83 instances where 18 voluntary consensus standards were found to be impracticable for agency use. Not all adopted standards were new standards or newly referenced by EPA. In several cases, the references included standards that had been previously adopted by EPA in other rulemaking activities.

One of the most notable examples of Agency rulemaking is found in the regulatory activities of the Office of Air and Radiation (OAR) in the area of National Emission Standards for Hazardous Air Pollutants. The following notation occurred in several OAR Federal Register notices this year:

As part of a larger effort, we are undertaking a project to cross-reference existing voluntary consensus standards in testing, sampling, and analysis, with current and future EPA test methods. When completed, this project will assist us in identifying potentially applicable voluntary consensus standards that can then be evaluated for equivalency and applicability in determining compliance with future regulations.

5.7 Federal Communications Commission (FCC) - FCC uses voluntary standards in several different ways:

to satisfy industry and user requirements where it appears that mandatory standards are unnecessary.

to correct problems that might otherwise require regulation.

as the basis for mandatory requirements--either incorporating voluntary standards by reference or including the normative portion of the standard in the FCC rules. 
The Commission increasingly uses voluntary standards. In many instances, they have chosen not to implement regulations (or more detailed regulations) because adequate voluntary industry standards already exist or are under development.

5.8 Federal Emergency Management Agency (FEMA) - Although FEMA is a small agency, they prefer using voluntary standards because no formal review process for standards usage has been imposed on the program directors. FEMA participates in the high frequency (HF) industry association working group to resolve HF standards problems, as well as the HF e-mail working group.

FEMA continues to use Military Standard (MIL-STD) 188.141B for HF radio, although the agency is working on a voluntary standard for transmitting e-mail via HF radio if landlines are not available. FEMA also continues to use several MilSpecs in conjunction with its National Emergency Management Information System.

5.9 General Services Administration (GSA) - GSA has become more selective in its participation in standards organizations. As a result, the number of organizations GSA participates in has decreased. GSA continues to emphasize the procurement of commercial offthe-shelf products and services. In addition, as a result of GSA s review of existing standards, 13 voluntary standards have been substituted for government-unique standards.

5.10 National Aeronautics and Space Administration (NASA) - In 1999, NASA completed its review of voluntary standards currently in use and adopted an additional 430 voluntary consensus standards, raising the total to 1,032. Citations for the adopted standards, along with internal and other standards used by NASA, are accessible in a NASA Preferred Technical Standards list publicly available on the Worldwide Web at <www.standards.nasa.gov>. This site also provides information on NASA participation in voluntary consensus standards development and gateways to other sources of standards.

An internal awareness campaign at NASA field centers, to make employees aware of the system, has resulted in continuously increasing usage of the system as a reference data base for programs. In 1999, two NASA-initiated voluntary consensus standards projects were completed with publication of standards, and two new projects were initiated. Meetings have also been held with several SDOs to establish a basis for future cooperation, including possible transition of NASA internal standards to voluntary consensus standards.

5.11 Nuclear Regulatory Commission (NRC) - The NRC staff used information gained from its stakeholder meeting in Chicago in September 1998 to prepare a Recommendation ${ }^{2}$ to the

${ }^{2}$ SECY-99-029, NRC Participation in the Development and Use of Consensus Standards, January 28, 1999. 
Commission to develop guidance for NRC staff when participating in the development and utilization of consensus standards. The Commission supported the staff Recommendation. ${ }^{3}$ Based on the success of this meeting, future meetings will be held periodically.

Also, NRC staff prepared a management directive $e^{4}$ to support the NRC standards strategy. The management directive defines NRC organizational responsibilities for standards activities and provides direction for staff participation in the development and use of consensus standards. Specifically, the management directive provides direction for identifying and prioritizing needed new and revised technical standards, selecting and nominating staff as authorized agency representatives on SDO committees, and coordinating standards activities with SDOs and other stakeholders. The management directive also requires periodic training of staff involved with standards activities to update them on Federal requirements for standards development and to discuss related issues.

\section{AGENCY USE OF GOVERNMENT-UNIQUE STANDARDS IN LIEU OF VOLUNTARY CONSENSUS STANDARDS}

6.1 Department of Defense (DOD) - The Department relies on MilSpecs and standards in lieu of voluntary consensus documents when the requirement can be justified as truly military-unique, when a voluntary standard does not exist and development is not imminent, or when there is no industry interest to develop an appropriate voluntary standard.

Since the Department has a massive number of procurements, we have chosen to use the categorical basis as our means of conveying information on our voluntary consensus standards use.

6.2 National Aeronautics and Space Administration (NASA) - Because NASA uses the categorical method of reporting, use of government-unique standards is reported in terms of additions to the NASA Technical Standards Management System, as opposed to tracking individual procurement transactions. During 1999, NASA developed 11 NASA-unique technical standards in three categories, namely: information technology, engineering, and safety and mission assurance. There are four engineering standards, two of which are internal procedures for the application of voluntary consensus standards and two are unique applications based on spacecraft experiences with no current external interest. There are three safety and mission assurance standards, with two being internal procedures and one based on aerospace applications. The last four standards are from the information technology area and are all procedural documents for the application of commercial software.

${ }^{3}$ Staff Requirements, SECY-99-029, February 17, 1999.

${ }^{4}$ Management Directive 6.5, NRC Participation in the Development and Use of Consensus Standards, issued November 1999. 
6.3 Environmental Protection Agency (EPA) - In FY 1999, EPA found impracticable the use of 18 existing voluntary consensus standards in 10 final rules, citing issues such as lack of validation data, or in the case of one ISO standard (8178), on the standard s inability to accommodate broad application because the standard relies too heavily on reference test conditions. This resulted in 83 instances where EPA used government-unique standards in lieu of voluntary consensus standards. Because the regulatory test procedures need to be used not only for certification, but also for production line testing, selective enforcement audits, and inuse testing, they must be broadly based. The Agency determined that the ISO procedures are not sufficiently broad in their current form and thus could not be adopted by reference.

In one National Emissions Standards for Hazardous Air Pollutants (NESHAP) rule, more than 12 standards were rejected in lieu of government-unique standards. EPA s reasoning and justification are consistent with the NTTAA. The Federal Register notice states:

Candidate voluntary consensus standards for materials analysis were identified for freeformaldehyde content. Consensus comments provided by industry experts were that the candidate standards did not meet industry materials analysis requirements. Therefore, EPA has determined these voluntary consensus standards are impractical for the mineral wool production NESHAP. The EPA, in consultation with the North American Insulation Manufacturers Association (NAIMA), has formulated an industry-specific materials analysis consensus standard for free-formaldehyde content, which is promulgated in this rule.

There has been an increase in EPA s instances reported of government-unique standards used in lieu of voluntary consensus standards from the previous report. This is due, in part, to two different phenomena. First, from 1997 to 1999, EPA put a series of tools in place that have improved its rule writers ability to find and evaluate standards. Second, EPA s use of voluntary consensus standards cannot be analyzed by comparing absolute numbers from year-to-year, since the Agency s regulatory agenda varies annually in the number and kinds of regulations promulgated. Because of this fluctuation each year, the Agency s opportunity to use voluntary consensus standards in regulation will vary. The EPA has included additional information at the back of their portion of the report.

6.4 Federal Emergency Management Agency (FEMA) - As required by Public Law (P.L.) 104-113, identification of all instances when the agency used government-unique standards in lieu of voluntary consensus standards:

FEMA continues to use Military Standard (MIL-STD) 188.141B for HF radio, although the agency is working on a voluntary standard for transmitting e-mail via HF radio if landlines are not available.

Developers of the National Emergency Management Information System used and continue to use MIL-STD 498, Software Development and Documentation; MIL-STD 490A, Specification Practices; MIL-STD 1521B, Technical Reviews and Audits for Systems, 
Equipment and Computer Programs; and MIL-STD 2168, Defense System Software Quality Program, et al. The Agency used these standards as part of a large project started in 1995. At that time, the Agency wanted to use standards with which contractors were familiar. A solid, proven standard that worked and would keep costs in line.

\section{CONCLUSIONS}

In FY 1999, Federal agencies have continued to implement P.L. 104-113 and OMB Circular A-119.

Agencies continue to improve their procedures to track their uses of standards in both regulation and procurement activities. The decline in agency participation in standards committees, as first noted in the FY 1997 and 1998 reports, continues. This is most likely due to staff attrition, budget cuts, and streamlining of agency standards programs. NIST is working with all agencies on the timeliness of their annual reports to NIST and its report to OMB. NIST is also publishing the annual report both in hard copy and on the Web at $<$ http://ts.nist.gov/icsp $>$, so that agencies and the public have ready access.

Agencies conduct standards related activities for a variety of reasons, such as to improve procurement efforts, facilitate adoption of a standard in regulatory activities, better manage agency programs through internal adoption of appropriate voluntary consensus standards, represent the United States in standards activities with important potential trade implications, advance U.S. technology both domestically and internationally, improve the U.S. standards and conformity assessment systems, comply with treaty obligations, and share with industry information and data from ongoing research efforts. These different reasons may create difficulty in reporting due to confusion in determining which activities to report and how to report them. NIST is working with individual agencies on specific problems, and provides general information to the ICSP. 
Table 1. FEDERAL AGENCY INFORMATION ON PARTICIPATION/ADOPTION OF VOLUNTARY STANDARDS ACTIVITIES REQUIRED BY OMB CIRCULAR A-119 (DATA AS OF 9/30/99)

\begin{tabular}{|c|c|c|c|c|c|c|c|}
\hline AGENCY & $\begin{array}{c}\text { NO. OF } \\
\text { VOLUNTARY } \\
\text { CONSENSUS } \\
\text { STANDARDS } \\
\text { BODIES N WHICH } \\
\text { AGENCY } \\
\text { PARTICIPATES }\end{array}$ & $\begin{array}{c}\text { CHANGE } \\
\text { FROM FY } 98\end{array}$ & $\begin{array}{l}\text { NO. OF AGENCY } \\
\text { EMPLOYEES } \\
\text { PARTICIPATING }\end{array}$ & $\begin{array}{c}\text { CHANGE } \\
\text { FROM FY } 98\end{array}$ & $\begin{array}{c}\text { NO. OF } \\
\text { VOLUNTARY } \\
\text { CONSENSUS } \\
\text { STANDARDS } \\
\text { USED SINCE } \\
10 / 98\end{array}$ & $\begin{array}{c}\text { NO. OF } \\
\text { VOLUNTARY } \\
\text { CONSENSUS } \\
\text { STANDARDS } \\
\text { SUBSTITUTED } \\
\text { FOR GOVT- } \\
\text { UNIQUE } \\
\text { STANDARDS }\end{array}$ & $\begin{array}{c}\text { NO. OF GOVT- } \\
\text { UNIQUE } \\
\text { STANDARDS } \\
\text { USED IN LEU } \\
\text { OF } \\
\text { VOLUNTARY } \\
\text { CONSENSUS } \\
\text { STANDARDS }\end{array}$ \\
\hline USDA & 25 & -21 & 39 & -29 & 0 & 0 & 0 \\
\hline DOC & 138 & 0 & 382 & +3 & 0 & 0 & 0 \\
\hline DOD & 48 & -41 & 420 & -263 & $627^{(1)}$ & 491 & - \\
\hline NCS (DOD) & 12 & -5 & 15 & +1 & 0 & 0 & 0 \\
\hline DOED & 1 & 0 & 6 & 0 & 0 & 0 & 0 \\
\hline DOE & 58 & -7 & $668^{(2)}$ & -13 & 916 & 0 & 0 \\
\hline HHS & $43^{(3)}$ & -3 & 255 & -19 & 90 & 0 & 0 \\
\hline HUD & 5 & -5 & 6 & -1 & 2 & 0 & 0 \\
\hline DOI & 54 & 0 & 84 & 0 & 144 & 0 & 0 \\
\hline DOJ & 3 & 0 & 8 & 0 & 59 & 0 & 0 \\
\hline DOL & 22 & 0 & 65 & +2 & 15 & 0 & 0 \\
\hline STATE & 1 & 0 & 6 & 0 & 0 & 0 & 0 \\
\hline DOT & 120 & +14 & 229 & -63 & 238 & 28 & 0 \\
\hline TREASURY & 9 & +1 & 19 & -2 & 6 & 0 & 0 \\
\hline VA & 26 & +23 & 12 & +8 & 36 & 0 & 0 \\
\hline CPSC & 65 & +15 & 25 & +4 & 4 & 0 & 0 \\
\hline EPA & 15 & +1 & 197 & -3 & 34 & 0 & $83^{(4)}$ \\
\hline FCC & $24^{(5)}$ & 0 & 50 & +1 & 0 & 0 & 0 \\
\hline FEMA & 1 & +1 & - & - & 1 & - & 5 \\
\hline GSA & 79 & -12 & 49 & +4 & 0 & 13 & 0 \\
\hline NASA & 45 & +2 & 145 & -3 & $430^{(6)}$ & 8 & 0 \\
\hline NARA & 8 & -6 & 8 & 0 & 22 & 0 & 0 \\
\hline NSF & 3 & 0 & 3 & -1 & 0 & 0 & 0 \\
\hline NRC & $18^{(7)}$ & +2 & 141 & -4 & 45 & 2 & 0 \\
\hline TOTALS & 823 & -41 & 2,832 & -378 & 2,669 & 542 & 88 \\
\hline
\end{tabular}


(1) Total number of DOD-adopted voluntary consensus standards is 8,618 .

(2) DOE reports 1,306 total agency participations in standards development groups.

${ }^{(3)}$ HHS staff participates on a total of 544 voluntary consensus standards development committees among these 43 bodies.

(4) EPA distinguishes between the total number of standards substituted and the number of rulemaking decisions in which the standards were used. For more information with regard to this, refer to the EPA s submission, which begins on page B-5. NOTE: EPA s submission includes supplemental information that can be found in the table at the back of their portion of the report. The 83 instances to use government unique standards refer, however, to only 18 individual voluntary consensus standards.

(5) FCC participations cover approximately 100 sub-groups with the 24 standards bodies.

(6) Total number of NASA-adopted voluntary consensus standards is 1,032 .

(7) NRC staff participates on a total of 267 standards writing, consensus, and board-level committees among the 18 standards developing organizations indicated. 


\section{RECOMMENDATIONS}

Most Federal agencies have continued to progress in their use of voluntary consensus standards for agency programs and missions for both procurement and regulatory activities. Where appropriate, strategic alliances and teaming arrangements between Federal agencies and SDOs may be beneficial in ensuring that this trend continues.

All Federal agencies should continue to strengthen their efforts to plan and allocate resources and staff for participation in appropriate voluntary consensus standard activities.

Federal agencies should continue to develop policies and systems needed to implement the NTTAA and OMB Circular A-119. Actions that should be considered include: (1) the establishment of an agency standards policy, (2) monitoring standards activity participation and resource allocation, and (3) taking steps to improve reporting and program effectiveness.

Decreasing Federal resources and staff can lower the priorities for standards and conformity assessment activities within a department or agency. Some agencies are finding it difficult to actively participate in the ICSP or its working groups. Resources for participation in standards activities also appear to be diminishing making it difficult for agencies to ensure adequate representation on appropriate committees. The ICSP Participation Work Group, led by DOD, will strengthen its activities in FY 2000 to better understand the causes of these problems and to assist the ICSP in taking appropriate action to improve the situation.

Federal agencies should make more effective use of today s technology in coordinating standards participation across government, in positions on standards committee ballots, and in preparing reports on status of standards activities including the annual report for OMB.

Since the 1996 revisions of the Circular, a number of reporting issues have arisen. In particular, agencies are having some difficulties knowing when to report instances of government standards being used in lieu of voluntary consensus standards. NIST plans to hold a workshop in FY 2000 to address this and other reporting issues to harmonize reporting from the agencies.

Some agencies report difficulty in updating out-of-date standards in their regulations. In a 1997 survey of the U.S. Code of Federal Regulations, ASTM found that of the 1,000 references to ASTM standards, more than 90 percent were at least 10 years out of date, some were more than 30 years. Current standards may reflect new technology; new products; more precise methods of testing; and faster, cheaper, and better ways of doing things. It is vital that those who are regulated have the ability to use current technology embedded in the standards and not be weighed down or even endangered by out-of-date standards. It is also imperative that agencies review newly revised voluntary standards to ensure that they adequately address all regulatory concerns. The time and effort required to conduct such reviews, combined with the resources 
needed to go through rulemaking, can require the commitment of substantial agency resources-resources which may not be available given other agency priorities. The ICSP RAWG is focusing on procedures for improving the timeliness of updates of standards used in regulations.

These are just a few of the many problems that agencies have reported in their implementation efforts. Yet most agencies are diligently trying to comply with both the Law and Circular. There is increased use of voluntary standards by Federal agencies in both regulation and procurement, and conformity assessment activities are now receiving greater attention than before passage of the Law. 

APPENDIX A:

Cabinet Department Reports 


\section{DEPARTMENT OF AGRICULTURE (USDA)}

The following information was prepared for the National Institute of Standards and Technology (NIST) by USDA as required annually under Office of Management and Budget (OMB) Circular A-119, Federal Participation in the Development and Use of Voluntary Standards.

\section{BACKGROUND}

In the Department of Agriculture, the Chief Information Officer (CIO) also serves as the Standards Executive. This has made the Office of the Chief Information Officer (OCIO) the coordinating organization within USDA for reporting on OMB Circular A-119 activities.

\section{METHOD}

To prepare this report, OCIO sought information from USDA Agency Heads. Based on the requirements sent out by NIST, the CIO requested the agencies to:

identify the number of voluntary consensus standards used since October 1, 1998, based on the procedures set forth in sections 11 and 12 of the Circular. For each instance, include agency rationale for such use, as well as specific government-unique standard used.

identify voluntary consensus standards that have been substituted for government-unique standards as a result of any agency review under section $15 b(7)$ of the Circular.

identify the number of voluntary consensus standards bodies in which there is agency participation, as well as the number of agency employees participation.

evaluate the effectiveness of Circular A-119 policy and recommendations for any changes.

\section{USDA PARTICIPATION IN THE DEVELOPMENT AND USE OF VOLUNTARY STANDARDS IN FISCAL YEAR (FY) 1999}

Two USDA agencies, the Rural Utilities Service and the Agricultural Marketing Service reported participation in voluntary standards development and use during FY 1999.

\section{Rural Utilities Service (RUS)}

The RUS has engineering missions to provide quality engineering for RUS customers in the RUS Electric, Telecommunications, and Water and Waste Programs. Many RUS employees participated in organizations that are developing voluntary standards. 
RUS policy is to use, to the fullest extent possible, standards, rules, and regulations of recognized standards-writing organizations in lieu of producing separate RUS specifications. This policy, which is included in $\$ 1728.20$ of 7 CFR 1728 , was in effect many years before the OMB Circular A-119 was published.

RUS maintains membership on a number of committees. RUS's interest is to oversee all aspects of the various committees' standards-writing efforts to ensure that rural electric, telecommunications, and water and waste concerns are included. The ultimate goal is to either:

adopt the various standards, as appropriate, rather than generate individual RUS standards.

or ensure that those standards that are regulatory in nature and generally must be observed by borrowers contain cost-effective, reasonable requirements for rural areas and thus, ensure or protect the security of government loans.

\section{Electric Program}

Over the years, the Electric Program of RUS has adopted or referenced the following standard specifications, etc., in its specifications and regulations which RUS electrification borrowers must comply with when using loan funds:

Seventeen (17) procurement-type standards of the American Society for Testing and Materials (ASTM).

Twenty-one (21) procurement-type standards of the American Wood Preservers Association (AWPA).

Four (4) national design standards of the American Society of Civil Engineers (ASCE), the American Concrete Institute (ACI), the Prestressed Concrete Institute (PCI), and the American Welding Society (AWS).

Three (3) building codes of the International Conference of Building Officials (ICBO) Uniform Building Code, the Building Officials and Code Administrators (BOCA) National Building Code, and the Southern Building Code Congress (SBCC) Standard Building Code.

Two (2) national lumber grading rules of the Southern Pine Inspection Bureau (SPIB) Grading Rules and the West Coast Lumber Inspection Bureau (WCLB) Grading Rules. Fourteen (14) procurement-type standards of the American National Standards Institute (ANSI).

One (1) national safety code of the ANSI.

One (1) procurement-type standard of the Institute of Electrical and Electronics Engineers (IEEE).

Two (2) procurement-type standards of the Insulated Cable Engineers Association. 


\section{Telecommunications Program}

Over the years, the Telecommunications Program of RUS has adopted or referenced the following standard specifications, etc., in its specifications and regulations which RUS telecommunications borrowers must comply with when using loan funds:

Four (4) procurement-type standards of the American Society for Testing and Materials (ASTM).

Two (2) Underwriters Laboratories procurement-type standards.

Two (2) regulation and 1 procurement-type standard of the American National Standards Institute (ANSI).

Three (3) procurement-type standards of the Electronic Industries Association (EIA).

Two (2) procurement-type standards of the IEEE.

One (1) procurement-type standard of the Alliance for Telecommunications Industry

Solutions (ATIS) Protection Engineers Group.

Three (3) procurement-type standards of the Aluminum Association.

Two (2) procurement-type standards of the International Radio Consultive Committee (CCIR).

Three (3) procurement-type Military Standards.

\section{Water and Waste Program}

Over the years, the Water and Waste Programs of RUS have adopted or referenced the following standard specifications, etc., in its specifications and regulations which RUS water and waste borrowers must comply with when using loan funds:

All appropriate piping standards of the ASTM.

All appropriate piping standards of the American Water Works Association (AWWA).

For water system testing, leakage must not exceed the limits set by ASTM or AWWA, whichever is more stringent.

Inasmuch as RUS has had the policy of referencing available recognized national or industrytype standards whenever possible, long before publication of OMB Circular A-119, there is almost no change in RUS reporting for all programs since the last report. All new or revised RUS standards produced during 1999 have included, whenever possible, appropriate standards of those other organizations to simplify and streamline RUS documents/requirements.

\section{Agricultural Marketing Service (AMS)}

AMS reports that 21 employees participated in 8 national voluntary standards bodies, and 18 employees participated in 17 international voluntary consensus standards bodies in FY 1999. 
Since October 1, 1997, the agency has used the following voluntary consensus standards: Agreement on the International Carriage of Perishable Foodstuffs and Special Equipment, Certification Standards of the American Association of Seed Certifying Agencies, Codex Alimentarius International Grade Standards, Universal Cotton Standards Agreement, Analytical Standards of the ANSI, Test Standards of the ASTM, and International Meat Purchase Specifications. With the participation of the industry, AMS has developed 602 grade and classification standards that have been accepted by the industry for marketing of 230 agricultural commodities. These standards were created in response to the needs expressed by the industry for uniform standards that could be used and certified nationwide. The usage of these standards is voluntary.

In addition, AMS guided the development of 25 International Organization for Standardization standards for the accreditation of the laboratories performing microbiological and chemical testing, and the (3-A) Sanitary Standards of the International Association of Food Protection to provide specifications for the dairy processing equipment.

At the request from and with the participation of the industry, AMS has developed 602 grade and classification standards that are generally recognized by the industry for use in marketing of 230 agricultural commodities. While developed and maintained by AMS, these standards were created in response to the needs expressed by the industry for uniform standards that could be used nationwide. The usage of these standards is voluntary.

The American Dairy Products Institute has published a series of milk and dry milk standards that can be used when USDA certification is not requested by the buyer or seller. These standards are based on the USDA standards and contain the same requirements as the U.S. Grade standards. However, the majority of the industry prefers USDA certification because of its official value in certification.

AMS has developed numerous grading and classification standards in response to requests from the industry. AMS does not view these standards and classifications as government-unique since they were developed with full consultation and participation of the industry and their usage by the industry is voluntary. AMS uses government-unique specifications for the grading and certification of tobacco products. Authority for this program is contained in the Tobacco Statistics Act of 1929 and the Tobacco Inspection Act of 1935, as amended. Provisions of these acts require that all tobacco sold at auction must be inspected and graded by USDA according to the U.S. standards. AMS also uses government-unique specifications for purchases of commodities for the School Lunch Program and other domestic feeding programs when voluntary consensus standards do not meet the nutritional or program requirements of these programs.

The above statement means that USDA develops unique specifications to meet the need of the food program, which may not be consistent with specifications of commercially similar products. 
These specifications are used for nutritional reasons; for example, a commercial standard might allow for peaches to be packed in heavy syrup; whereas, AMS specifications ensure that peaches are packed in light syrup. Frequently, these specifications allow for less salt, fat, and sugar than commercial specifications. 


\section{DEPARTMENT OF COMMERCE (DOC)}

The DOC encourages its staff to participate in standards committee activities relating to the mission of the Department, subject to resource availability. Agency employees participate in the standards development activities of : (1) U.S. private sector standardization bodies; (2) local, state, and Federal governments; and (3) both private and governmental (treaty and nontreaty) international standardization organizations. Standards of interest to the Department cover a broad range of technical areas including: (1) energy conservation, (2) information and computer technology, (3) telecommunications, (4) environmental safety and health, and (5) a variety of other product sectors and fields of technology.

The Standards Assistance and Management Information (SAMI) project in the Office of Standards Services (OSS), National Institute of Standards and Technology (NIST), collects and disseminates information on DOC staff participation in standards development activities. The SAMI project publishes an annual directory containing statistics on standards committee participation, alphabetical listings of staff participants and standards organizations and committees, and a list of acronyms and abbreviations.

The DOC standards participant information is divided into two parts: NIST and other DOC agencies. During FY 1999, 393 DOC staff participated in the standards writing activities of 152 (110 national and 42 international) standards developing organizations. NIST had 326 participants in the activities of 110 standards organizations (76 national and 34 international). NIST participated on 368 committees and held 1,175 memberships on these committees. Ten of the standards organizations in which NIST staff members participated had 15 or more NIST memberships. Sixty-eight staff members of other DOC agencies participated in 66 committees of 42 standards organizations (27 national and 15 international). They held 139 memberships on those committees. Eight of those standards organizations had five or more DOC participants.

The following organizations/agencies accounted for 66 percent (92) of the 139 other DOC committee memberships:

Organizations with Other DOC Members:

American National Standards Institute

Office of Management and Budget

Department of Defense/Federal Aviation

Administration/Department of Commerce

Federal Committee for Metrological Service and

Supporting Research

Department of State
No. of Committee Memberships

19

26

6

6

15 
International Organization for Standardization 8

International Telecommunication Union - Telegraph

International Telecommunication Union - Radio 5

Total $\overline{92}$

The following standards organizations accounted for 81 percent (949) of the 1,175 NIST committee memberships:

Organizations with NIST Members: $\quad$ No. of Committee Memberships

American Society for Testing and Materials $\quad 572$

American National Standards Institute $\quad 111$

Institute of Electrical and Electronic Engineers $\quad 41$

$\begin{array}{ll}\text { International Organization for Standardization } & 68\end{array}$

American Society of Mechanical Engineers 33

International Organization of Legal Metrology 26

International Electrotechnical Commission $\quad 33$

$\begin{array}{ll}\text { American Concrete Institute } & 21\end{array}$

Telecommunications Industry Association $\quad 20$

$\begin{array}{ll}\text { CIE } & 24\end{array}$

Total $\quad 949$

\section{OTHER DOC AGENCIES: SUMMARY OF STANDARDS-RELATED ACTIVITIES}

National Oceanic and Atmospheric Administration (NOAA)

Standardization of data acquisition and data management practices is vital to the mission at NOAA. NOAA seeks to establish voluntary standards with selected industrial associations, academia, and national organizations of state and local governments (e.g., the American Association of State Climatologists), as well as through participation in professional societies (e.g., American Meteorological Society). All NOAA line organizations participate in standards development activities. In general, standards used in many NOAA activities are established in conjunction with other Federal agencies (e.g., Department of Defense, Federal Aviation Administration, U.S. Department of Agriculture) either through joint participation in international organizations such as the World Metrological Organization, or by means of bilateral and multilateral agreements with other nations. These standardization activities apply to all phases of environmental data acquisition, processing and distribution. 
National Telecommunications and Information Administration (NTIA)

The NTIA contributes to the development and application of national and international telecommunication standards by participating and holding leadership roles in various voluntary standards committees at the national and international levels (e.g., Telecommunications Industry Association, International Telecommunication Union). These standards enhance the quality and reliability of the domestic telecommunications infrastructure, promote healthy competition in telecommunications products and services, and expand international trade opportunities for U.S. telecommunications firms.

\section{Patent and Trademark Office (PTO)}

The PTO participates and contributes to the resolution of identified requirements for international standards, primarily through the Permanent Committee on Industrial Property Information of the World Intellectual Property Organization. PTO staff also participates in standardization activities of the International Patent Classification Union and the American National Standards Institute (ANSI) committee on Patent Standards.

\section{Bureau of the Census}

DOC s Bureau of the Census is active in the development of standards and specifications for: (1) the definition of metropolitan statistical areas; (2) the digitizing of geographic information; and (3) the definition of statistical, economic, and geographic terms.

NIST: Summary of Standards-Related Activities

In addition to the activities described above, NIST s OSS operates a number of standards-related programs and services to assist business, industry, and government in using and understanding standards, technical regulations, and conformity assessment procedures affecting trade in the global marketplace.

The National Center for Standards and Certification Information (NCSCI) is the U.S. focal point for standards-related information at home and abroad; it provides information on U.S., foreign, regional, and international voluntary standards bodies, mandatory government regulations, and conformity assessment procedures for nonagricultural products. NCSCI is the U.S. member of the International Organization for Standardization (ISO) Information Network, and serves as the U.S. inquiry point under the World Trade Organization Agreement on Technical Barriers to Trade, the North American Free Trade Agreement (NAFTA), and the Asia Pacific Economic Cooperation Subcommittee on Standards and Conformance. NCSCI maintains an extensive collection of reference materials, including U.S. military and other Federal Government specifications, U.S. industry and national standards, international standards, and selected foreign national standards. 
Staff members respond to requests for specialized standards information, arrange for translations of foreign standards and regulations, and disseminate information to U.S. industry concerning proposed foreign regulations and general standards issues.

Two telephone hotlines provide weekly updates on draft European standards and on proposed foreign technical regulations that might significantly affect trade.

\section{$\underline{\text { NIST Standards Advisory Committee (SAC) }}$}

To coordinate internal standards activities, NIST established a SAC. The SAC created a NIST Voluntary Standards Policy, which was approved by NIST management in 1999 and is now being implemented. This policy directs NIST organizational units to review their standardsrelated activities to ensure that they are in line with the agency s mission and goals so that resources and participation are targeted most effectively. NIST currently has about 330 employees participating in more than 1,200 standards committee activities. The policy is expected to assist in aligning this participation as closely as possible with applicable NIST and industry needs. Because NIST also coordinates standards activities within DOC, including publishing the Annual Directory ${ }^{5}$ and providing DOC input for the Annual Report, NIST chartered a Commerce Standards Committee in 1999 to improve communication and coordination on standards-related activities among DOC agencies.

\section{$\underline{\text { Federal Information Processing Standards (FIPS) }}$}

Under the Information Technology Management Reform Act (Public Law (P.L.) 104-106), the Secretary of Commerce approves standards and guidelines that are developed by NIST for Federal computer systems. Under section 513 of the Information Technology Management Reform Act of 1996 and the Computer Security Act of 1987, P.L. 104-106, NIST develops standards, guidelines, and associated methods and techniques for Federal computer systems, including those needed to assure the cost-effective security and privacy of sensitive information in Federal computer systems, when there are compelling Federal requirements and there are no existing voluntary industry standards. These standards and guidelines are issued by NIST as FIPS for use government-wide. FIPS address Federal requirements for the interoperability of different systems, for the portability of data and software, and for computer security. When FIPS are considered necessary, NIST announces proposed FIPS in the Federal Register for public review and comment. No new FIPS were published in FY 1999, which required justification.

${ }^{5}$ Directory of DOC Staff Memberships on Outside Standards Committees. 
Following is a quick summary of 1999 Federal Register notices regarding FIPS:

Federal Register: January 15, 1999 (Volume 64, Number 10)

This notice announced proposed FIPS 46-3, Data Encryption Standard (DES), to provide for the use of ANSI X9.52, Triple DES.

Federal Register: November 5, 1999 (Volume 64, Number 214)

This notice announced the approval of FIPS 46-3, Data Encryption Standard, to provide for the use of ANSI X9.52, Triple DES.

Federal Register: November 17, 1999 (Volume 64, Number 221)

This notice announced proposed draft FIPS 140-2, Security Requirements for Cryptographic Modules, to supersede FIPS 140-1, which required review within 5 years of its issuance. The proposed FIPS concerns the security requirements for the modules that implement FIPSapproved cryptographic algorithms.

Federal Register: September 15, 1999 (Volume 64, Number 178)

This notice announced the continuation of the process to develop a FIPS for an Advanced Encryption Standard (AES) specifying an Advanced Encryption Algorithm. The notice solicited comments on algorithms that had been submitted by interested individuals and the private sector and that are being publicly reviewed as candidates for the AES.

Conformity Assessment Activities - National Cooperation for Laboratory Accreditation (NACLA)

Section 12b of the National Technology Transfer and Advancement Act (NTTAA) of 1995 directed NIST to coordinate conformity assessment activities of Federal, state, and local entities to eliminate any unnecessary duplication of conformity assessment activities. In response, NIST has been a driving force behind the creation of NACLA. NACLA is composed of organizations in the United States, with observers from Mexico and Canada, that actively support development of a system for recognizing the competence of testing and calibration laboratories leading to worldwide acceptance of test and calibration reports from those laboratories. Concerned with costly, multiple, duplicate assessments, and the lack of domestic or international recognition of laboratory accreditations, the group has explored solutions that could lead the United States, and perhaps eventually its NAFTA partners, toward the goal of having only one assessment of a laboratory in a given field of testing, based on internationally acc epted procedures. The NACLA vision is for a U.S. and eventually a North American laboratory accreditation system that achieves the following goals:

- for the testing laboratory, a single accreditation in a given field of testing, with worldwide recognition of the laboratory's competence.

- for the manufacturer/supplier, a test performed once, with worldwide acceptance. 
- for the acceptance body (that is a govemment agency or an industry specifier), an accreditation based on uniform criteria and intended to ensure that a laboratory is qualified to provide data of consistent quality.

Mutual Recognition Agreements (MRAs)/Arrangements

NIST has also worked to reduce duplication and complexity in conformity assessment activities by participating in, or providing technical support for, various MRAs and related agreements such as the Asia Pacific Laboratory Accreditation Cooperation and the U.S./Standards Council of Canada agreement on calibration laboratory accreditation. To implement the Agreement of Mutual Recognition Between the United States of America and the European Community (U.S.EU MRA), NIST works through its National Voluntary Conformity Assessment Systems Evaluation program to provide U.S. Government assurance of the competence of U.S. conformity assessment bodies to meet European governmental requirements. The ultimate goal is to help U.S. manufacturers satisfy applicable product requirements mandated by other countries through conformity assessment procedures conducted in the United States prior to export, thereby reducing or eliminating the need for retesting by the importing country.

National Workshop on Conformity Assessment and the Conformity Assessment Network (CAN)

On February 9, 1999, NIST co-sponsored a major national workshop on conformity assessment issues with ANSI and ACIL, formerly the American Council of Independent Laboratories. This meeting concluded that: (1) the U.S. conformity assessment system is very complex and all parties need to work together to simplify it, and (2) both the Federal Government and the private sector need to harmonize their conformity assessment activities to reduce duplication and complexity. One outcome of the meeting was the formation of a public/private sector organization known as the CAN. This organization identified the lack of basic information on conformity assessment-related topics as a key concern for the community. To address this need, NIST created a one-stop shopping Web site for conformity assessment-related information, ranging from ISO 9000 issues to conformity assessment topics under the U.S.-EU MRA.

\section{Conformity Assessment Guidance}

OMB Circular A-119, revised February 19, 1998, recognized the conformity assessment requirements and obligations defined in the Act and the role of DOC in this area. The Circular directed the Secretary of Commerce to issue guidance to agencies to ensure effective coordination of Federal conformity assessment activities. On November 3, 1999, NIST published proposed guidance on Federal conformity assessment activities in the Federal Register. The proposed guidance focuses on ways for Federal agencies to eliminate unnecessary duplication and complexity in their conformity assessment activities. The comment period on the proposed guidance ended January 18, 2000, and comments including recommendations appearing in a recent Government Accounting Office report, are currently being reviewed. Final guidance will be published later this year. 


\section{Other Standards Management Guidance}

NIST has further recognized that to address the tenets of the NTTAA, a new style of managing standards activities is required. To this end, NIST created a model plan for strategic management of standards activities. Because each agency s standards efforts tend to be unique, the generic plan can be tailored to suit the needs of individual agencies. This guidance was published in 1999, both as a NIST publication and in ASTM Standardization News. NIST is also updating its Guidelines to Standards Participants in coordination with Environmental Protection Agency s revision of its Rule Writer s Guide for Standards Participants and has provided an outline of these guidelines to the Interagency Committee on Standards Policy to serve as a model for other agencies efforts. 


\section{DEPARTMENT OF DEFENSE (DOD)}

The DOD implements the provisions of Public Law (P.L.) 104-113 and Office of Management and Budget (OMB) Circular A-119 through DOD 4120.3-M, Defense Standardization Program Policies and Procedures. As set forth in our existing policies, our activities routinely consider meeting the Department's requirements with items or materials that are normally procured using voluntary consensus standards. Our guidance further tasks standards developers to actively look for opportunities to replace government-unique documents with voluntary consensus standards.

One major thrust of the Department s Military Specifications (MilSpec) Reform initiative was the emphasis on replacing military unique documents with voluntary consensus standards wherever there was a dual-use application. As a result of this initiative, DOD carefully reviewed all of its 40,000 MilSpecs and standards and identified documents with voluntary standards potential. In instances where replacement voluntary consensus standards were available, the Department acted quickly to cancel the military documents and begin using voluntary consensus standards. In cases where voluntary consensus replacements were needed but not available, the DOD began working with standards developers to create appropriate standards.

Also, the Department has put into place a very stringent system to review every new requirement for a document to determine if a voluntary consensus document would be more appropriate. At a minimum, new documents and revisions to existing documents must be approved by a DOD senior executive. In addition, DOD activities are directed to review all available sources to locate an appropriate voluntary consensus document rather than create a military-unique document. Further, our 5-year review process identifies documents that did not have a voluntary consensus counterpart at one time, but for which an appropriate document may now have been created.

The Department's initial review and correction procedures, coupled with oversight in the creation of new military documents, and periodic review of existing military documents, ensures very little proliferation of government-unique documentation.

In summary, the Department relies on MilSpecs and standards in lieu of voluntary consensus documents when the requirement can be justified as truly military-unique; when a voluntary standard does not exist and development is not imminent; when there is no industry interest to develop an appropriate voluntary standard.

Since the Department has a massive number of procurements, we have chosen to use the categorical basis as our means of conveying information on our voluntary consensus standards use.

DOD Employee Participation -- The Department has 420 employees participating in the standards development activities of 48 voluntary standards bodies. 
DOD Adopted Voluntary Standards -- Since our input for the fiscal year (FY) 1998 report, we have adopted an additional 627 voluntary standards, bringing the total number of DOD-adopted voluntary standards to 8,618 .

Government Standards Replaced by Voluntary Standards -- The following 491 governmentunique specifications and standards were replaced by voluntary standards since our FY 1998 report:

Defense and Federal Specifications and Standards Superseded by Non-Government Standards Between October 1, 1998 and September 30, 1999

\section{NGS BODY}

Ameri can Natio nal Stand ards Insti tute (ANSI)

American Society for Testing and Materials (ASTM)

International Electrotechnical Commission (IEC)

National Aerospace Standards Committee (NA/NAS)

National Aerospace Standards Committee (NA/NAS)

\section{MILITARY/FED DOCUMENT}

MIL-B-55130/2 NOT 2

MIL-T-6945A NOT 2

MS14302 NOT 1

MIL-T-16343C(1) NOT 3

MIL-P-22296B NOT 2

MIL-D-24194(1) NOT 3

MIL-P-43988C NOT 2

MIL-R-46089C NOT 1

MS51561(1) NOT 1

MS51562(1) NOT 1

MS51563(1) NOT 1

MS51564(1) NOT 1

MS51565(1) NOT 1

MS51566(1) NOT 1

MS51567(1) NOT 1

MS51568(1) NOT 1

MS51569(1) NOT 1

MS51570(1) NOT 1

MS51571(1) NOT 1

MS51572(1) NOT 1

MS51573(1) NOT 1

MS51574(1) NOT 1

MIL-B-18/31D NOT 1

MIL-B-18/3D NOT 1

AN42THRUAN49 REV 6 NOT 1

AN229 REV 5 NOT 1

AN256 REV 5 NOT 2

AN302 NOT 3

AN315 REV 10 NOT 1

AN316 REV 11 NOT 1

AN320 REV 14 NOT 1

AN501 REV 6 NOT 1

AN961 REV 2 NOT 1

MS3212B NOT 2

MS3213A NOT 2

MS3369D NOT 1

MIL-P-5673D NOT 1

MIL-B-6812E NOT 1

MIL-B-7838C(1) NOT 1

MIL-DTL-7885/2D NOT 2

MIL-DTL-7885/6D NOT 2

MIL-R-7885/7C (1) NOT 2

\section{NGS REPLACEMENT DOC}

ANSI-C18.2

ASTM-B135-95

ASTM-B42-98

ASTM-A500-99

ASTM-D1710-96

ASTM-F859-95

ASTM-D3905-93

ASTM-D1056-98

ASTM-F1 145-92R97

ASTM-F1 145-92R97

ASTM-F1 145-92R97

ASTM-F1 145-92R97

ASTM-F1 145-92R97

ASTM-F1 145-92R97

ASTM-F1 145-92R97

ASTM-F1 145-92R97

ASTM-F1 145-92R97

ASTM-F1 145-92R97

ASTM-F1 145-92R97

ASTM-F1 145-92R97

ASTM-F1 145-92R97

ASTM-F1 145-92R97

IEC60086-2

IEC60086-2

NASM42THRU49

NASM229

NASM256

NASM302

NASM315

NASM316

NASM320

NASM501

NASM961

NASM3212

NASM3213

NASM3369

NASM5673

NASM6812

NASM7838

NAS9301-98

NAS9304-98

NAS9305-98 
MIL-R-7885/3C(1) NOT 2

MIL-B-8906C(2) NOT 1

MIL-F-8975/1A NOT 2

MIL-F-8975/7 NOT 1

MIL-F-8975/6 NOT 1

MIL-F-8975/3A NOT 1

MIL-F-8975/4A(1) NOT 1

MIL-F-8975/5A NOT 1

MS14144C(1) NOT 1

MS14145C NOT 1

MS14151(1) NOT 2

MS14155 NOT 2

MS14157B NOT 2

MS14219A NOT 1

DS14289 NOT 1

DS14290 NOT 3

MS16187B NOT 1

MS16205A NOT 3

MS16206A NOT 3

MS16228A(1) NOT 1

MIL-G-16491/1 NOT 1

MIL-G-16491/2 NOT 1

MIL-G-16491/3 NOT 1

MS16536A NOT 1

MS16556B(1) NOT 2

MS16562C NOT 2

MS17855A NOT 2

MS17984F NOT 1

MS17985G NOT 1

MS17986G NOT 1

MS17987G NOT 1

MS17989E NOT 1

MS17990E NOT 1

MS18067A NOT 2

MS20004THRUMS20024E NOT 1

MS20033THRUMS20046C NOT 1

MS20066A NOT 2

MS20067A NOT 2

MS20068A NOT 2

MS20392F NOT 1

MS20427H NOT 1

MS20604K NOT 1

MS20615G NOT 1

MS21042M NOT 1

MS21044H NOT 1

MS21047F NOT 1

MS21048F NOT 1

MS21050D NOT 1

MS21052F NOT 2

MS21053D NOT

MS21054E NOT 2

MS21057G NOT 1

MS21059J NOT 1

MS21061G NOT 1

MS21069G NOT 1

MS21072G(1) NOT 1

MS21073G NOT 1

MS21075H NOT 1

MS21078G(2) NOT 1

MS21079F NOT 1

MS21080D NOT 1

MS21082F NOT 1

MS21084B NOT 1

MS21086D NOT 1

MS21087B NOT 1
NAS9302-98

NASM8906

NASM8975/1

NASM8975/7

NASM8975/6

NASM8975/3

NASM8975/4

NASM8975/5

NASM14144

NASM14145

NASM14151

NASM14155

NASM14157

NASM14219

NASM14289

NAM14290

NASM16187

NASM16205

NASM16206

NASM16228

NASM16491/1

NASM16491/2

NASM16491/3

NASM 16536

NASM16556

NASM 16562

NASM17855

NASM17984

NASM17985

NASM17986

NASM17987

NASM17989

NASM17990

NASM18067

NASM20004THRU20024

NASM20033THRU20046

NASM20066

NASM20067

NASM20068

NASM20392

NASM20427

NASM20604

NASM20615

NASM21042

NASM21044

NASM21047

NASM21048

NASM21050

NASM21052

NASM21053

NASM21054

NASM21057

NASM21059

NASM21061

NASM21069

NASM21072

NASM21073

NASM21075

NASM21078

NASM21079

NASM21080

NASM21082

NASM21084

NASM21086

NASM21087 
MS21094(1) NOT 1

MS21095A NOT 2

MS21125F NOT 1

MS21130E NOT 1

MS21134 NOT 2

MS21140J NOT 1

MS21250L NOT 2

MS21258A NOT 1

MS21262D NOT 2

MS21266E(1) NOT 3

MS21287B NOT 2

MS21299A NOT 1

MS21314B NOT 1

MS21315A NOT 1

MS21318A NOT 2

MS21322D NOT 1

MS21333F NOT 1

MS21334B NOT 1

MIL-S-21472C NOT 1

MIL-DTL-22529/1C NOT 1

MIL-C-24066/4 D NOT 1

MS24661C NOT 1

MS24662B NOT 1

MS24665F NOT 2

MS24673D(1) NOT 1

MS24677D NOT 1

MS24678E NOT 1

MS24692D NOT 2

MIL-R-27384B NOT 1

MIL-K-27545B NOT 1

MS27576E NOT 1

MS27975D NOT 1

MS27984B NOT 3

MS33522C NOT 2

MS35140D NOT 1

MS35273C(1) NOT 2

MS35274C(1) NOT 1

MS35672B NOT 2

MS35674A NOT 2

MS35675B NOT 2

MS35677A NOT 2

MS35678B NOT 3

MS35751E NOT 1

MS35756E NOT 1

MS35792B NOT 1

MS35812E NOT 1

MS39086B NOT 2

MS39087F(1) NOT 1

MIL-S-43770(3) SUP 1 NOT 1

MIL-S-43770/1 A NOT 3

MIL-S-43770/2 A NOT 2

MIL-S-43770/3 NOT 3

MIL-S-43770/4 NOT 3

MIL-S-43770/5 NOT 3

MIL-S-43770/6 NOT 3

MIL-S-43770/7 NOT 3

MIL-S-43770/8 NOT 3

MIL-S-43770/9 NOT 3

MIL-S-43770/1 0 NOT 3

MIL-S-43770/1 1 NOT 3

MIL-S-43770/1 2A NOT 3

MIL-S-43770/1 3 NOT 3

MIL-S-43770/1 4 NOT 3

MIL-R-47195A NOT 2

MIL-R-47196A(1) NOT 3
NASM21094

NASM21095

NASM21125

NASM21130

NASM21134

NASM21140

NASM21250

NASM21258

NASM21262

NASM21266

NASM 21287

NASM21299

NASM21314

NASM21315

NASM21318

NASM21322

NASM21333

NASM21334

NASM21472

NASM22529/1

NASM24066/4

NASM24661

NASM24662

NASM24665

NASM24673

NASM24677

NASM24678

NASM24692

NASM27384

NASM27545

NASM27576

NASM27975

NASM27984

NASM33522

NASM35140

NASM35273

NASM35274

NASM35672

NASM35674

NASM35675

NASM35677

NASM35678

NASM35751

NASM35756

NASM35792

NASM35812

NASM39086

NASM39087

NASM43770

NASM43770/1

NASM43770/2

NASM43770/3

NASM43770/4

NASM43770/5

NASM43770/6

NASM43770/7

NASM43770/8

NASM43770/9

NASM43770/10

NASM43770/11

NASM43770/12

NASM43770/13

NASM43770/14

NASM47195

NASM47196 
National Electric al Manu facture rs Associa tion (NEMA)

Parachute Industry Association

Society of Automotive Engineers (SAE)

Society of Automotive Engineers (SAE)
MS51021C NOT 1

MS51023C NOT 1

MS51029B NOT 1

MS51031B NOT 1

MS51038B NOT 1

MS51109B NOT 2

MS51110B NOT 3

DS51417 NOT 1

MS51575A NOT 1

MS51833E(1) NOT 1

MS51834E(1) NOT 1

MS51896A(1) NOT 1

MS51923C NOT 1

MS51956A NOT 1

MS51958C(1) NOT 1

MS51963C NOT 1

MS51964E NOT 2

MS51975E NOT 1

MS51976A NOT 2

MS51977C NOT 1

MS51981C NOT 1

MS51982A NOT 1

MS51987A NOT 1

MIL-F-81177/1 NOT 2

MIL-F-81177/2 NOT 2

MIL-F-81177/3 NOT 2

MIL-R-83459/1 B NOT 1

MIL-R-83459/3 B NOT 2

MIL-N-85353/1( 1) NOT 2

MS122196 THRUMS122235D NOT 2

MS122236 THRUMS122275D NOT 1

MS124731 THRUMS1247 70D NOT 3

MIL-W-16878/4C(1) NOT 1

MIL-W-16878/24 A(1) NOT 1

MIL-W-16878/23 A(1) NOT 1

MIL-W-16878/13 B(1) NOT 1

MIL-W-16878/12 D(1) NOT 1

MIL-W-16878/11 B(1) NOT 1

MIL-W-16878/35 A NOT 1

MIL-W-16878/34 A(1) NOT 1

MIL-W-16878/28 A(1) NOT 1

MIL-W-16878/27 A(1) NOT 1

MIL-W-16878/26 A(1) NOT 1

MIL-W-16878/25 A(1) NOT 1

MIL-W-16878/5C(1) NOT 1

MIL-W-16878/20 A(1) NOT 1

MIL-W-16878/21 A(1) NOT 1

MIL-W-16878/22 A(1) NOT 1

MIL-W-16878/6C(1) NOT 1

MIL-W-80043C NOT 1

MS70085D NOT 2

MS70092B NOT 2

AN490 REV 8 NOT 1

MIL-C-601G(1) NOT 1

AN774 REV 7 NOT 1

AN775 REV 13 NOT 1

AN783 REV J NOT 1

AN784 REV L NOT 1
NASM51021

NASM51023

NASM51029

NASM51031

NASM51038

NASM51109

NASM51110

NASM51417

NASM51575

NASM51833

NASM51834

NASM51896

NASM51923

NASM51956

NASM51958

NASM51963

NASM51964

NASM51975

NASM51976

NASM51977

NASM51981

NASM51982

NASM51987

NASM81177/1

NASM81177/2

NASM81177/3

NASM83459/1

NASM83459/3

NASM85353/1

NASM122196THRU122235

NASM122236THRU122275

NASM124731THRU124770

NEMA-HP3-97

NEMA-HP3-97

NEMA-HP3-97

NEMA-HP4-97

NEMA-HP4-97

NEMA-HP4-97

NEMA-HP3-97

NEMA-HP3-97

NEMA-HP3-97

NEMA-HP3-97

NEMA-HP3-97

NEMA-HP3-97

NEMA-HP3-97

NEMA-HP3-97

NEMA-HP3-97

NEMA-HP3-97

NEMA-HP3-97

NEMA-EW1-88

PIA-PS70085

PIA-PS70092

SAE-AS4901

SAE-AS6011

SAE-AS5160

SAE-AS5161

SAE-AS1036D

SAE-AS1032C 


\begin{tabular}{|c|c|}
\hline AN804 REV G NOT 1 & SAE-AS1033C \\
\hline AN806 REV 7 NOT 1 & SAE-AS5168 \\
\hline AN807 REV 6 NOT 1 & SAE-AS5180 \\
\hline AN814 REV 14 NOT 1 & SAE-AS5169 \\
\hline AN815 REV 9 NOT 1 & SAE-AS5174 \\
\hline AN821 REV 8 NOT 1 & SAE-AS1034C \\
\hline AN824 REV 7 NOT 1 & SAE-AS1035C \\
\hline AN827 REV 7 NOT 1 & SAE-AS1036D \\
\hline AN833 REV 8 NOT 1 & SAE-AS1038C \\
\hline AN834 REV 9 NOT 1 & SAE-AS1039C \\
\hline AN837 REV 8 NOT 1 & SAE-AS1040C \\
\hline AN841 REV 5 NOT 1 & SAE-AS5184 \\
\hline AN849 REV 11 NOT 1 & SAE-AS5189 \\
\hline AN910 REV J NOT 1 & SAE-AS4859 \\
\hline AN911 REV 9 NOT 1 & SAE-AS4860 \\
\hline AN912 REV 9 NOT 1 & SAE-AS4861 \\
\hline AN914 REV 9 NOT 1 & SAE-AS4854 \\
\hline AN915 REV K NOT 1 & SAE-AS4855 \\
\hline AN916 REV 10 NOT 1 & SAE-AS4856 \\
\hline AN917 REV 8 NOT 1 & SAE-AS4857 \\
\hline AN918 REV 8 NOT 1 & SAE-AS4858 \\
\hline AN919 REV 9 NOT 1 & SAE-AS5174 \\
\hline AN933 REV 6 NOT 1 & SAE-AS4862 \\
\hline MS3320N NOT 2 & SAE-AS33201 \\
\hline MIL-U-3963A NOT 1 & SAE-AS39631 \\
\hline MIL-B-3990D(3) NOT 1 & SAE-AS39901 \\
\hline MIL-G-4343C NOT 1 & SAE-AMS-G-4343 \\
\hline MIL-S-4383C NOT 2 & SAE-AMS-S-4383 \\
\hline MIL-R-5001B NOT 1 & SAE-AMS-R-5001 \\
\hline MIL-L-5057F(2) NOT 1 & SAE-AS50571 \\
\hline MIL-F-5373D NOT 1 & SAE-AS53731 \\
\hline MIL-H-5440H SUP 1 NOT 1 & SAE-AS5440 \\
\hline MIL-C-5604B(3) NOT 1 & SAE-AS5604 \\
\hline MIL-C-5809/1 NOT 2 & SAE-AS58091/1 \\
\hline MIL-S-5944C NOT 1 & SAE-AS5944 \\
\hline MIL-G-6032D(1) NOT 1 & SAE-AMS-G-6032 \\
\hline MIL-B-6038A NOT 1 & SAE-AS6038 \\
\hline MIL-R-6130C NOT 1 & SAE-AMS-R-6130 \\
\hline MIL-C-6183B NOT 1 & SAE-AMS-C-6183 \\
\hline AN6289 REV 7 NOT 2 & SAE-AS5179 \\
\hline MIL-T-6302B(2) NOT 1 & SAE-AS6302 \\
\hline MIL-H-6399B NOT 2 & SAE-AS6399 \\
\hline MIL-S-6451E NOT 1 & SAE-AS6451 \\
\hline MIL-S-6758B NOT 1 & SAE-AMS-S-6758 \\
\hline MIL-T-6841D NOT 1 & SAE-AMS-T-6841 \\
\hline MIL-R-6855E SUP 1 NOT 1 & SAE-AMS-R-6855 \\
\hline MIL-W-6858D(1) NOT 2 & SAE-AMS-W-6858 \\
\hline MIL-H-6875H(2) NOT 1 & SAE-AMS-H-6875A \\
\hline MIL-W-6882F(2) NOT 1 & SAE-AS6882 \\
\hline MIL-I-7068A NOT 1 & SAE-AMS-I-7068 \\
\hline MIL-F-7092(2) NOT 4 & SAE-AS7092 \\
\hline MIL-T-7099E(1) SUP 1 NOT 1 & SAE-AS70991 \\
\hline MIL-P-7105B(1) NOT 1 & SAE-AS71051 \\
\hline MIL-S-7124B NOT 2 & SAE-AMS-S-7124 \\
\hline MIL-I-7171D NOT 1 & SAE-AMS-I-7171 \\
\hline MIL-F-7190B(1) NOT 1 & SAE-AMS-F-7190 \\
\hline MIL-H-7199A(2) NOT 2 & SAE-AMS-H-7199 \\
\hline MIL-L-7768B(1) NOT 1 & SAE-AS7768 \\
\hline MIL-L-7768/1 NOT 1 & SAE-AS7768/1 \\
\hline MIL-P-7788F(1) NOT 1 & SAE-AS7788 \\
\hline MIL-T-7928G(1) SUP 1 NOT 1 & SAE-AS7928 \\
\hline MIL-T-7928/7 NOT 1 & SAE-AS7928/7 \\
\hline MIL-T-7928/6A(1) NOT 1 & SAE-AS7928/6 \\
\hline MIL-T-7928/2C NOT 1 & SAE-AS7928/2A \\
\hline MIL-T-7928/1D NOT 1 & SAE-AS7928/1A \\
\hline
\end{tabular}


MIL-T-7928/5B(1) NOT 1

MIL-T-7928/4A(1) NOT 1

MIL-C-8073D(1) NOT 2

MIL-S-8559A(1) NOT 1

MIL-B-8568B NOT 1

MIL-S-8660C(2) NOT 1

MIL-K-8662E(1) NOT 2

MIL-I-8700A(1) NOT 1

MIL-H-8796C(1) NOT 1

MIL-S-8802F(4) NOT 2

MIL-C-8837B(1) NOT 1

MIL-S-8840B(1) NOT 1

MIL-F-8905B(1) NOT 1

MIL-B-8914B(3) NOT 1

MIL-B-8952B NOT 1

MIL-B-8964 NOT 1

MIL-B-8976(4) NOT 1

MS9021D NOT 2

MIL-T-9046J(2) NOT 2

MS9058D NOT 1

MIL-C-9084C(1) NOT 1

MS9112 NOT 2

MS9142A(1) NOT 2

MS9144A NOT 2

MS9201B NOT 2

MS9202A(1) NOT 3

MS9203A(2) NOT 3

MS9204A(1) NOT 1

MS9205A(1) NOT 1

MS9217 NOT 2

MS9284 NOT 2

MS9364A NOT 2

MS9373A(1) NOT 1

MS9451A(1) NOT 1

MS9455A(1) NOT 1

MS9456A(1) NOT 1

MS9549 NOT 2

MS9582B NOT 2

MS9588D(1) NOT 1

MS9686 NOT 2

MS9697A NOT 2

MS9734 NOT 2

MS9741 NOT 2

MS9771 NOT 3

MS9772 NOT 2

MS9805 NOT 2

MS9808 NOT 2

MS9842 NOT 2

MS9843 NOT 2

MS9845 NOT 2

MS9846 NOT 2

MS9847 NOT 2

MS9848 NOT 1

MS9882 NOT 2

MS9885 NOT 2

MS9955 NOT 2

MS9956 NOT 1

MS9966 NOT 2

MS9967 NOT 2

Society of Automotive Engineers (SAE)
AND10081 REV 4 NOT 1

MS14101J NOT

MS14114 NOT 2

DS14243 NOT 2

DS14244 NOT 2

DS14488 NOT 1
SAE-AS7928/5

SAE-AS7928/4

SAE-AMS-C-8073

SAE-AMS-S-8559

SAE-AS 8568

SAE-AS 8660

SAE-AS8662

SAE-AS8700

SAE-AS8796

SAE-AMS-S-8802

SAE-AMS-C- 8837

SAE-AMS-S- 8840

SAE-AS8905

SAE-AS8914

SAE-AS8952

SAE-AMS-B-8964

SAE-AS8976

SAE-AS3578

SAE-AMS-T-9046

SAE-AS9058

SAE-AMS-C-9084

SAE-AS9112

SAE-AS9142

SAE-AS9144

SAE-AS9201

SAE-AS9202

SAE-AS9203

SAE-AS9204

SAE-AS9205

SAE-AS9217

SAE-AS9284

SAE-AS9364

SAE-AS9373

SAE-AS9451

SAE-AS9455

SAE-AS9456

SAE-AS9549

SAE-AS9582

SAE-AS9588

SAE-AS9686

SAE-AS9697

SAE-AS9734

SAE-AS9741

SAE-AS9771

SAE-AS9772

SAE-AS9805

SAE-AS9808

SAE-AS9842

SAE-AS9843

SAE-AS9845

SAE-AS9846

SAE-AS9847

SAE-AS9848

SAE-AS9882

SAE-AS9885

SAE-AS9955

SAE-AS9956

SAE-AS9966

SAE-AS9967

SAE-AS10081

SAE-AS14101

SAE-AS14114

SAE-AS14243

SAE-AS14244

SAE-AS14244 
MIL-R-17852C(1 ) NOT 1

MS17983 NOT 2

MS18013A NOT 1

MS18121G NOT 1

MIL-L-18276C(1) NOT 1

MIL-F-18280F SUP 1 NOT 1

MIL-L-18331B NOT 1

MIL-P-19692E SUP 1 NOT 1

MIL-S-20708E(2) SUP 1B NOT 1

MS20819G NOT 1

MS20913G NOT 1

MIL-T-21014D(1) NOT 1

MS21155B NOT 2

MIL-A-21180D(1) NOT 1

MS21230B NOT 2

MS21231B NOT 2

MS21232A NOT 2

MS21233B NOT 2

MS21234 NOT 2

MS21235 NOT 2

MS21236 NOT 2

MS21237 NOT 2

MS21431A NOT 1

MS21438C NOT 1

MS21439B NOT 1

MS21447A NOT 1

MIL-F-21608E(1) NOT 1

MS21935C NOT 1

MS21938D NOT 1

MS21945C NOT 1

MIL-W-21985(2) NOT 1

MIL-T-22085E NOT 1

MIL-A-22145C NOT 1

MIL-DTL-22499D NOT 1

MIL-DTL-22499/4A NOT 1

MIL-DTL-22499/1B NOT 1

MIL-DTL-22499/2A NOT 1

MIL-DTL-22499/3B NOT 1

MIL-C-22587B NOT 1

MIL-A-22771D NOT 1

MIL-S-22805B(1) NOT 1

MIL-P-22968B NOT 1

MIL-I-23011C NOT 1

MIL-DTL-23053E SUP 1A NOT 1

MIL-DTL-23053/8C NOT 1

MIL-DTL-23053/7C NOT 1

MIL-DTL-23053/17B NOT 1

MIL-DTL-23053/16B NOT 1

MIL-DTL-23053/15B NOT 1

MIL-DTL-23053/14B NOT 1

MIL-DTL-23053/13B NOT 1

MIL-DTL-23053/12C NOT 1

MIL-DTL-23053/11C NOT 1

MIL-DTL-23053/10D NOT 1

MIL-DTL-23053/1C NOT 1

MIL-DTL-23053/4D NOT 1

MIL-DTL-23053/5C NOT 1

MIL-DTL-23053/6D NOT 1

MIL-S-23190/1 A NOT 1

MIL-S-23190/3 NOT 1

MIL-I-23479B(1) NOT 3

MIL-A-23899B NOT 1

MS24000F NOT 1

MS24001F NOT 1

MS24388H NOT 1
SAE-AS17852

SAE-AS17983

SAE-AS18013

SAE-AS18121

SAE-AS18276

SAE-AS18280

SAE-AMS-L-18331

SAE-AS19692A

SAE-AS20708

SAE-AS5176

SAE-AS4863

SAE-AMS-T-21014

SAE-AS21155

SAE-AMS-A-21180

SAE-AS21230

SAE-AS21231

SAE-AS21232

SAE-AS21233

SAE-AS21234

SAE-AS21235

SAE-AS21236

SAE-AS21237

SAE-AS21431

SAE-AS21438

SAE-AS21439

SAE-AS214

SAE-AS21608

SAE-AS21935

SAE-AS21938

SAE-AS21945

SAE-AS21985

SAE-AMS-T-22085

SAE-AS22145

SAE-AMS-DTL-22499

SAE-AMS-DTL-22499/4

SAE-AMS-DTL-22499/1

SAE-AMS-DTL-22499/2

SAE-AMS-DTL-22499/3

SAE-AMS-C-22587

SAE-AMS-A-22771

SAE-AS22805

SAE-AMS-P-22968

SAE-AMS-I-23011

SAE-AMS-DTL-23053

SAE-AMS-DTL-23053/8

SAE-AMS-DTL-23053/7

SAE-AMS-DTL-23053/17

SAE-AMS-DTL-23053/16

SAE-AMS-DTL-23053/15

SAE-AMS-DTL-23053/14

SAE-AMS-DTL-23053/13

SAE-AMS-DTL-23053/12

SAE-AMS-DTL-23053/11

SAE-AMS-DTL-23053/10

SAE-AMS-DTL-23053/1

SAE-AMS-DTL-23053/4

SAE-AMS-DTL-23053/5

SAE-AMS-DTL-23053/6

SAE-AS23190/1

SAE-AS23190/3

SAE-AS23479

SAE-AS23899

SAE-AS24000

SAE-AS24001

SAE-AS1031C 
MS24389F NOT

MS24390F NOT 1

MS24391H NOT 1

MS24392F NOT 1

MS24394G NOT 1

MS24395G NOT 1

MS24396E NOT 1

MS24401D NOT 1

MS24402D NOT 1

MS24403E NOT 1

MS24404E NOT 1

MS24405D NOT 1

MS24509K NOT 1

MS24510K NOT 1

MS24518B NOT 1

MS24519C NOT 1

MS24522B NOT 1

MS24563F NOT 1

DOD-F-24610 NOT 1

MS24651C NOT 1

MS24652B NOT 1

MS24654C NOT 1

MS25019G NOT 2

MS25027F NOT 1

MIL-C-25050A(2) NOT 2

MIL-E-25109 NOT 3

MIL-G-25667B(1) NOT 3

MIL-G-25871B(1) NOT 2

MIL-DTL-27536C NOT 1

MS33620B NOT 1

MS33658A NOT 3

MS35867C NOT 2

MS35868B NOT 2

MS35869C NOT 2

MS35870C NOT 2

MS35871C NOT 1

MS35872C NOT 2

MS35873C NOT 2

MS35926C NOT 2

MIL-C-38334A(2) NOT 2

MS39155 NOT 1

MS49008B NOT 1

MIL-A-81596A NOT 1

MIL-R-81835(1) NOT 1

MIL-T-81914/4 NOT 1

MIL-T-81914/5 NOT 3

MIL-C-81986(1) NOT 2

MIL-C-85061B(2) NOT 1

AN115401THRUAN115450 REV 2 NOT AN115501THRUAN115550 REV 2 NOT AN115601THRUAN115650 REV 2 NOT AN115651THRUAN115700 REV 3 NOT AN115901THRUAN115950 REV 3 NOT AN115951THRUAN116000 REV 3 NOT AN116001THRUAN116050 REV 3 NOT AN116101THRUAN116150 REV 4 NOT AN116925THRUAN116960 REV 1 NOT AN121651THRUAN121700 REV 3 NOT AN121701THRUAN121750 REV 3 NOT AN121851THRUAN121925 REV 3 NOT AN128687THRUAN128998 REV 2 NOT AN150301THR UAN150400 NOT 2

AN151401THRUAN151700 REV 2 NOT AN151701THRUAN152000 REV 4 NOT AN153201THRUAN153500 REV 5 NOT
SAE-AS1032C

SAE-AS1033C

SAE-AS5169

SAE-AS5174

SAE-AS1038C

SAE-AS1039C

SAE-AS1040C

SAE-AS1034C

SAE-AS1035C

SAE-AS1036D

SAE-AS5168

SAE-AS24405

SAE-AS24509

SAE-AS24510

SAE-J1231-97

SAE-J1231-97

SAE-J1231-97

SAE-AS24563

SAE-AMS-F-24610

SAE-AS24651

SAE-AS24652

SAE-AS24654

SAE-AS25019

SAE-AS25027

SAE-AS25050

SAE-AS25109

SAE-AMS-G-25667

SAE-AMS-G-25871

SAE-AS5355

SAE-AIR797E

SAE-AS5132

SAE-J513-94

SAE-J513-94

SAE-J513-94

SAE-J513-94

SAE-J513-94

SAE-J513-94

SAE-J513-94

SAE-J513-94

SAE-AMS1640

SAE-J516-94

SAE-J513-94

SAE-AMS-A-81596

SAE-AMS-R-81835

SAE-AMS-T-81914/4

SAE-AMS-T-81914/5

SAE-AMS-C-81986

SAE-AS5356

SAE-AS115401THRUAS115450 SAE-AS115501THRUAS115550 SAE-AS115601THRUAS115650 SAE-AS115651THRUAS115700 SAE-AS115901THRUAS115950 SAE-AS115951THRUAS116000 SAE-AS116001THRUAS 116050 SAE-AS116101THRUAS116150 SAE-AS116925THRUAS 116960 SAE-AS121651THRUAS121700 SAE-AS121701THRUAS 121750 SAE-AS121851THRUAS121925 SAE-AS128687THRUAS 128998 SAE-AS150301THRUAS150400 SAE-AS151401THRUAS 151700 SAE-AS151700THRUAS 152000 SAE-AS153201THRUAS153500 
Effectiveness of Circular A-119 Policy -- The current OMB Circular A-119 provides clear guidance on using voluntary consensus standards and participating in voluntary consensus standards bodies. As written, this circular reinforces DOD policies regarding use of voluntary consensus standards, reliance on performance documents, and encouragement of participation in voluntary standards bodies. DOD believes the Circular s plain language format greatly enhances its effectiveness. DOD does not believe additional changes are required at this time. 


\section{NATIONAL COMMUNICATION SYSTEM (NCS)}

Dr. Peter M. Fonash, Chief, Technology and Programs Division, and Chair, Federal Telecommunications Standards Committee (FTSC), is the Office of the Manager, National Communications System (OMNCS), focal point for telecommunications and related information system standards. His telephone number is (703) 607-6200, and his email address is fonashp@ncs.gov.

The OMNCS provides the chair of the FTSC. This interagency committee prepares standards and recommendations on matters affecting national security and emergency preparedness (NS/EP) and in other areas of communications approved by the committee on the basis of requests from members. It also provides advice to members on how to best represent the Government s NS/EP interests in work in industry and international standards committee.

The FTSC and members of the OMNCS work extensively with voluntary standards organizations to ensure that Government requirements are considered as the standards are developed. The OMNCS has 15 employees who participate in industry voluntary standards activities. The following paragraph lists the committees in which they participate.

Staff of the OMNCS participate in the following voluntary standards related committees:

Organizations Accredited by the American National Standards Institute (ANSI):

- Committee T1, Telecommunications, and its technical subcommittees

- Telecommunications Industry Association committees TR-8, TR-45

- Institute of Electrical and Electronics Engineers

Commercial and Multi-National Organizations Not Accredited by ANS I:

- $\quad$ ATM Forum

- Internet Engineering Task Force

- Network Interconnection Interoperability Forum (NIFF)

- Telecommunications and Internet Protocol Harmonization Over Networks (TIPHON)

- TeleManagement Forum

- Electronic Communications Implementation Committee (ECIC)

Federal, State, and Local Committees:

- Federal Telecommunication Standards Committee (OMNCS furnishes Chair and Executive Secretary)

- International Telecommunication Advisory Committee and its study groups (Department of State) 
- Association of Public Safety Communications Officials (APCO)

-- Project 25 (land mobile radio)

-- Project 34 (wireless high-speed data)

International Organizations:

- International Telecommunications Union-Telecommunications Sector (ITU-T)

(OMNCS heads U.S. delegations to 3 study groups)

- International Telecommunications Union-Radio Sector (ITU-R) 


\section{DEPARTMENT OF EDUCATION (DOED)}

For the past several years, DOED has been actively working with the American National Standards Institute (ANSI) on developing EDI transaction sets through their Accredited Standards Committee (ASC) X12 committee. This committee is charged with developing uniform standards for electronic interchange of business transactions. The X12 Committee develops standards to facilitate electronic interchange relating to such business transactions as order placement and processing, shipping and receiving, invoicing, payment, and cash application data associated with the provision of products and services.

DOED s National Center for Education Statistics (NCES) has one voting member and has sponsored the work of task groups to attend ANSI ASC X12 meetings. Information about the activities that NCES has been involved in can be obtained at $<$ http://nces. ed.gov/edi $>$. In addition, DOED has had another voting member that is part of the Department s Office of Postsecondary Education. The Department has been involved in developing EDI transaction sets for Student Financial Aid. These activities fall under the umbrella of Project EASI. For more information on Project EASI, please visit $<$ http://easi.ed.gov/inside_projecteasi/HTML/inside_main.html $>$.

Participation in this voluntary consensus building body has allowed DOED to forge ahead in developing standards while including the necessary members of the affected communities to help transition to adoption.

Transaction sets that DOED has promulgated for information about students (both at the elementary/secondary level and at the postsecondary level) and other aspects of education are the following:

Transaction Sets Relating to Individual Student Records

TS 130 - Student Educational Record (Transcript)

TS 131 - Student Educational Record (Transcript) Acknowledgment

TS 138 - Testing Results Request and Report

TS 146 - Request for Student Educational Record (Transcript)

TS 147 - Response to Request for Student Educational Record (Transcript)

TS 189 - Application for Admission to Educational Institutions

Implementation Guides

Transaction Sets Relating to Personnel Records

TS 132 - Personnel Information 


\section{Transaction Sets Relating to Student Financial Aid Records}

TS 135 - Student Loan Application

TS 139 - Student Loan Guarantee Result

TS 144 - Student Loan Transfer and Status Verification

TS 190 - Student Enrollment Verification

TS 191 - Student Loan Pre-Claims and Claims

TS 810 - Invoice

TS 820 - Payment Order/Remittance Advice

Transaction Sets Relating to Institutional Records

TS 133 - Educational Institutional Profile

TS 152 - Statistical Government Information used to transmit CCD, IPEDS and Library surveys to NCES

TS 188 - Educational Course Inventory 


\section{DEPARTMENT OF ENERGY (DOE)}

The DOE implements the Federal guidance and requirements of Office of Management and Budget (OMB) Circular A-119 and the statutory requirements of Public Law (P.L.) 104-113 (15 U.S.C. 272) on the use of voluntary consensus standards through specific Departmental directives (policy, requirements, guides, and technical standards) and supporting management systems.

Foremost is DOE's Integrated Safety Management System (ISMS). ISMS incorporates principles of management that serve to integrate management of DOE's worker, public, and environmental health and safety with its business management, using standards as one of its primary tools.

DOE also has established internal policies as the top tier of DOE requirements driving the implementation of Federal Law and Policy. DOE Policy 251.1, Directives System, establishes a Directives System for managing DOE requirements and guidance documents and incorporates technical standards (i.e., those standards that are specifically addressed in P.L. 104-113) as a key element of the Department s directives system hierarchy. The focus of the Directives System is DOE's environment, safety and health requirements, and guidance. The Directives System policy clearly states DOE s preference to adopt National Consensus Standards and other commercial and industry standards ... in the conduct of DOE's activities. This policy also pertains to the use of mandated government-unique standards in DOE rulemaking, Orders, and procurement processes. DOE requirements specified in Orders and rules reference appropriate voluntary consensus standards when they are acceptable to meet requirements. Another policy, DOE Policy 410.1A, Promulgating Nuclear Safety Requirements, also requires notice and comment to promulgate new nuclear safety requirements. New nuclear safety requirements promulgated by the Department are performance-based rules and Orders that permit the adoption of voluntary consensus standards as acceptable methods to implement requirements. DOE also specifies responsibilities for managers and organizations in managing and implementing P.L. 104-113 and OMB Circular A-119 requirements in its DOE Manual 411.1-1A, "Safety Management Functions, Responsibilities, and Authorities Manual (FRAM)."

These Departmental policies, requirements, and responsibilities on the use of voluntary consensus standards are implemented through a DOE-wide management system and infrastructure established through DOE Order 252.1, Technical Standards Program, an accompanying program Guide, DOE Guide 252.1-1, "Technical Standards Program Guide," and Technical Standards Program Procedures (TSPPs).

DOE Order 252.1 establishes the DOE Technical Standards Program (TSP), and is designed to implement Federal and DOE technical standards requirements and manage internal standards development activities across DOE. DOE Order 252.1 updates DOE Order 1300.2A, 
incorporating references to P.L. 104-113 and the February 1998 revision to OMB Circular A-119. The new Order reinforces the requirement for DOE elements to use voluntary consensus standards in preference to Federal and DOE (i.e., government unique) standards, consistent with P.L. 104-113 and OMB Circular A-119. The TSP further encourages and supports staff participation in the planning, development, and coordination activities of national and international standards developing organizations (SDOs).

The TSP Guide and TSPPs provide information on the TSP functions and management, program resources and services, and the DOE processes and procedures for selecting, developing, and maintaining DOE Technical Standards and using voluntary consensus standards. The TSP Guide also provides basic information on reporting the use of government-unique standards in both regulation (DOE is nominally self-regulating in key areas such as nuclear safety) and procurement (where most reporting is category-based). The DOE TSP plans to develop further reporting procedures to assist program officials conducting procurements. The DOE TSPPs incorporate working level implementation of the technical standards provisions of P.L. 104-113 and OMB Circular A-119, and DOE currently manages its technical standards activities in conformance with Federal policy and requirements.

Another element serving implementation of P.L. 104-113 and OMB Circular A-119 is DOE s Department Standards Program. This Program was established to institute standards (in this application, standards include policy, laws, rules, guides, and technical standards) as the basis for work throughout the Department. A Department Standards Committee (DSC) was established in 1994 to establish DOE standards policy and help remove barriers to implementing a Department-wide standards-based culture. The DSC assists DOE line organizations in the implementation of this Department Standards Program. The Criteria for the Department s Standards Program, DOE/EH/-0416, August 1994, describes elements of the standards-based operating culture envisioned by DOE leadership. Information on the Department Standards Program and the DSC can be accessed at the following Intemet address (Uniform Resource Locator $\{\mathrm{URL}\})$ :

$<$ http://tis.eh.doe.gov/dsc $>$

The DSC has sponsored development and implementation of a DOE-wide process that enables DOE contractors to select voluntary consensus standards as the basis for their work in-lieu-of DOE-developed or other government-unique standards, when such standards are appropriate for the work and work-related hazards. This Work Smart standards approach (also referred to as the necessary and sufficient process) enables DOE laboratory and management and operating or integrating contractors, with DOE approval, to identify and apply the set of standards (including technical standards) that best fits their activities and adequately addresses related hazards. This approach focuses on outcomes and performance, rather than detailing how things are to be done within DOE. The process is part of the DOE ISMS and is supported by a major contract reform effort designed to more closely link performance expectations with contractual obligations based on standards. 
Key Departmental policy and requirements documents defining the "Work Smart" approach include DOE Policy 450.3, Authorizing Use of the Necessary and Sufficient Process for Standards-Based Environment, Safety and Health Management, and DOE Manual 450.3-1, The Department of Energy Closure Process for Necessary and Sufficient Sets of Standards. Field pilot projects of the approach have been completed, and significant efficiencies and costsavings have been demonstrated. The Work Smart standards approach now covers a broad range of Department programs and facilities. During fiscal year (FY) 1999, DOE developed and updated additional guidance and standards to support the Work Smart process.

The DOE Standards Executive, Richard L. Black, Director, Office of Nuclear Safety Policy and Standards, continues to be responsible for developing and implementing the DOE TSP thro ugh DOE's TSP Manager and the TSP. He also advises and provides staff support to the Department Standards Committee. Through Mr. Black s participation on the Interagency Committee on Standards Policy (ICSP), DOE supports ICSP activities and policy implementation, and provides "lessons-learned" information to other Federal agencies on the DOE s approach to establishing a standards-based culture.

As noted above, DOE Order 252.1 emphasizes the use of voluntary consensus standards within the Department. DOE's Technical Standards Program Office (TSPO) operates under this Order to implement program policy, support the conversion of Department standards to voluntary consensus standards, identify voluntary consensus standards that can suit Department needs, develop and maintain databases to support the program and meet reporting requirements, and coordinate day-to-day Department technical standards activities. The TSPO has developed procedures, methods, and training approaches to implement the DOE TSP; communicate the policy to use voluntary consensus standards throughout DOE; and support participation in SDO activities related to DOE missions and functions. The TSPPs establish a 5-year standards review cycle to check for continued applicability. The procedures also provide guidance on the conversion of Department standards to voluntary consensus standards.

Information on the TSP and the TSPO can be accessed at the following Internet address (URL):

$<$ http://tis.eh.doe.gov/techstds/>

To coordinate consistent implementation of Federal and DOE policy and requirements at the working level, DOE senior managers have designated Technical Standards Managers (approximately 70 individuals) representing the various Department headquarters, field, laboratory and contractor organizations. Established in 1992, the Technical Standards Managers Committee (comprised of these Technical Standards Managers) operates under the DOE TSP, supports the DOE sites in technical standards activities, facilitates communications on program implementation issues, and participates in establishing program goals and procedures.

Publications documenting the voluntary consensus standards adopted by DOE and the personnel participating in the activities of SDOs are developed by the TSPO. The information in those publications is electronically posted for Internet access and provided to OMB annually. 
During FY 1999, the TSP continued the recognition of topical standards committees within DOE. Topical committees provide a venue for DOE-wide coordination with national and international SDOs in such diverse areas as laboratory accreditation, metrology, fire protection, environmental management systems, chemical safety, emergency management, and nuclear safety training. These committees are composed of subject matter experts from across the DOE community, and serve as focal points for standards activities in specific technical areas. The topical committees provide a forum for all interested DOE parties to join and participate in reviewing technical standards produced by counterpart SDOs, address standards application issues within their area of technical expertise, and work to develop Department and Federal positions on standards issues. As of November 10, 1999, the TSP has recognized 23 DOE topical committees. (These committees are identified on the program Internet address listed above.)

The Department has also established a DOE Information Technology Standards Program (Internet address is: $<\mathrm{http}: / / \mathrm{www}$-it.hr.doe.gov/Standards/index.html $>$ ) that is conducted in accordance with the DOE TSP. The DOE Information Technology Standards Program is managed by staff from DOE s Office of the Chief Information Officer with assistance from over 70 designated DOE and contractor Information Technology Points-of-Contact representing key programs and sites. It coordinates information technology standards activities Department-wide, including the identification, adoption, implementation, and retirement of non-Government and Government information technology standards in support of the DOE Information Architecture. This program has stressed the use of international and voluntary consensus information technology standards over development of internal standards in its adoption processes.

The Department also implements a legislativ ely mandated, multiyear effort to improve the energy efficiency in the Nation s buildings through energy efficiency standards, codes and guidelines for buildings, building equipment, and appliances through its Office of Energy Efficiency and Renewable Energy (Internet address is: $<$ http://www.eren.doe.gov/ $>$ ). The Department s codes and standards development efforts in these areas are closely coordinated with SDOs and include early involvement of industry and state stakeholders and relevant Federal agencies.

DOE continues to take a proactive approach to standards and standards management even as its mission continues to evolve in response to the conclusion of the Cold War and shrinking Congressional appropriations. Within DOE, a number of programs and facilities have shifted their focus from production, research, and/or development to environmental remediation and restoration, where DOE will literally be breaking new ground and setting standards for others to follow. In addition, Department staffing levels are declining to meet Congressional budget constraints. Still, in the face of a changing mission and a reduced workforce, DOE continues to actively use and support the develop ment of voluntary consensus standards to meet its needs. In FY 1999, the number of voluntary consensus standards adopted for use increased to 916 (840 in 1998 and 809 in 1997). However, the number of individuals participating in voluntary consensus standards activities decreased to 668 (681 in 1998 and 871 in 1997), and the number of documented participations in standards developing groups declined to 1,306 (1,321 in 1998 and 
1,540 in 1997). The Department believes this reflects the very significant downsizing and budget cuts experienced by DOE in recent years, rather than any reduced interest on the part of DOE organizations.

Also, DOE (through the TSPO) is continuing its initiative (in response to contacts from SDOs on how the Department is meeting P.L. 104-113) to better define candidate DOE Technical Standards for conversion to voluntary consensus standards. The Department is continuing to work with representatives of the American National Standards Institute (ANSI) Nuclear Standards Board (NSB) on the conversion of selected DOE Technical Standards to voluntary consensus standards. (Four candidate standards are in the conversion process.)

Other highlights of DOE s interaction with SDOs include the following:

From FY 1993 through FY 1997, DOE conducted annual national workshops promoting the TSP and the use of voluntary consensus standards within the Department.

Approximately 150 standards developers and users attended each workshop.

In August 1998, DOE hosted the first-ever Federal Technical Standards Workshop with the goal of furthering the implementation of P.L. 104-113 throughout the Federal Government. The Workshop was cosponsored with the National Institute of Standards and Technology; Environmental Protection Agency, National Aeronautics and Space Administration; Food and Drug Administration; and the Partnership in Reliability, Maintainability, and Supportability Standards. More than 200 standards developers and users attended the workshop. Contingent on receipt of additional program funding as increased ICSP support, DOE would like to organize and conduct another Federal-level workshop in FY 2000.

In addition to the ANSI-NSB, DOE representatives participate on ANSI s Board of Directors and Executive Standards Council. DOE also participates in a number of international standards groups such as: International Organization for Standardization (ISO)/Technical Committee (TC) 85, Nuclear Energy; ISO/TC 176, Quality Assurance; and ISO/TC 207, Environmental Management.

Reporting Requirements for OMB Circular A-119:

The number of voluntary consensus standards bodies in which there is agency participation, as well as the number of agency employees participating:

- Number of standards bodies: 58

- Number of agency personnel participating: 668

- Total number of agency participation: 1,306 
The number of voluntary consensus standards the agency has used since October 1, 1998, based on the procedures set forth in sections 11 and 12 of the Circular:

916

Identification of voluntary consensus standards that have been substituted for government-unique standards as a result of an agency review under section $15 b(7)$ of the Circular:

0

An evaluation of the effectiveness of this policy and recommendations for any changes:

The guidance in OMB Circular A-119 appears to be sufficient in terms of outlining the basic functions and responsibilities of Federal agency standards management and standards participation activities. It allows sufficient latitude for each Federal agency to develop its own approach tailored to specific agency needs, and places the emphasis on outcomes rather than processes.

As required by P.L. 104-113, when the agency used government-unique standards in lieu of voluntary consensus standards:

There were no recorded cases in FY 1999 where the Department selected to use an internal standard in lieu of an equivalent, existing voluntary consensus standard. 


\section{DEPARTMENT OF HEALTH AND HUMAN SERVICES (HHS)}

Food and Drug Administration (FDA)

Summary of the nature and extent of FDA participation in the development and utilization of voluntary consensus standards:

The number of instances when the agency used government-unique standards in lieu of voluntary consensus standards:

0

The number of voluntary consensus standards the agency has used since October 1, 1998, based on the procedures set forth in sections 11 and 12 of the Circular:

$90^{*}$

* NOTE: Includes standards recognized under the Food and Drug Administration Modernization Act of 1997 (FDAMA).

Identification of voluntary consensus standards that have been substituted for government-unique standards as a result of an agency review under section $15 b(7)$ of the Circular:

0

The number of voluntary consensus standards bodies in which there is agency participation:

43

The number of agency employees participating:

$255^{*}$ (on 544 voluntary consensus standards development committees)

* NOTE: Individual employees with specific expertise often participate simultaneously on two or more standards development committees within the same or different standards bodies. Therefore, 255 agency employees participate on 544 standards development committees, within 43 voluntary consensus standards development bodies. 
Evaluation of the effectiveness of Circular A-119 policy and recommendations for any changes:

The policy and recommendations contained in Circular A-119 are consistent with FDA s framework for standards management as announced in the Federal Register of October 11, 1995, and enhanced by FDAMA. Resource constraints oblige the agency to focus attention on the highest priority activities and to strive to make its participation in those activities very effective.

Voluntary consensus standards are most relevant for medical devices, where they are used extensively in the agency s regulatory work and where the majority of the agency s standards activities are centered. Voluntary consensus standards are less relevant in the areas of human and veterinary pharmaceuticals, biologicals, and food, where such standards are generally neither available nor being developed, and where standards of other international organizations (World Health Organization (WHO), Food and Agricultural Organization (FAO), International Conference on Harmonisation of Technical Requirements for Registration of Pharmaceuticals for Human Use (ICH)) as well as regulatory standards predominate.

\section{Narrative Summary}

The central purpose for FDA involvement in the development and use of standards is to assist the agency in fulfilling its domestic public health and regulatory missions. The Agency participates widely in the development of standards, both domestic and international, and adopts or uses standards when this action will enhance its ability to protect consumers and the effectiveness or efficiency of its regulatory efforts. Further, using standards, especially international ones, is a means to facilitate the harmonization of FDA regulatory requirements with those of foreign governments, and thus to further domestic and global public health protection. Therefore, FDA encourages participation in the development of standards as a useful adjunct to regulatory controls.

FDA has been involved in standards activities for more than 20 years. In January 1977, the Agency promulgated a final regulation now found at 21 CFR 10.95 , covering participation by FDA employees in standards development activities outside the agency. This regulation encourages FDA participation in standards activities that are in the public interest, and specifies the circumstances under which FDA employees can participate in various types of standards bodies.

The Agency built upon that rule with a draft policy statement published in the Federal Register on November 28, 1994, and a subsequent final policy published on October 11, 1995. Entitled International Harmonization; Policy on Standards, it provides the Agency s overall policy on development and use of standards for all product areas regulated by the Agency. In an initiative aimed at furthering harmonization, on January 28, 1995, FDA published in the Federal Register a 
proposed rule to facilitate the sharing of draft regulations and other predecisional documents with State and foreign officials. The final rule, Public Information; Communications with State and Foreign Government Officials, was published on December 8, 1995.

FDA s development and use of voluntary con sensus standards varies within each of the Agency s centers, because of differing availability and applicability of such standards in each product area. Voluntary consensus standards are most relevant to medical devices, and consequently the majority of the Agency s standards activities addressed by Circular A-119 are centered there.

\section{$\underline{\text { Center for Devices and Radiological Health (CDRH) }}$}

On October 10, 1997, a draft guidance document was made available for public comment on the Agency s Internet home page, which provided guidance to FDA medical device reviewers on the use of the International Electrotechnical Commission (IEC) 60601 series of standards, including declaration of conformity to the standards, during the evaluation of premarket submissions for electrical medical devices. A notice announcing the availability of the draft guidance entitled Use of IEC 60601 Standards - Medical Electrical Equipment was published in the Federal Register on January 13, 1998. Written comments were due to the Agency by April 13, 1998.

Section 204 of the Food and Drug Administration Modernization Act of 1997 (FDAMA) (P.L. 105-115, 111 Stat. 2296), November 21, 1997, amended section 514 of the Federal Food, Drug, and Cosmetic Act (21 U.S.C. 360d), allowing the Agency to recognize consensus standards established by international and national standards developing organizations that may be used to satisfy identified portions of device premarket review submissions or other requirements. In a Federal Register notice published on February 25, 1998, the Agency announced the availability of a guidance document entitled Recognition and Use of Consensus Standards describing how FDA planned to implement that part of FDAMA, and providing an initial list of recognized standards.

The Agency decided not to finalize the draft guidance document entitled Use of IEC 60601 Standards - Medical Electrical Equipment, and withdrew it in a Federal Register notice on October 16, 1998. In its place, the Agency published modifications to the initial list of standards (originally published in the February 25, 1998 notice) that will be recognized for use in the premarket review process. Recognition of the standards became effective on November 16, 1998, and assist manufacturers who elect to declare conformity with consensus standards to meet all or part of medical device review requirements. Periodic updates are announced.

Due to its extensive participation in voluntary consensus standards activities, CDRH has maintained a database to track the standards activities of its employees for many years. The Center recently invested in, and routinely uses, searchable ROM databases of voluntary consensus standards to facilitate reference to current voluntary consensus standards by agency reviewers. 
In June 1999, CDRH hosted the Global Harmonization Task Force (GHTF), an intergovernmental consortium to foster medical device regulatory harmonization. During the meeting, the CDRH official serving as GHTF Chair signed a Memorandum of Understanding with the Chair of the Interagency Organization for Standardization (ISO) committee responsible for many aspects of device standards (Technical Committee 210).

Center for Drug Evaluation and Research (CDER)/Center for Biologics Evaluation and Research $\underline{(\mathrm{CBER})}$

Voluntary consensus standards are less applicable to pharmaceutical and biological products. Therefore, CDER and CBER have extremely limited involvement in such activities, but do participate on relevant committees of at least two voluntary consensus standards bodies.

While the Agency s involvement with voluntary consensus standards development is limited in these particular areas (mostly because such standards are not available nor under development in these areas), it should be noted that the Agency does participate in many other types of standards development activities that are excluded from Circular A-119 reporting requirements.

Numerous employees in CDER and other FDA Centers are involved in the standards development activities of the United States Pharmacopeia (USP), a private, voluntary, not-forprofit national standard setting body of more than 1,500 health care professionals, recognized authorities in medicine, pharmacy, and allied sciences. USP publishes and revises the USP and the National Formulary, the legally recognized compendia of drug standards in the United States.

Both CDER and the CBER participate in the ICH. This ongoing project, started in 1989, has been undertaken by government agencies responsible for regulation of pharmaceuticals and by industry trade organizations for the European Union, Japan, and the United States. ICH brings together regulatory authorities and experts from the pharmaceutical industry in the three regions to discuss scientific and technical aspects of new product registration. The work products, created in working groups of experts from the regulatory agencies and industry, consist of a series of consensus guideline documents to harmonize pharmaceutical testing guidelines. FDA officials also participate in a consensus standards development activity sponsored by the Council for International Organizations of Medical Sciences and implemented in ICH, that is aimed at standardizing the safety-related terminology used in adverse experience reporting.

FDA actively participates with the WHO in developing international standards for ensuring the quality of pharmaceutical and biological products, and the Organization for Economic Cooperation and Development (OECD) on good laboratory practices for animal studies. In 1997, a new hemispheric initiative was launched on pharmaceutical harmonization in the Americas, with emphasis on relevant ICH and WHO standards. The Pan American Health Organization is the convener. FDA sent participants to conferences held in January and November 1999, which helped advance this initiative. 
Although FDA s work with USP is specifically excluded from reporting under Circular A-119, and $\mathrm{ICH}, \mathrm{OECD}$, and $\mathrm{WHO}$ do not meet the definition of voluntary consensus standard bodies under the Circular, substantial agency resources are devoted to the development of these various standards, and this work is the core part of FDA s overall standards activities for pharmaceuticals.

Center for Food Safety and Applied Nutrition (CFSAN)/Center for Veterinary Medicine (CVM)

Voluntary consensus standards have limited relevance to food and veterinary medicine products. However, the standards activities of multilateral organizations such as the WHO, FAO, World Trade Organization (WTO), and the OECD are often important in these areas, and CFSAN and CVM are actively engaged in standards and policy development with these organizations. The principal international standards activities in the areas of food and veterinary medicine fall under the activities of the Codex Alimentarius Commission under the FAO and the WHO, and the Office of International Epizootics (for veterinary medicine). FDA experts from CFSAN, CVM, the Office of International Programs, and the Office of Regulatory Affairs are heavily involved in Codex Alimentarius activities, and also in those of methods validation organizations on which Codex Alimentarius relies such as ISO, AOAC International (formerly the Association of Official Analytical Chemists), and IDF/FIL (International Dairy Federation).

CVM is very active in a harmonization initiative similar to the ICH for human pharmaceuticals, that is developing harmonized requirements for the registration of veterinary drugs. It is known as VICH, for Veterinary ICH. Agency employees participate on numerous committees that are drafting VICH guidelines.

\section{International/Treaty Standards-Related Activities}

FDA takes part in a variety of international standards activities that fall under treaty organizations, and thus are not reportable under the provisions of Circular A-119. These standards activities are nonetheless important to the Agency in fulfilling its public health regulatory mission. Some of these are referred to above; i.e., WHO, FAO, and OECD.

The Agency participates in international trade discussions of the WTO, specifically committees on the Agreement on Technical Barriers to Trade, the Agreement on Sanitary and Phytosanitary Measures, and the same counterpart committees of the North American Free Trade Agreement, to ensure that FDA $s$ requirements are preserved and its regulatory practices can remain focused on fulfilling the Agency s mission to protect the public health while being supportive of emerging, broader U.S. Government obligations and policies. FDA has participated in several initiatives that are part of the Asia Pacific Economic Cooperation forum. FDA topics have included food safety, food labeling, bulk drugs, standards for latex gloves and condoms, and medical device regulation. 


\section{FDA Standards Policy and Program Management}

It is the intent of FDA s standards policy to: (1) enable the agency to participate in international standards activities that will assist it in implementing statutory provisions for safeguarding the public health; (2) increase its efforts to harmonize its regulatory requirements with those of foreign governments, including setting new standards that better serve the public health; and, (3) respond to laws and policies that encourage agencies to use voluntary standards that provide the desired degree of protection.

FDA conducts a comprehensive review of its existing regulations on an ongoing basis. As part of this review, the Agency considers the appropriateness of existing regulations and policies, as specified in Circular A-119.

The FDA Standards Policy Committee (SPC) is chaired by the Agency Standards Executive, and composed of top management representatives from all centers and offices within the Agency. The SPC meets periodically to review and discuss both domestic and international standards issues, and recommend agency-wide standards policy to the Commissioner. The committee oversees the coordination of FDA standards activities and policies regarding official participation of employees in standards development endeavors both within and outside FDA; tracks, compiles, and reports required information; and ensures appropriate standards review when applicable.

The Agency experts on quality systems and environmental management serve as liaison members to the FDA SPC, to strengthen agency expertise and participation in issues and activities related to these areas. The agency also has a contact group of experts on private laboratory issues that holds meetings as needed to assure coordination of testing and conformity assessment issues.

In November 1999, FDA conducted HHS-wide training on the requirements set forth in Office of Management and Budget Circular A-119. The FDA Standards Executive also serves as the Department (HHS) Standards Executive. The training was designed for regulation writers and employees involved in standards development and management activities in FDA and all other HHS agencies, which are increasingly involved in the development and use of voluntary consensus standards. Additional HHS-wide training and coordination activities are planned.

Due to reorganization of the international activities in the Office of the Commissioner, the Standards Executive responsibility was shifted along with the standards management function, on January 1, 2000. The current Standards Executive is listed below. 
FDA/HHS Standards Executive:

Janet Showalter

Director, International Scientific Activities and Standards Staff Office of International Programs Food and Drug Administration 5600 Fishers Lane, Room 15-22 (HFY-020) Rockville, MD 20857
Phone: (301) 827-0865

Fax: (301) 443-0232

Email: jshowalt@oc.fda.gov 


\section{DEPARTMENT OF HOUSING AND URBAN DEVELOPMENT (HUD)}

In response to the requirements of Office of Management and Budget (OMB) Circular A-119, February 19, 1998, HUD reports the following information:

There is a total of six HUD employees participating in standards developing organizations (SDOs). Three employees from the Manufactured Housing \& Standards Division, two employees from the Office of Lead Hazard Control, and one from the Office of Information Technology, are participating on five voluntary consensus SDOs and a National Institute of Standards and Technology standards activity. SDOs in which they participate:

- American Society of Civil Engineers

- ASTM (formerly the American Society for Testing and Materials)

- Council of American Building Officials

- National Committee for Information Technology Standards

- Underwriters Laboratories

Two new voluntary consensus standards have been adopted that resulted from agency participation in a standards development group.

No new voluntary consensus standards have been adopted during this period for the purpose of promoting environmentally sound and energy-efficient materials, products, systems, services, or practices.

HUD supports the policy of OMB Circular A-119 and references more ASTM voluntary consensus standards than any other Federal agency. 


\section{DEPARTMENT OF THE INTERIOR (DOI)}

Based on a survey of offices and bureaus, the DOI s response is as follows:

The number of voluntary consensus standards bodies in which there is agency participation, as well as the number of agency employees participating:

54 consensus standards bodies, with 84 agency employees participating

The number of voluntary consensus standards the agency has used since October 1, 1998, based on the procedures set forth in sections 11 and 12 of the Circular:

144

Identification of voluntary consensus standards that have been substituted for government-unique standards as a result of agency review under section $15 \mathrm{~b}(7)$ of the Circular:

None

An evaluation of the effectiveness of the guidelines of Circular A-119 and recommendations for any changes:

DOI has no recommendations for any changes to the Circular at this time.

As required by P.L. 104-113, identification of all instances when the agency used government-unique standards in lieu of voluntary consensus standards:

None 


\section{DEPARTMENT OF JUSTICE (DOJ)}

As required by Office of Management and Budget (OMB) Circular A-119 and Public Law (P.L.) 104-113, DOJ s response follows:

The Department uses all standards involved in complying with P.L. 102.486, Executive Orders 12759 and 12845, and Federal Regulation Interim Rule 1 and Bulletin C-35 concerning Energy-Star qualifying computer equipment. The Government also is required to use the security standards for protection of information unless a waiver is granted. For example, the following security standards are mandatory:

$\begin{array}{lc}\text { FIPS 46-2, 46-3 } & \begin{array}{c}\text { Data Encryption Standard } \\ \text { FIPS 102 }\end{array} \\ \begin{array}{l}\text { FIPS 112 } \\ \text { FIPS 140-1 }\end{array} & \begin{array}{c}\text { Certification and Accreditation } \\ \text { FIPS 171 }\end{array} \\ \begin{array}{l}\text { FIPS 180-1 } \\ \text { FIPS 185 }\end{array} & \text { Cryptographic Modules } \\ \text { FIPS 186-1 } & \text { Escrowed Encryption Standard } \\ \text { FIPS 196 } & \text { Digital Signature Standard } \\ & \text { Entity Authentication Using Public Key Cryptography Secure } \\ \text { ISAKMP X.509 } & \text { Socket Layer (S SL) } \\ \text { NIST PUB 800-18System Security Plans }\end{array}$

The Department has issued 59 consensus standards since October 1, 1998.

The Department completed the development of technical reference model, December 1998, which was distributed in 1999. The following standards have been substituted for government standards:

$\begin{array}{lc}\text { IETF DCHP } & \text { Dynamic Configuration Host Protocol } \\ \text { DNS IETF 13/RFC 1034 } & \text { Domain Name Service } \\ \text { TCP/IP Transmission Control Protocol/Internet Protocol } \\ \begin{array}{lc}\text { XML-971208 } & \text { Extensible Markup Language (XML) } \\ \text { SMTP } & \text { Simple Mail Transfer Protocol }\end{array}\end{array}$

The Department has eight individuals that participate in three consensus standards bodies.

Circular A-119 policy is appropriate and has increased the awareness, value, and usage of consensus standards. 


\section{DEPARTMENT OF LABOR (DOL)}

Below are the responses from the only two agencies within DOL that have activities to report:

Mine Safety and Health Administration (MSHA)

As required by P.L. 104-113, identification of all instances where the agency used government-unique standards in lieu of voluntary consensus standards (for each instance include agency rationale for such use, as well as the specific government-unique standard used):

Zero. For the most part, MSHA has already used the voluntary consensus standards that are applicable to mining. Any further action would be to update the revision referenced.

The number of voluntary consensus standards the agency has used since October 1, 1998, based on the procedures set forth in sections 11 and 12 of the Circular:

None

Identification of voluntary consensus standards that have been substituted for government-unique standards as a result of an agency review under section $15 b(7)$ of the Circular:

None

The number of voluntary consensus standards bodies in which there is agency participation, as well as the number of agency employees participating:

MSHA has approximately 35 individuals on 50 separate committees or subcommittees of various organizations, such as American National Standards Institute (ANSI); ASTM (formerly the American Society for Testing and Materials); American Institute of Mining, Metallurgical and Petroleum Engineers/Society for Mining, Metallurgy, and Exploration; and Society of Automotive Engineers.

An evaluation of the effectiveness of Circular A-119 policy and recommendations for any changes:

None 


\section{Occupational Safety and Health Administration (OSHA)}

As required by P.L. 104-113, identification of all instances where the agency used government-unique standards in lieu of voluntary consensus standards (for each instance include agency rationale for such use, as well as the specific government-unique standard used):

OSHA issued a standard addressing training for operators of Powered Industrial Trucks. OSHA drew from the ANSI standard, but did not adopt it because it went well beyond the scope of OSHA's rulemaking needs.

The number of voluntary consensus standards the agency has used since October 1, 1998, based on the procedures set forth in sections 11 and 12 of the Circular:

OSHA has used 15 voluntary consensus standards since the last report.

Identification of voluntary consensus standards that have been substituted for government-unique standards as a result of an agency review under section $15 b(7)$ of the Circular:

OSHA did not substitute any voluntary consensus standards for government-unique standards as a result of an agency review under section $15 b(7)$ of this circular.

The number of voluntary consensus standards bodies in which there is agency participation, as well as the number of agency employees participating:

OSHA participates in 4 voluntary consensus standards bodies with 34 agency employees participating.

An evaluation of the effectiveness of Circular A-119 policy and recommendations for any changes:

OSHA has no comment. 


\section{DEPARTMENT OF STATE}

The Department of State has a major policy role in telecommunications standards as obligated by international treaty, and coordination roles in other areas. The Bureau of Economic and Business Affairs (EB) represents the Department of State on the Interagency Committee on Standards Policy (ICSP), the Government Member Council, and the Information Infrastructure Standardization Panel and its steering committee at the American National Standards Institute (ANSI). The Department is not involved in the actual development of technical standards.

The Department represents the United States of America administration under the treaty obligations found in the Convention of the International Telecommunications Union (ITU), Minneapolis, 1998, and the Inter-American Telecommunications Conference (CITEL). The Department of State, through the EB Communications and Information Policy Deputate, provides the forum for development of positions and contributions for presentation at ITU and CITEL meetings where international telecommunication recommendations (voluntary standards) and telecommunication standardization policies are written. The Department authorizes and/or hosts public meetings under the Federal Advisory Committee Act, where advice on telecommunication standardization and policy issues is offered by the private sector telecommunications industry. The Department also bases its decisions on advice from other public sector Agencies (Department of Defense, National Institute of Standards and Technology (NIST), National Telecommunications and Information Administration, National Aeronautics and Space Administration, and the Federal Communications Commission). The Department coordinates, leads, and/or accredits U.S. delegations to ITU and CITEL technical and policy meetings.

More than 100 U.S. corporations are participating members of the ITU; more than 30 are associate members of CITEL s permanent Consultative Committee, under the sponsorship of the State Department. Those companies and interested Government agencies participate and play major roles in the ITU and CITEL Study Groups and Working Parties that actually write the standards. Within that process, a great deal of interaction takes place with other standards-setting organizations, such as the International Organization for Standardization, ANSI,

ANSI-accredited Committee T1, and the Telecommunications Industry Association.

In addition to accrediting and supporting delegations to the ITU and CITEL, the Department s International Organization Affairs Bureau accredits and funds participation by relevant specialized agencies (Departments of Agriculture, Commerce, and Transportation, and NIST) and private sector groups in the deliberations of the Economic Commission for Europe (ECE) Working Party on Standardization, especially where they have a direct bearing on U.S. commercial interests. While the standards developed in the ECE are not officially adopted for use in the United States, they serve as guides for adjusting product design and are widely taken into account in manufacturing plans. 


\section{DEPARTMENT OF TRANSPORTATION (DOT)}

In response to the request by the Office of Management and Budget (OMB) for information regarding DOT s implementation of OMB Circular A-119, Federal Participation in the Development and Use of Voluntary Standards, we respectfully submit this report. The included data represent the fiscal year (FY) 1999 activities for the Department and its agencies.

As required by Public Law (P.L.) 104-113, identification of all instances when the agency used government-unique standards in lieu of voluntary consensus standards (for each instance include agency rationale for such use, as well as the specific government-unique standard used):

No instances were reported where the agency used government-unique standards in lieu of voluntary consensus standards.

The number of voluntary consensus standards the agency has used since October 1, 1998, based on the procedures set forth in sections 11 and 12 of the Circular:

The total reported number of voluntary consensus standards used by DOT since October 1, 1998, based on the procedures set forth in sections 11 and 12 of the Circular is 203.

National Highway Traffic Safety Administration (NHTSA) - Since October 1, 1998, NHTSA has proposed to adopt 23 voluntary consensus standards based on the procedures set forth in sections 11 and 12 of the Circular.

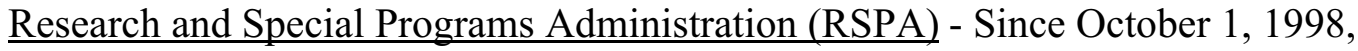
RSPA has used approximately 180 voluntary standards based on the procedures set forth in sections 11 and 12 of the Circular.

The identification of voluntary consensus standards that have been substituted for government-unique standards as a result of an agency review under section $15 b(7)$ of the Circular:

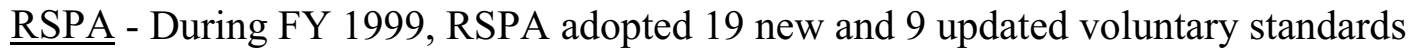
as a result of its participation in standards-developing groups. In addition, RSPA is actively considering adoption of numerous new, and updated versions of other, voluntary consensus standards. 
The number of voluntary consensus standards bodies in which there is agency participation, as well as the number of agency employees participating:

- The total reported number of DOT employees participating in at least one standards-developing group is approximately 88 although there are 4 operating administrations not included in this number. With the exception of the FAA and the FRA, the other Administrations have reported separately. Their reports follow this one.

- The total number of voluntary standards groups in which DOT employees participate is 67.

Federal Highway Administration (FHWA) - Ten employees of FHWA participate in at least one standards-developing group. These employees participate in 12 standards-developing groups.

Maritime Administration (MARAD) - Seven employees of MARAD participate in at least one standards-developing group. These employees participate in five standardsdeveloping groups.

NHTSA - Thirty-one employees of NHTSA participate in at least one standardsdeveloping group. These employees participate in four standards-developing groups.

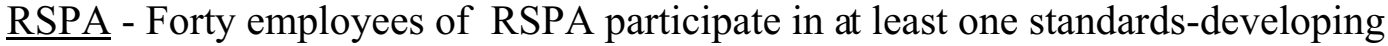
group. These employees participate in 46 standards-developing groups.

An evaluation of the effectiveness of Circular A-119 policy and recommendations for any changes:

The general consensus is that Circular A-119 is working effectively and that the use of voluntary standards can save both time and money for regulatory agencies. The only recommended change that was submitted came from the U.S. Coast Guard, which suggested that the circular be clarified, particularly with respect to section 12 , to better explain whether reporting should be on a categorical or transactional basis.

\section{Coast Guard FY 1999 Report on Standard Policy Activities (OMB Circular A-119)}

The number of voluntary consensus standards bodies in which there is agency participation, as well as the number of agency employees participating:

There has been no change in Coast Guard participation from its FY 1998 report. 
The number of voluntary consensus standards the agency has used since October 1, 1998, based on the procedures set forth in sections 11 and 12 of the Circular:

In FY 1999, the Coast Guard has used 35 voluntary consensus standards based on the procedures set forth in section 11 (use of standards in regulations) of the Circular.

Regarding section 12 of the Circular, the Coast Guard s Office of Procurement Management (G-CPM) reports that there is no database that can provide information on how Coast Guard procurement offices identify, manage, review, and use voluntary consensus standards in procurements. Plans are being developed to gather this information for future FYs.

The identification of voluntary consensus standards that have been substituted for government-unique standards as a result of an agency review under section $15 b(7)$ of the Circular:

No voluntary consensus standards have been substituted as a result of agency review under section $15 b(7)$ of the Circular.

An evaluation of the effectiveness of Circular A-119 policy and recommendations for any changes:

The Circular should be rewritten to make it easier to read and understand. More examples of voluntary consensus standards and voluntary consensus standards bodies should be given. The Circular should be clarified, with respect to section 12, to explain when reporting should be on a categorical or transactional basis.

As required by P.L. 104-113, identification of all instances when an agency used government-unique standards in lieu of a voluntary consensus standard (for each instance, include the agency rationale for such use, as well as the specific government-unique standard used):

No government-unique standards were used in lieu of voluntary consensus standards during this reporting period.

\section{$\underline{\text { Federal Transit Administration }}$}

Three employees of the Agency participate in the voluntary consensus standards development activities of the Institute of Electrical and Electronic Engineers (IEEE), Intelligent Transportation Systems (ITS) of America, and the American Public Transit Association (APTA). Some of the current activities are: (1) development of Rail Transit Vehicle Interface Standards in association 
with IEEE (five standards have been adopted so far), (2) development of technical specifications and procurement guidelines for transit buses in association with APTA, and (3) development of standards for the transit component of ITS. A modified version of J-1708, a standard of the Society of Automotive Engineers for information sharing in heavy trucks has been adopted as a standard by the transit industry for transit bus ITS application, and has also been submitted to the International Organization for Standardization for acceptance as an international standard.

The agency acts in the best interests of public transit agencies who use applicable standards in their procurements. The Agency itself does not build or operate transit systems.

Transit standards evolved over the course of time and the Agency has not promoted any government-unique standards. The five standards adopted by IEEE are expected to be used by the transit industry voluntarily.

OMB Circular A-119 and P.L. 104-113, the National Technology Transfer and Advancement Act of 1995, which encouraged Federal participation in the development of voluntary industry standards resulted in greater Agency participation for development of voluntary standards for public transit.

No government-unique standards are promoted in lieu of voluntary consensus standards. 


\section{DEPARTMENT OF THE TREASURY (TREASURY)}

The Department of the Treasury reports the following:

As required by Public Law (P.L.) 104-113, identification of all instances when the agency used government-unique standards in lieu of voluntary consensus standards (for each instance include agency rationale for such use, as well as the specific government-unique standards used):

Customs continues to support two govemment-unique standards, which are Customs and Trade Automated Interface Requirements (CATAIR) (Amendment 1, April 1996; Amendment 2, December 1996; Amendment 3, September 1997; and Amendment 4, 1998) and Customs Automated Manifest Interface Requirements (CAMIR) format (Amendment 1, April 1997; and Amendment 2, July 1998). CATAIR is used by the Customs brokerage industry and CAMIR is used by some parties in the transportation sector. The maintenance of the government-unique standards within Customs applications (the CATAIR and CAMIR formats), are at the request of the participating industry groups that use those standards.

The number of voluntary consensus standards the agency has used since October 1, 1998, based on the procedures set forth in sections 11 and 12 of the Circular:

The Department used six voluntary consensus standards. In addition, an unknown number of voluntary consensus standards are used as a result of implementing commercial off-the-shelf hardware and software.

Identification of voluntary consensus standards that have been substituted for government-unique standards as a result of an agency review under section $15 b(7)$ of the Circular:

No voluntary consensus standards have been substituted for government-unique standard as a result of our Department-wide review of existing standards.

The number of voluntary consensus standards bodies in which there is agency participation, as well as the number of agency employees participating:

The Department participated in 9 voluntary consensus standards bodies that accounted for approximately 19 employees participating. 
An evaluation of the effectiveness of A-119 policy and recommendations for any changes:

The Department believes that the guidelines prescribed in Circular A-119 are effective. Circular A-119 has placed the focus on using voluntary consensus standards as opposed to the development of government-unique standards. Wide use of voluntary consensus standards promotes the development of an increased number of standards compliant products facilitating the use of new technology and increasing flexibility to meet new requirements. 


\section{DEPARTMENT OF VETERANS AFFAIRS (VA)}

As required by Office of Management and Budget (OMB) Circular A-119, VA reports the following:

As required by Public Law (P.L.) 104-113, identification of all instances when the agency used government-unique standards in lieu of voluntary consensus standards (for each instance include agency rationale for such use, as well as the specific government-unique standard used):

None

The number of voluntary consensus standards the agency has used since October 1, 1998, based on the procedures set forth in sections 11 and 12 of the Circular:

36

Identification of voluntary consensus standards that have been substituted for government-unique standards as a result of an agency review under section $15 b(7)$ of the Circular:

None

The number of voluntary consensus standard bodies in which there is agency participation, as well as the number of agency employees participating:

VA has 12 employees participating in 26 voluntary consensus standard bodies.

An evaluation of the effectiveness of Circular A-119 policy and recommendations for any changes:

The Circular has no side effects to our present Department goal. VA accepts and conforms to the standards developed by the Joint Commission on Accreditation of Hospitals Organization (JCAHO) for the VA health care system in order to obtain JCAHO certification of VA health care facilities. Standards as outlined in the accreditation program for hospitals, psychiatric facilities mental health centers, longterm and hospice programs, ambulatory health care facilities, community and nursing homes under VA contract, State home facilities, hospital-based care programs, and various JCAHO accreditation standards (National Fire Protection Association, Life Safety Code requirements, and other building, plumbing, electrical, mechanical, and 
equipment standards/requirements) continue to be utilized in the regulatory, contractual, and grant determinations executed by the Veterans Health Administration. 


\section{Appendix B:}

\section{Other Agency and Commission Reports}




\section{AGENCY FOR INTERNATIONAL DEVELOPMENT (USAID)}

The nature of the activities funded by USAID greatly limits the Agency s use of standards in its procurement. USAID procures mostly professional and technical services. To the extent that USAID uses standards for its procurement or financing of commodities, the standards are industry standards.

The Agency has not used government-unique standards in lieu of voluntary consensus standards.

The Agency has not used any voluntary consensus standards based on the procedures in sections 11 and 12 of the Circular.

N/A.

None.

No recommendations for changes to A-119. 


\section{CONSUMER PRODUCT SAFETY COMMISSION (CPSC)}

The Consumer Product Safety Act, as amended, requires the Commission to defer to issued voluntary standards, rather than promulgate mandatory standards, when the voluntary standards would eliminate or adequately reduce the risk of injury addressed and it is likely that there will be substantial compliance with the voluntary standards. In addition, the Commission is required, after any notice or advance notice of proposed rulemaking, to provide technical and administrative assistance to persons or groups who propose to develop or modify an appropriate voluntary standard. Additionally, the Commission is encouraged to provide technical and administrative assistance to groups developing product safety standards and test methods, taking into account Commission resources and priorities.

Since its inception in 1973, the Commission has promoted the development of voluntary product safety standards. Policy statements in support of voluntary standards were published by the CPSC in 1975 and 1978. These policy statements were updated in 1988 (16 U.S.C. 1031), and a staff directive on implementation of portions of these policy statements was promulgated in October 1989.

Since the principles set forth in the Office of Management and Budget (OMB) Circular A-119 were published, they have been consistently supported by the Commission. The CPSC Voluntary Standards Coordinator also serves as CPSC s Standards Executive for the purpose of implementing OMB Circular A-119 and provides general oversight for staff involvement in existing standards projects. The Voluntary Standards Coordinator establishes agency views on standards issues and decisions through Commission response to staff briefing packages and recommendations. These views are reflected in the Commission's Operating Plan and Budget. Coordinating participation within the Commission and with others in voluntary standards activities is a responsibility of the Voluntary Standards Coordinator. Likewise, the Voluntary Standards Coordinator is responsible for meeting reporting requirements applicable to voluntary standards involvement of Commission staff.

The Commission had 25 employees directly participating in 65 voluntary standards development projects during fiscal year (FY) 1999. Since October 1, 1998, the Commission incorporated, by reference, portions of four voluntary standards in CPSC regulations. During FY 1999, there were no voluntary consensus standards that were substituted for government-unique standards as a result of an agency review of existing standards.

During FY 1999, the Commission's efforts to enhance voluntary standards development was complemented by the overall Federal policy set forth in the Circular. CPSC involvement in voluntary standards activities was consistent with Circular A-119. There are no recommendations for changes in the Circular at this time. 
For further information, please contact the CPSC s Standards Executive:

Mr. Colin B. Church

Voluntary Standards and International

Activities Coordinator

U.S. Consumer Product Safety Commission

Room 600C

Washington, D.C. 20207

Telephone: 301-504-0554, ext. 2229

Fax: 301-504-0407

E-mail: cchurch@cpsc.gov 


\section{ENVIRONMENTAL PROTECTION AGENCY (EPA)}

EPA is pleased to forward the following report to the National Institute of Standards and Technology for submission to the Office of Management and Budget (OMB) and Congress. The report details EPA s fiscal year (FY) 1999 implementation of Public Law (P.L.) 103-114, section 12(d), The National Technology Transfer and Advancement Act (NTTAA), and the corresponding OMB Circular A-119, Federal Participation in the Development and Use of Voluntary Standards and Conformity Assessment Activities.

\section{$\underline{\text { Highlights }}$}

In the FY 1999 reporting period, EPA promulgated 617 final rules, of which 207 (33.5 percent) referenced the NTTAA. In addition to these, the Agency published a variety of proposed rules, many of which also addressed compliance with the NTTAA. The total number of final and proposed rules that contained reference to the NTTAA was 326 . This number reflects an increase of more than 300 percent over the 1998 report on the number of final and proposed rules referencing the NTTAA. This increase reflects both the increasingly successful implementation of the NTTAA and OMB Circular within the Agency and the use of the interim Rule Writer s Guide made available last year.

In FY 1999, 10 final rules and 6 proposed rules adopted (or proposed for adoption) more than 45 voluntary consensus standards. Within 10 final rules, EPA found 83 instances where 18 voluntary consensus standards were found to be impracticable for agency use. Not all adopted standards were new standards or newly referenced by EPA. In several cases, the references included standards that had been previously adopted by EPA in other rulemaking activities.

One of the most notable examples of Agency rulemaking integrating the spirit as well as the letter of the OMB Circular is found in the regulatory activities of the Office of Air and Radiation (OAR) in the area of National Emission Standards for Hazardous Air Pollutants (NESHAP). The following notation occurs in several OAR Federal Register notices this year:

As part of a larger effort, the Agency is undertaking a project to cross-reference existing voluntary consensus standards in testing, sampling, and analysis, with current and future EPA test methods. When completed, this project will assist us in identifying potentially applicable voluntary consensus standards that can then be evaluated for equivalency and applicability in determining compliance with future regulations. 


\section{$\underline{\text { Required Reporting Elements under OMB Circular A-119 }}$}

The number of voluntary consensus standards bodies in which there is Agency participation, and the number of employees participating:

Currently, 197 EPA employees participate in 15 standards organizations, including:

The American National Standards Institute (ANSI)

The American Gas Association

The American Petroleum Institute (API)

The American Society of Quality Control (ASQ)

The American Society for Mechanical Engineers (ASME)

ASTM (formerly known as the American Society of Testing and Materials)

The National Fire Protection Association (NFPA)

NSF International

The Society of Automotive Engineers (SAE)

The Technical Ass ociation of the Pulp and Paper Industry (TAPPI)

Underwriters Laboratories, Inc. (UL)

The International Organization for Standardization (ISO)

The International Electrotechnical Commission (IEC)

NACE International (formerly National Association of Corrosion Engineers)

Standard Methods (the American Water Works Association, the Water Environment Federation, and the American Public Health Association jointly publish Standard Methods for the Examination of Water and Wastewater )

In addition to participation, EPA employees serve as officers on Boards and Committees. These include but are not limited to:

Board of Directors, American National Standards Institute

Technical Advisory Board, Society of Automotive Engineers

Chairman s Advisory Council, Underwriters Laboratories, Inc.

ANSI Accredited Standards Committee Z-1 on Quality and Environmental

Management

Ameri can Society for Quality Standards Committee, Convener for revision of ANSI/ ASQC E4-1994

U.S. Technical Advisory Group to ISO Technical Committee 176 on Quality Management

U.S. Technical Advisory Group to ISO Technical Committee 207 on Environmental Management 
The number of voluntary consensus standards the Agency has used since October 1, 1998:

In FY 1999, EPA adopted or incorporated by reference greater* than 34 voluntary consensus standards in final rulemaking actions. In 1998, EPA proposed the adoption of more* than eight specific voluntary consensus standards in proposed rulemaking activities.

In 22 proposed and final rules in 1998, EPA requested comment on, or assistance in identifying, voluntary consensus standards.

* In several rules, EPA noted that the Agency was using, or continuing its use of, voluntary consensus standards included in cited tables of test methods and other standards in the Federal Register. These rules did not specify the exact number of newly added or proposed voluntary consensus standards. For this reason, it is difficult to provide a precise answer to this requirement in A-119 to identify the number of voluntary consensus standards the Agency uses each year.

Identification of voluntary consensus standards that have been substituted for governmentunique standards as a result of an Agency review of existing standards:

In 1999, EPA did not specifically identify in its Federal Register publications situations where it substituted voluntary consensus standards for government-unique standards, but in seven proposed and final rules requested assistance in identification of any standards that would allow such substitution that the Agency could use in future rulemakings.

Agency use of government-unique standards in lieu of voluntary consensus standards:

Within 10 final rules in FY 1999, excerpts of which follow starting on page B-8, in 83 instances, EPA rejected 18 existing voluntary consensus standards based on impracticability, citing issues such as lack of validation data or, in the case of one International Organization for Standardization (ISO) standard (8178), based on the inability of the standard to accommodate broad application because the standard relies too heavily on reference test conditions. Because the test procedures in the regulations need to be used not only for certification, but also for production line testing, selective enforcement audits and in-use testing, they must be broadly based. The Agency determined that the ISO procedures are not sufficiently broadly usable in their current form and thus could not be adopted by reference.

There has been a dramatic increase in EPA s instances reported of government unique standards used in lieu of voluntary consensus standards from the previous report. This is due, in part, to two different phenomena. First, from 1997 to 1999, EPA put a series of tools in place that have improved its rule writers ability to find and evaluate standards. Second, EPA s use of voluntary consensus standards cannot be analyzed by comparing 
absolute numbers from year to year. Since the Agency s regulatory agenda varies annually in the number and kinds of regulations promulgated. Because of this fluctuation each year, the Agency s opportunity to use voluntary consensus standards in regulation will vary.

In one NESHAP rule, more than 12 of these standards were rejected in lieu of government- unique standards. EPA s reasoning and justification are consistent with the NTTAA. The Federal Register notice states:

Candidate voluntary consensus standards for materials analysis were identified for free-formaldehyde content. Consensus comments provided by industry experts were that the candidate standards did not meet industry materials analysis requirements. Therefore, EPA has determined these voluntary consensus standards are impractical for the mineral wool production NESHAP. The EPA, in consultation with the North American Insulation Manufacturers Association (NAIMA) has formulated an industry-specific materials analysis consensus standard for free-formaldehyde content, which is promulgated in this rule.

\section{Excerpts from Preambles to Final Rules Published by EPA During FY 1999 Pertaining to Compliance with the National Technology Transfer and Advancement Act of 1995} (Prepared as a Supplement to EPA s 1999 Report on The Implementation of The National Technology Transfer and Advancement Act, Sec. 12(d), and OMB Circular A-119")

\section{National Emission Standards for Hazardous Air Pollutants: Pesticide Active Ingredient Production, FR 33550, June 23, 1999.}

\section{National Technology Transfer and Advancement Act}

Section 12(d) of the National Technology Transfer and Advancement Act (NTTAA), P.L. 104-113 (March 7, 1996), directs all Federal agencies to use voluntary consensus standards in regulatory and procurement activities unless to do so would be inconsistent with applicable law or otherwise impracticable. Voluntary consensus standards are technical standards (e.g., materials specifications, test methods, sampling procedures, and business practices) developed or adopted by one or more voluntary consensus bodies. The NTTAA requires Federal agencies to provide Congress, through annual reports to OMB, with explanations when an agency does not use available and applicable voluntary consensus standards. This section summarizes the EPA's response to the requirements of the NTTAA for the analytical and test methods to be required by today's final rule.

Consistent with the NTTAA, the EPA conducted a search to identify voluntary consensus standards. The search identified 22 voluntary consensus standards that appeared to have possible use in lieu of EPA standard reference methods in this rule. However, after reviewing available standards, EPA determined that 14 of the candidate consensus standards identified for measuring 
emissions of the HAP or surrogates subject to emission standards in the rule would not be practical due to lack of equivalency, documentation, validation data or other important technical and policy considerations. Eight of the remaining candidate consensus standards are new standards under development that EPA plans to follow, review, and consider adopting at a later date.

One consensus standard, ASTM Z7420Z, is potentially practical for EPA use in lieu of EPA Method 18 (See 40 CFR Part 60, Appendix A). At the time of EPA's search, the ASTM standard was still under development and EPA had provided comments on the method. The EPA also compared a draft of this ASTM standard to methods previously approved as alternatives to EPA Method 18 with specific applicability limitations. These methods, designated as ALT-017 and CTM-028, are available through EPA's Emission Measurement Center Internet site at www.epa.gov/ttn/emc/tmethods.html. The proposed ASTM Z7420Z standard is very similar to these approved alternative methods. When finalized and adopted by ASTM, the standard may be equally suitable for specific applications. However, this rule does not adopt the ASTM standard as it is not practical to do so until the potential candidate is final and EPA has reviewed the final standard. The EPA plans to continue to follow the progress of the standard and will consider adopting the ASTM standard at a later date.

This final rule requires standard EPA methods known to the industry and States. Approved alternative methods also may be used with prior EPA approval.

2. National Emission Standards for Hazardous Air Pollutants: Oil and Natural Gas Production and National Emission Standards for Hazardous Air Pollutants: Natural Gas Transmission and Storage, 64 FR 32610, June 17, 1999.

\section{J. National Technology Transfer and Advancement Act}

Section 12(d) of the National Technology Transfer and Advancement Act (NTTAA), P.L. 104-113 (March 7, 1996), directs all Federal agencies to use voluntary consensus standards in regulatory and procurement activities unless doing so would be inconsistent with applicable law or otherwise impracticable. Voluntary consensus standards are technical standards (e.g., materials specifications, test methods, sampling procedures, and business practices) developed or adopted by one or more voluntary consensus bodies. The NTTAA requires Federal agencies to provide Congress, through annual reports to OMB, with explanations when an agency does not use available and appli cable voluntary consensus standards. This section summarizes the EPA's response to the requirements of the NTTAA for the analytical and test methods required by this final rule.

Consistent with the NTTAA, the EPA conducted a search to identify voluntary consensus standards. The search identified 16 voluntary consensus standards that appeared to have possible use in lieu of EPA standard reference methods. However, after reviewing available standards, the EPA determined that eight of the candidate consensus standards identified for measuring 
HAP or surrogate pollutant emissions subject to the emission standards in the rule would not be practical due to lack of equivalency, documentation, validation data and other important technical and policy considerations. Seven of the remaining candidate consensus standards are new standards under development that the EPA plans to follow, review, and consider adopting at a later date.

One consensus standard, ASTM Z7420Z, is potentially practical for EPA use in lieu of EPA Method 18 (See 40 CFR part 60, appendix A). At the time of the EPA's search, the ASTM standard was still under development and the EPA had provided comments on the method. The EPA also compared a draft of this ASTM standard to methods previously reviewed as alternatives to EPA Method 18 that were approved with specific applicability limitations. These methods are designated as ALT-017 and CTM-028 and available through EPA's Emission Measurement Center Internet site at www.epa.gov/ttn/emc/tmethods.html. The proposed ASTM Z7420Z standard is very similar to these approved alternative methods. When finalized and adopted by ASTM, the standard may be equally suitable for the same applications as the approved *32628 alternatives. However, this rule does not adopt the ASTM standard since it is not practical to do so until the potential candidate is final and the EPA has review the final standard. The EPA plans to continue to follow the progress of the standard and will consider adopting the ASTM standard at a later date.

Similarly, the Gas Research Institute has developed a sampling method for glycol dehydration units, the "Atmospheric Rich/Lean Method for Determining Glycol Dehydrator Emissions" (GRI-95/0368.1). The development of this procedure included a field evaluation program and technical review by the EPA. A report documenting this procedure has been available to the public from the GRI since 1996. This procedure provides a simpler, cheaper, and technically appropriate means of determining HAP emissions from glycol dehydration unit process vents when direct measurement is necessary. Consistent with the Agency's commitment to reduce costs to the private sector where technically feasible and in accordance with Clean Air Act requirements, the EPA has included the "Atmospheric Rich/Lean Method for Determining Glycol Dehydrator Emissions" as an alternative control device performance test procedure. This rule requires standard EPA methods known to the industry and States. Approved alternative methods also may be used with prior EPA approval.

\section{National Emission Standards for Hazardous Air Pollutants for Source Categories: Wool Fiberglass Manufacturing, 64 FR 31695, June 14, 1999.}

\section{National Technology Transfer and Advancement Act}

Section 12(d) of the National Technology Transfer and Advancement Act (NTTAA), P.L. 104-113 (March 7, 1996), directs the EPA to use voluntary consensus standards in regulatory and procurement activities unless to do so would be inconsistent with applicable law or otherwise impractical. Voluntary consensus standards are technical standards (such as materials specifications, test methods, sampling procedures, and business practices) which are 
developed or adopted by voluntary consensus standard bodies. Where available and potentially applicable voluntary consensus standards are not used by EPA, the Act requires the Agency to provide Congress, through the $\mathrm{OMB}$, an explanation for not using such standards. This section summarizes the EPA's response to the requirements of the NTTAA for the analytical test methods promulgated as part of this final rule.

Consistent with the NTTAA, the EPA conducted searches to identify voluntary consensus standards for the EPA's emissions sampling and analysis reference methods and industry recommended materials analysis procedures cited in this rule. Candidate voluntary consensus standards for materials analysis were identified for product loss on ignition (LOI), product density, and free formaldehyde content. Consensus comments provided by industry experts were that the candidate standards did not meet industry materials analysis requirements. Therefore, EPA has determined these voluntary consensus standards were impractical for the wool fiberglass manufacturing NESHAP. The EPA, in consultation with the North American Insulation Manufacturers Association (NAIMA), has formulated industry-specific materials analysis, consensus standards which are promulgated in this rule. $* 31708$

The EPA search to identify voluntary consensus standards for the EPA's emissions sampling and analysis reference methods cited in this rule identified 17 candidate standards that appeared to have possible use in lieu of EPA standard reference methods. However, after reviewing available standards, EPA determined that 12 of the candidate consensus standards identified for measuring emissions of the HAPs or surrogates subject to emission standards in the rule would be not be practical due to lack of equivalency, documentation, validation data and other important technical and policy considerations. Five of the remaining candidate consensus standards are new standards under development that EPA plans to follow, review and consider adopting at a later date. This rule requires standard EPA emission test methods known to the industry and States. Approved alternative methods also may be used with prior EPA approval.

\section{National Emission Standards for Hazardous Air Pollutants for Source Categories: Portland Cement Manufacturing Industry, 64 FR 31898, June 14, 1999.}

\section{Voluntary Consensus Standards}

Comment: One commenter (IV-D-17) stated that EPA's actions (in developing and proposing the precursor to EPA Fourier Transform Infrared Spectroscopy [FTIR] test method 320) directly conflict with the guidance of and directives of the 1995 National Technology Transfer and Advancement Act and the Office of Management and Budget (OMB) Circular A-119 because: (1) the American Society of Testing and Materials (ASTM) FTIR consensus based test method is available, and (2) the EPA Emission Measurement Center (EMC) representatives were made aware of the development of the ASTM method and chose duplicative measures in developing and proposing the precursor to EPA FTIR test method 320. (The OMB Circular states specifically that "If a voluntary consensus standards body is in the process of developing or adopting a voluntary consensus standard that would likely be lawful and practical for an agency 
to use, and would be developed on a timely basis, an agency should not be developing its own government unique standard and instead should be participating in the activities of the voluntary consensus standards body.")

Response: The Agency has been actively developing extractive FTIR-based methods for HAPs since 1992. Methods 320 and 321 are direct products of this long-term effort to apply an innovative approach to emissions measurement in the form of extractive FTIR. The Agency has tested these methods in the laboratory and in the field extensively (conducting testing at two portland cement facilities), and has conducted multiple validation tests of these methods. The Portland Cement Association (PCA), in representing various members of the regulated ind ustry, has conducted its own series of validation tests of these methods. Actually, Method 321 was developed and validated by PCA, and has been adopted by the Agency as Method 321. Agency personnel informed ASTM in 1996 that the Agency methods were in active development, and an ASTM standard seemed redundant. Additionally, the ASTM standard has not undergone field validation, which is essential in establishing the precision and accuracy of any test method. The Agency has conducted a review of the ASTM method. While the ASTM method is in some ways similar to Method 320, the ASTM method is not sufficiently detailed to document proper application, and does not contain the quality assurance procedures the Agency requires in compliance methods. Specifically, the ASTM method does not address specific calibration transfer standards, nor does it address the preparation of reference spectra. Therefore, EPA has determined that it is impractical to adopt the ASTM method at this time and is promulgating Method 320.

\section{National Technology Transfer and Advancement Act}

Section 12(d) of the National Technology Transfer and Advancement Act (NTTAA) directs all Federal agencies to use voluntary consensus standards in regulatory and procurement activities unless to do so would be inconsistent with applicable law or otherwise impracticable. Voluntary consensus standards are technical standards (e.g., materials specifications, test methods, sampling procedures, and business practices) developed or adopted by one or more voluntary consensus bodies. The NTTAA requires Federal agencies to provide Congress, through annual reports to $\mathrm{OMB}$, with explanations when an agency does not use available and applicable voluntary consensus standards.

Consistent with the NTTAA, the EPA conducted a search to identify voluntary consensus standards. The search identified 21 voluntary consensus standards that appeared to have possible use in lieu of EPA standard reference methods. However, after reviewing available standards, EPA determined that 14 of the candidate consensus standards identified for measuring emissions of the HAPs or surrogates subject to emission standards in the rule would not be practical due to lack of equivalency, documentation, validation data and other important technical and policy considerations. Six of the remaining candidate consensus standards are new standards under development that EPA plans to follow, review and consider adopting at a later date. 
One consensus standard, ASTM D6216-98, appears to be practical for EPA use in lieu of EPA Performance Specification 1 (See 40 CFR Part 60, Appendix B). On September 23, 1998, EPA proposed incorporating by reference ASTM D6216-98 under a separate rulemaking (63 FR 50824) that would allow broader use and application of this consensus standard. EPA plans to complete this action in the near future. For these reasons, EPA defers taking action in this rulemaking that would adopt D6216-98 in lieu of PS-1 requirements as it would be impractical for EPA to act independently from other rulemaking activity already undergoing notice and comment.

Additionally, EPA received comments that ASTM FTIR Standard D6348 should be used in lieu of EPA's proposed Fourier transform infrared spectroscopy (FTIR) emission test methods. EPA has determined for a number of reasons that the ASTM Standard D6348 is one of the 14 standards determined to be impractical to adopt for the purposes of this rulemaking. EPA review comments on ASTM Standard D6348 are included in the docket for this rulemaking and summarized in the response to comments section of this preamble. ASTM has also been advised of the reasons for impracticality and ASTM Subcommittee D22-03 is now undertaking a revision of the ASTM standard. Upon demonstration of technical equivalency with the EP A FTIR methods, the revised ASTM standard could be incorporated by reference for EPA regulatory applicability at a later date.

This rule requires standard EPA methods known to the industry and States. Approved alternative methods also may be used with prior EPA approval.

5. National Emission Standards for Hazardous Air Pollutants: Phosphoric Acid Manufacturing and Phosphate Fertilizers Production, 64 FR 31358, June 10, 1999.

\section{H. National Technology Transfer and Advancement Act}

Section 12(d) of the National Technology Transfer and Advancement Act (NTTAA), directs all Federal agencies to use voluntary consensus standards in regulatory and procurement activities unless to do so would be inconsistent with applicable law or otherwise impracticable. Voluntary consensus standards are technical standards (e.g., materials specifications, test methods, sampling procedures, and business practices) developed or adapted by one or more voluntary consensus bodies. The NTTAA requires Federal agencies to provide Congress, through annual reports to OMB, with explanations when an agency does not use available and applicable voluntary consensus standards.

Consistent with the requirements of the NTTAA, today's rulemaking incorporates the analytical methods of two consensus standard bodies. Instead of developing its own methods for determining the phosphate content of feedstocks to the processes covered by the standards, the Agency is incorporating by reference into today's rules certain analytical protocols of the Association of Official Analytical Chemists and of The Association of Florida Phosphate Chemists. 
Also, consistent with the NTTAA, the EPA conducted a search to identify voluntary consensus standards for emissions test methods. The search identified 17 voluntary consensus standards that appeared to have possible use in lieu of EPA standard reference methods. However, after reviewing available standards, EPA determined that 12 of the candidate consensus standards identified for measuring emissions of the HAPs or surrogates subject to emission standards in the rule would not be practical due to lack of equivalency, documentation, validation data and other important technical and policy considerations. Five of the remaining candidate consensus standards are new standards under development that EPA plans to follow, review and consider adopting at a later date. This rule requires standard EPA methods known to the industry and States. Approved alternative methods also may be used with prior EPA approval.

\section{National Emission Standards for Hazardous Air Pollutants for Source Categories: National Emission Standards for Hazardous Air Pollutants for Mineral Wool Production, 64 FR 29420, June 1, 1999.}

\section{J. National Technology Transfer and Advancement Act}

Section 12(d) of the National Technology Transfer and Advancement Act (NTTAA), P.L. 104-113 (March 7, 1996), directs the EPA to use voluntary consensus standards in regulatory and procurement activities unless to do so would be inconsistent with applicable law or otherwise impractical. Voluntary consensus standards are technical standards (such as materials specifications, test methods, sampling procedures, and business practices) which are developed or adopted by voluntary consensus standard bodies. Where available and potentially applicable voluntary consensus standards are not used by EPA, the Act requires the Agency to provide Congress, through the $\mathrm{OMB}$, an explanation for not using such standards. This section summarizes the EPA's response to the requirements of the NTTAA for the analytical test methods promulgated as part of this final rule.

Consistent with the NTTAA, the EPA conducted searches to identify voluntary consensus standards for the EPA's emissions sampling and analysis reference methods and industry recommended materials analysis procedures cited in this rule. Candidate voluntary consensus standards for materials analysis were identified for free-formaldehyde content. Consensus comments provided by industry experts were that the candidate standards did not meet industry materials analysis requirements. Therefore, EPA has determined these voluntary consensus standard are impractical for the mineral wool production NESHAP. The EPA, in consultation with the North American Insulation Manufacturers Association (NAIMA), has formulated an industry-specific materials analysis, consensus standard for free-formaldehyde content which is promulgated in this rule.

The EPA search to identify voluntary consensus standards for the EPA's emissions sampling and analysis reference methods cited in this rule identified 17 voluntary consensus standards that appeared to have possible use in lieu of EPA standard reference methods. However, after reviewing available standards, EPA determined that 12 of the candidate consensus standards 
identified for measuring emissions of the HAPs or surrogates subject to emission standards in the rule would not be practical due to lack of equivalency, documentation, validation data and other important technical and policy considerations. Five of the remaining candidate consensus standards are new standards under development that EPA plans to follow, review and consider adopting at a later date. This rule requires standard EPA emission test methods known to the industry and States. Approved alternative methods also may be used with prior EPA approval.

\section{National Emission Standards for Hazardous Air Pollutants for Polyether Polyols Production,} 64 FR 29420, June 1, 1999.

\section{J. National Technology Transfer and Advancement Act}

Section 12(d) of the National Technology Transfer and Advancement Act (NTTAA), P.L. 104-113 (March 7, 1996), directs all Federal agencies to use voluntary consensus standards in regulatory and procurement activities unless to do so would be inconsistent with applicable law or otherwise impracticable. Voluntary consensus standards are technical standards (e.g., materials specifications, test methods, sampling procedures, and business practices) developed or adopted by one or more voluntary consensus bodies. The NTTAA requires Federal agencies to provide Congress, through annual reports to $\mathrm{OMB}$, with explanations when an agency does not use available and applicable volun tary consensus standards. This section summarizes the EPA's response to the requirements of the NTTAA for the analytical and test methods to be required by this final rule.

Consistent with the NTTAA, the EPA conducted a search to identify voluntary consensus standards. The search identified 15 voluntary consensus standards that appeared to have possible use in lieu of EPA standard reference methods in this rule. However, after reviewing available standards, EPA determined that eight of the candidate consensus standards identified for measuring emissions of the HAP or surrogates subject to emission standards in the rule would not be practical due to lack of equivalency, documentation, validation data or other important technical and policy considerations. Seven of the remaining candidate consensus standards are new standards under development that EPA plans to follow, review and consider adopting at a later date. $* 29439$

One consensus standard, ASTM Z7420Z, is potentially practical for EPA use in lieu of EPA Method 18 (See 40 CFR part 60, appendix A). At the time of EPA's search, the ASTM standard was still under development and EPA had provided comments on the method. The EPA also compared a draft of this ASTM standard to methods previously approved as alternatives to EPA Method 18 with specific applicability limitations. These methods, designated as ALT-017 and CTM-028, are available through EPA's Emission Measurement Center Internet site at www.epa.gov/ttn/emc/tmethods.html. The proposed ASTM Z7420Z standard is very similar to these approved alternative methods. When finalized and adopted by ASTM, the standard may be equally suitable for specific applications. However, today's rule does not adopt the ASTM standard at this time as it is not practical to do so until the potential candidate is final and EPA 
has reviewed the final standard. The EPA plans to continue to follow the progress of the standard and will consider adopting the ASTM standard at a later date.

This rule requires standard EPA methods known to the industry and States. Approved alternative methods also may be used with prior EPA approval.

8. Phase 2 Emission Standards for New Nonroad spark-Ignition Nonhandheld Engines At or Below 19Kilowatts, 64 FR 15208, March 30, 1999.

\section{F. National Technology Transfer and Advancement Act}

Section 12(d) of the National Technology Transfer and Advancement Act of 1995 ("NTTAA"), Public Law No. 104-113, Section 12(d) (15 U.S.C. 272 note), directs EPA to use voluntary consensus standards in its regulatory activities unless doing so would be inconsistent with applicable law or otherwise impractical. Voluntary consensus standards are technical standards (e.g., materials specifications, test methods, sampling procedures, and business practices) that are developed or adopted by voluntary consensus standards bodies. The NTTAA directs EPA to provide Congress, through OMB, explanations when the Agency decides not to use available and applicable voluntary consensus standards.

This final rule involves technical standards. While commenters suggested the use of ISO 8178 test procedures for measuring emissions, the Agency has decided not to rely on the ISO procedures in this rulemaking. The Agency has determined that these procedures would be impractical because they rely too heavily on reference testing conditions. Since the test procedures in these regulations need to be used not only for certification, but also for production line testing, selective enforcement audits, and in-use testing, they must be broadly based. In-use testing is best done outside tightly controlled laboratory conditions so as to be representative of in-use conditions. EPA has determined that the ISO procedures are not sufficiently broadly usable in their current form for this program, and therefore cannot be adopted by reference. EPA has instead chosen to continue to rely on the procedures outlined in 40 CFR Part 90. EPA is hopeful that future ISO test procedures will be developed that are usable for the broad range of testing needed, and that such procedures could then be adopted by reference.

9. National Primary Drinking Water Regulations: Interim Enhanced surface Water Treatment, 63 FR 69478, December 16, 1998.

\section{National Technology Transfer and Advancement Act}

Under section 12(d) of the National Technology Transfer and Advancement Act ("NTTAA"), the Agency is required to use voluntary consensus standards in its regulatory activities unless to do so would be inconsistent with applicable law or otherwise impractical. Voluntary consensus standards are technical standards (e.g., materials specifications, test methods, sampling procedures, business practices, etc.) that are developed or adopted by voluntary consensus 
standards bodies. Where available and potentially applicable voluntary consensus standards are not used by EPA, the Act requires the Agency to provide Congress, through the Office of Management and Budget, an explanation of the reasons for not using such standards.

Today's rule requires the use of previously approved technical standards for the measurement of turbidity. In previous rulemakings, EPA *69510 approved three methods for measuring turbidity in drinking water. Turbidity is a method-defined parameter and therefore modifications to any of the three approved methods requires prior EPA approval. One of the approved methods was published by the Standard Methods Committee of American Public Health Association, the American Water Works Association, and the Water Environment Federation, a voluntary consensus standard body. That method, Method 2130B is published in Standard Methods for the Examination of Water and Wastewater (19th ed.). Standard Methods is a widely used reference which has been peer-reviewed throughout the scientific community. In addition to this voluntary consensus standard, EPA approved Great Lakes Instrument Method 2 as an alternate test procedure for the measurement of turbidity. Finally, the Agency approved a revised EPA Method 180.1 for turbidity measurement in August 1993 in Methods for the Determination of Inorganic Substances in Environmental Samples (EPA- 600/R-93-100).

In 1994, EPA reviewed and rejected an additional technical standard for the measurement of turbidity, the ISO 7027 standard, which measures turbidity at a higher wavelength than the approved test measurement standards. The ISO 7027 is an analytical method for the measurement of turbidity. ISO 7027 measures turbidity using either 90degrees scattered or transmitted light depending on the turbidity concentration evaluated. Although instruments conforming to ISO 7027 specifications are similar to the GLI instrument, only the GLI instrument uses pulsed, multiple detectors to simultaneously read both 90degrees scattered and transmitted light. EPA has no data upon which to evaluate whether the separate 90degrees scattered or transmitted light measurement evaluations according to the ISO 7027 method would produce results that are equivalent to results produced using GLI Method 2, Standard Method 2130B, or EPA Method 180.1.

Today's final rule also requires continuous individual filter monitoring for turbidity and requires PWSs to calibrate the individual turbidimeter according to the turbidimeter manufacturer's instructions. These calibration instructions may constitute technical standards as that term is defined in the NTTAA. EPA has looked for voluntary consensus standards with regard to calibration of turbidimeter. The American Society for Testing and Materials (ASTM) is developing such voluntary consensus standards; however, there do not appear to be any voluntary consensus standards available at this time.

10. Control of Emissions of Air Pollution From Nonroad Diesel Engines, 63 FR 56968 , October 23, 1998.

F. National Technology Transfer and Advancement Act 
Section 12(d) of the National Technology Transfer and Advancement Act of 1995 ("NTTAA"), Public Law 104-113, section 12(d) (15 U.S.C. $272 * 56994$ note) directs EPA to use voluntary consensus standards in its regulatory activities unless doing so would be inconsistent with applicable law or otherwise impractical. Voluntary consensus standards are technical standards (e.g., materials specifications, test methods, sampling procedures, and business practices) that are developed or adopted by voluntary consensus standards bodies. The NTTAA directs EPA to provide Congress, through OMB, explanations when the Agency decides not to use available and applicable voluntary consensus standards.

This final rule involves technical standards. While commenters suggested the use of ISO 8178 test procedures for measuring emissions, the Agency has decided not to rely on these ISO procedures in this rulemaking. The Agency has determined that these procedures would be impracticable because they rely too heavily on reference testing conditions. Because the test procedures in these regulations need to represent in-use operation typical of operation in the field, they must be based on a range of ambient conditions. EPA has determined that the ISO procedures are not broadly usable in their current form, and therefore cannot be adopted by reference. EPA has instead chosen to continue to rely on the procedures outlined in 40 CFR Part 89. EPA is hopeful that future ISO test procedures will be developed that are usable for the broad range of testing needed, and that such procedures could then be adopted by reference. EPA also expects that any development of revised test procedures will be done in accordance with ISO procedures and in a balanced manner and thus include the opportunity for involvement of a range of interested parties (potentially including parties such as industry, EPA, state governments, and environmental groups) so that the resulting procedures can represent these different interests

Evaluation of the effectiveness of OMB Circular A-119 policy and recommendations for any changes:

EPA finds that the policies of the Circular work well, and does not recommend any changes at this time. However, EPA would welcome clarification on the issue of whether or not Departments and Agencies may use appropriated funds for membership in voluntary standards bodies. While it is implied, particularly in section 7 , it may be helpful to provide specific language in future revisions. 


\section{EPA Standards-related Activities}

EPA is integrating voluntary consensus standards into an increasingly broad area of activities. In some instances, this integration is possibly as important to the intent of the NTTAA and OMB Circular as EPA s actual incorporation of standards into regulations. That is: EPA s influence goes beyond the borders of regulation. By using existing voluntary standards in setting up excellence programs or engaging standards organizations to identify pollution prevention opportunities, EPA not only avoids re-creating the wheel, but leverages the interests, economics, and expertise of the entire community to reach environmental goals of the Administration.

The Office of Prevention Pesticides and Toxic Substances demonstrates this through the collaborative efforts between its Pollution Prevention Division and one U.S. standards developing organization (SDO), Underwriters Laboratories (UL). EPA and UL are working to develop standards that incorporate the best environmental information into product standards available for the general consumer and also government procurement. Another good example is found in the Office of Underground Storage Tanks (USTs) within the Office of Solid Waste and Emergency Response. While the UST program used no voluntary stan dards in rul emaking, several ASTM standards were distributed to States and EPA Regional Offices with a memo noting the extent to which the standards were consistent with EPA s goals and guidance.

In addition, EPA serves an important role in encouraging the use of international voluntary consensus standards in key organizations with which it works, including the Organization for Economic Cooperation and Development, the United Nations Environmental Program, and the United Nations Conference on Trade and Development. This encouragement is not only important to achieving environmental goals but means that U.S. business and industry stakeholders have a vested interest in, and opportunity to participate in, the international standards that reflect harmonization among governments as well as industry users.

Inside the Agency, EPA s Voluntary Standards Network, which internally coordinates standards activities, is serving an expanded role of making standards activities in the Agency more visible to senior management. This is largely due to three factors: officially designated EPA Standards Coordinators from each Office and Region; the Administrator s emphasis on seeking performance-based measures as a basis for regulatory compliance, and the visibility of standards issues in context of the trade agreements.

Additional specifics on some of these areas are provided below:

\section{Performance-Based Measurement System Initiative}

EPA s Administrator Browner announced 2 years ago that EPA would, where possible, move from prescribed measurement methods to a flexible selection process whereby the regulated community might adopt alternative methods as long as they could be 
demonstrated to meet agreed upon performance objectives. EPA is working with ASTM Committees through a facilitated, accelerated process to develop voluntary consensus standards that will meet the needs of the Administration and public confidence in this important area.

Representatives from EPA s Offices of: Research and Development, Air and Radiation, Solid Waste, and Enforcement and Compliance Assurance, are working through ASTM to develop a standard concerning the demonstration of validity of analytical data. The purpose of this standard is to ensure the scientific and legal defensibility of the compliance monitoring data gathered by the regulated community. EPA hopes that once the standard is completed, the Agency will be able to cite it in the implementation of the Performance-Based Measurement System Initiative.

\section{Child Resistant Packaging (CRP) and Pesticides Registrants}

EPA uses ASTM D3475 Standard Classification of Child-Resistant Packages as part of the Agency s identification of CRP. Additionally, EPA is constantly referring pesticide registrants to ASTM for standards related to their packaging (e.g., weathering of packages) as concerns CRP testing.

One area where EPA does not use a possible $\mathrm{ISO}^{6}$ standard is in the area of child-resistant packaging. EPA and the U.S. Consumer Product Safety Commission (CPSC) both have regulations internally consistent in the United States. There is no U.S. voluntary standard that might be applicable as a testing procedure, but there is an ISO standard. EPA, CPSC, and other U.S. representatives (manufacturers, testing organizations, etc.) to the ISO technical committee on this matter all agree that the ISO standard does not meet the stringency required and desired for United States purposes.

\section{$\underline{\text { Voluntary Standards, Sustainability, Products and Government Procurement }}$}

An EPA employee chairs the task group at ASTM, a major SDO that is developing data collection standards to assess sustainability of building products.

EPA is charged, under Executive Order 13101 (1998 \& 1993) with providing guidance to Federal agencies on Environmentally Preferable Purchasing. By working with the diverse sectors of the building industry that comprise ASTM s Buildings Performance Committee to develop voluntary consensus standards on sustainability, EPA hopes to not only contribute to promoting environmentally preferable purchasing in construction, but also

${ }^{6}$ The International Organization for Standardization (ISO) is a standards developing body composed of national standards bodies representatives from around the world, as well as liaison and nonvoting members from a wide variety of international organizations. The American National Standards Institute (ANSI) is the official U.S. member. 
encourage improved environmental performance on the part of suppliers of building products.

One of the tools EPA has developed to assist purchasers in implementing environmentally preferable purchasing is a database of environmental standards and environmental attributes. The database, which will be expanded in the next year, includes product-specific information developed by government programs, both U.S. and international as well as nongovernmental organizations. The standards included in the database have been developed through a wide variety of processes, not limited to voluntary consensus standards.

\section{Office of Air: Voluntary Consensus Standards Save Cost to EPA}

EPA s Emission Measurement Center (EMC) within the Office of Air Quality Planning Standards has interacted closely with ASTM subcommittee D22-03, which is responsible for developing and approving new emission measurement techniques. An EMC representative has joined D22-03 and worked closely with its task groups in developing and modifying ASTM standards such that they can be incorporated by reference in applicable Federal regulations. This cooperative effort between EPA and ASTM has had immediate beneficial results in the recognition of many new emission test methods at essentially zero cost to EPA.

EMC has several actions ongoing with ASTM. Two that were completed in 1999 are: (1) EPA s Performance Standard No.1 (PS-1) was formally revised to include ASTM D6216-98, which greatly increases the stringency of quality assurance by manufacturers of Continuous Opacity Monitoring Systems; and (2) ASTM method measure total and speciated mercury emissions at coal-fired utilities was adopted by EMC as the official method under a special EPA-industry project involving 84 coal-fired utilities throughout the nation.

\section{Organization for Economic Cooperation and Development (OECD)}

Although the Organization for Cooperation and Development is not, strictly speaking, a standards developing body under the definition of the OMB Circular A-119, it has a Test Guidelines Program (TGP) that develops consensus documents to which the United States as a member of OECD subscribes. The Agency believes participation in the development of the Test Guidelines (TGs) to be consistent with the intent of the Circular.

The OECD is a formal intergovernmental organization that currently consists of 29 member countries with advanced market economies producing and using over 75 percent of the world s chemicals. The OECD s TGP was established in 1981 with their publication of 51 consensus TGs for the conduct of a variety of test methods to assess the characteristics of chemicals (e.g., solubility in water, toxicity to rodents, to fish, 
etc.). The purpose of the OECD s TGs is to help minimize nontariff trade barriers between member countries, avoid the duplication of testing, and to minimize the use of animals in testing. There are currently 95 OECD TGs.

The U.S. National Coordinator has a contact list of about 60 groups, organizations, and/or individuals with expertise who have indicated an interest in providing expert comments on some or all of the OECD TGs distributed to the United States. This list includes distributions to expert contacts at several Federal and State agencies, industry associations, chemical industry and testing laboratories and a variety of expert contacts at nongovernmental organizations such as academic institutions.

The U.S. comments received on any OECD TG are included in the U.S. responses to the OECD. The OECD s TGs are consensus documents and the U.S. comments, and those of all member countries, are considered in developing that consensus. The OECD s TGs are likely to be among the most widely used to test chemicals in the industrialized world.

\section{$\underline{\text { Participation in International Standards Development }}$}

The Agency actively participates in a number of standards development and revision committees within ISO. Examples include ISO committees on environmental management systems, quality systems, and those dealing with air and water quality testing. In addition, personnel from the Office of Mobile Sources participate in two ISO technical committees relevant to the Office of Air. In the case of environmental management systems, the Agency has recently established a policy group to test-out and coordinate programs and pilot projects that research and evaluate the viability of ISO 14001 and other standards as the basis for effective environmental management, including compliance management.

What follows is a table which further explicates the voluntary consensus standards found impractical in EPA FY 1999 regulations. 


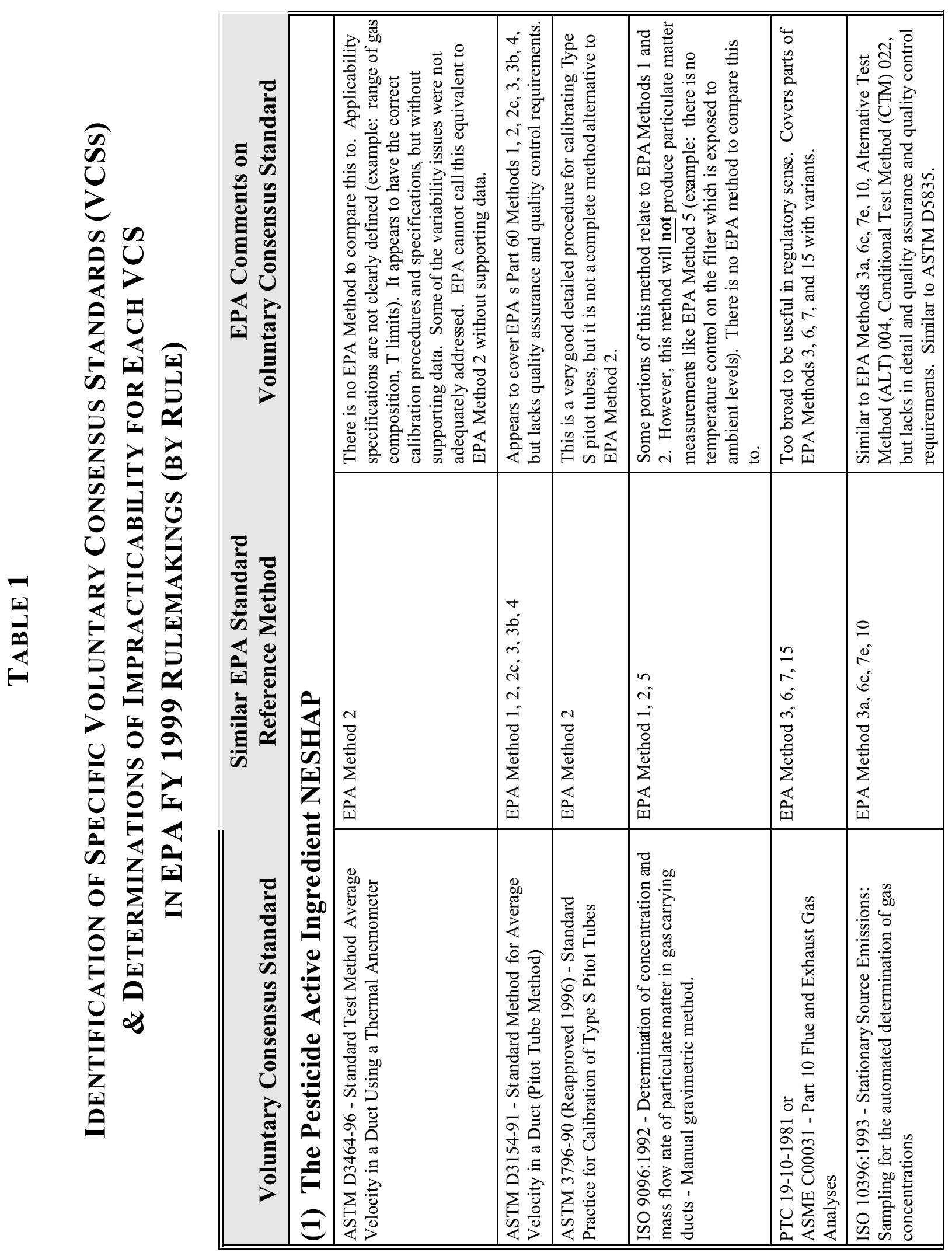




\begin{tabular}{|c|c|c|c|c|c|c|c|}
\hline 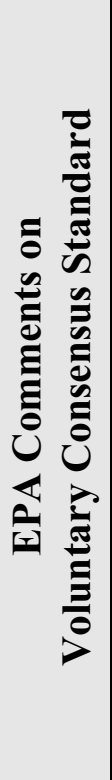 & 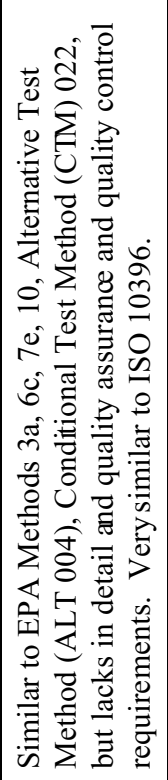 & 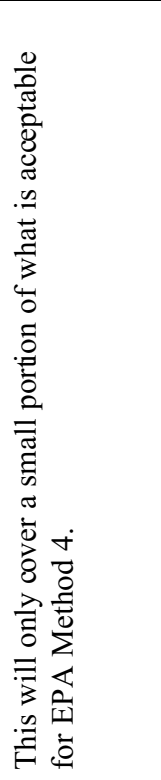 & 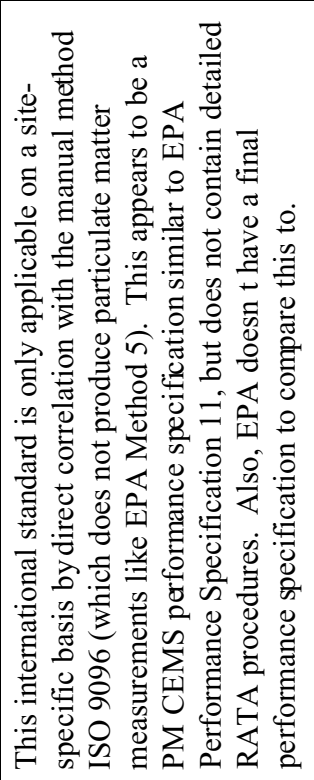 & 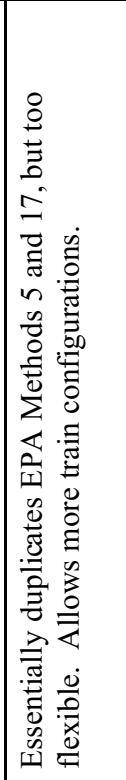 & 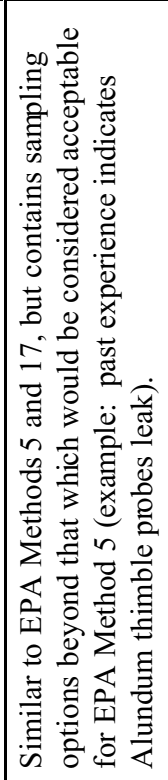 & 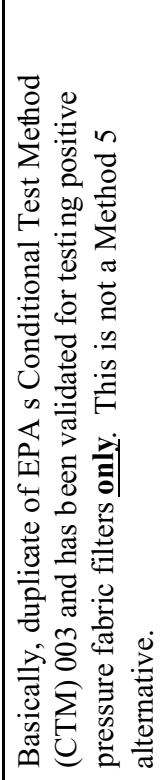 & 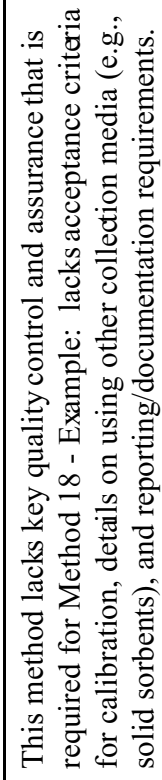 \\
\hline 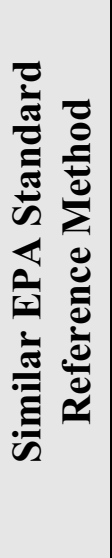 & 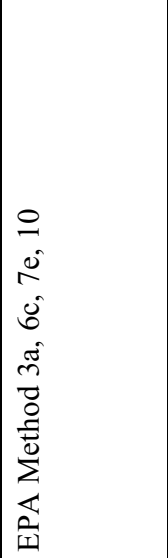 & & 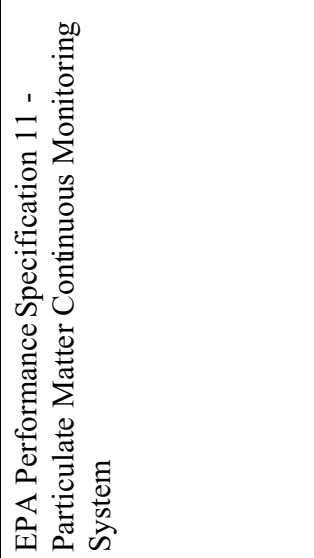 & 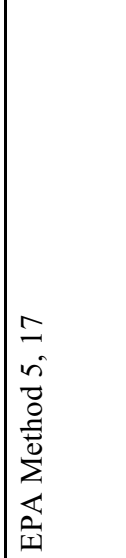 & 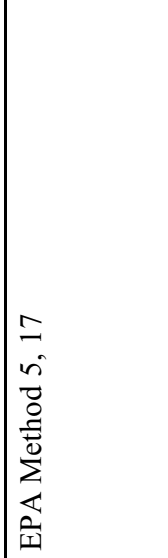 & 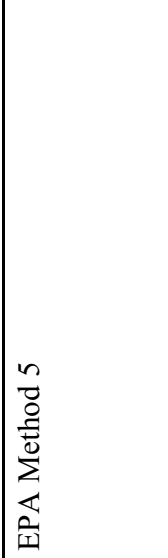 & 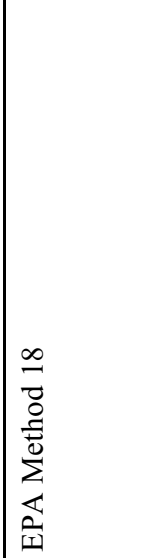 \\
\hline 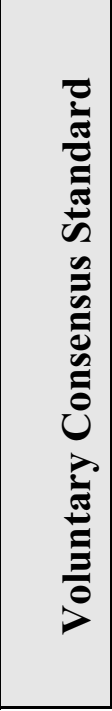 & 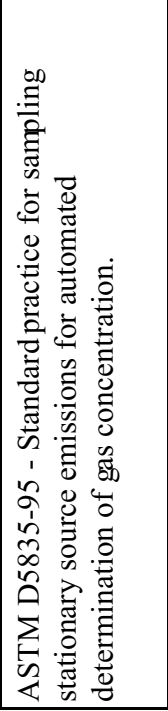 & 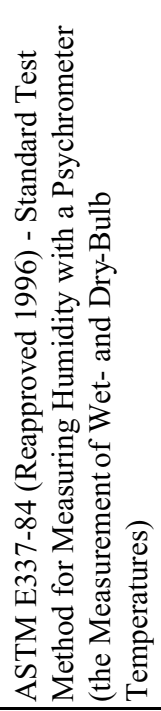 & 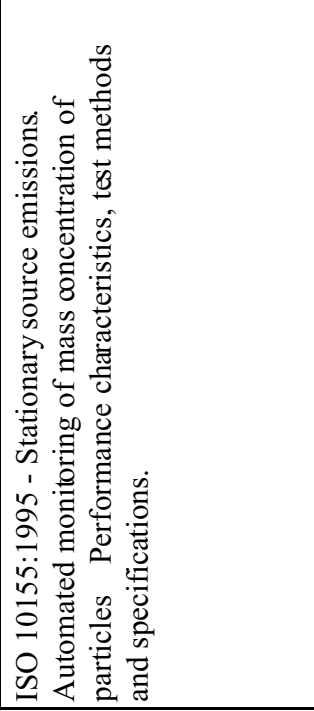 & 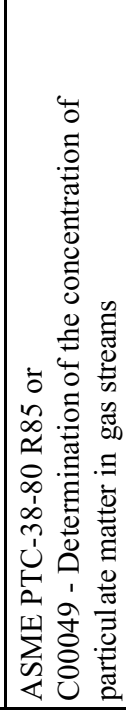 & 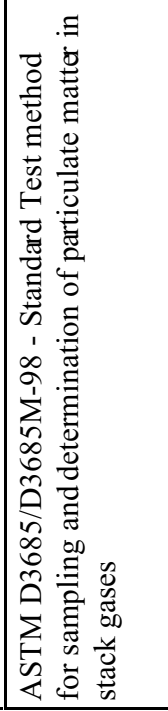 & 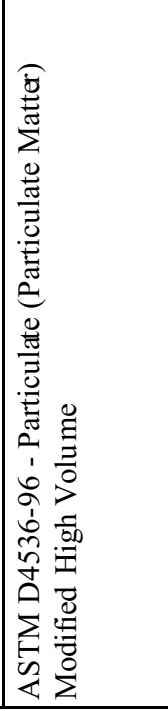 & 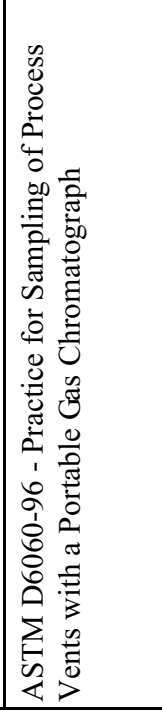 \\
\hline
\end{tabular}




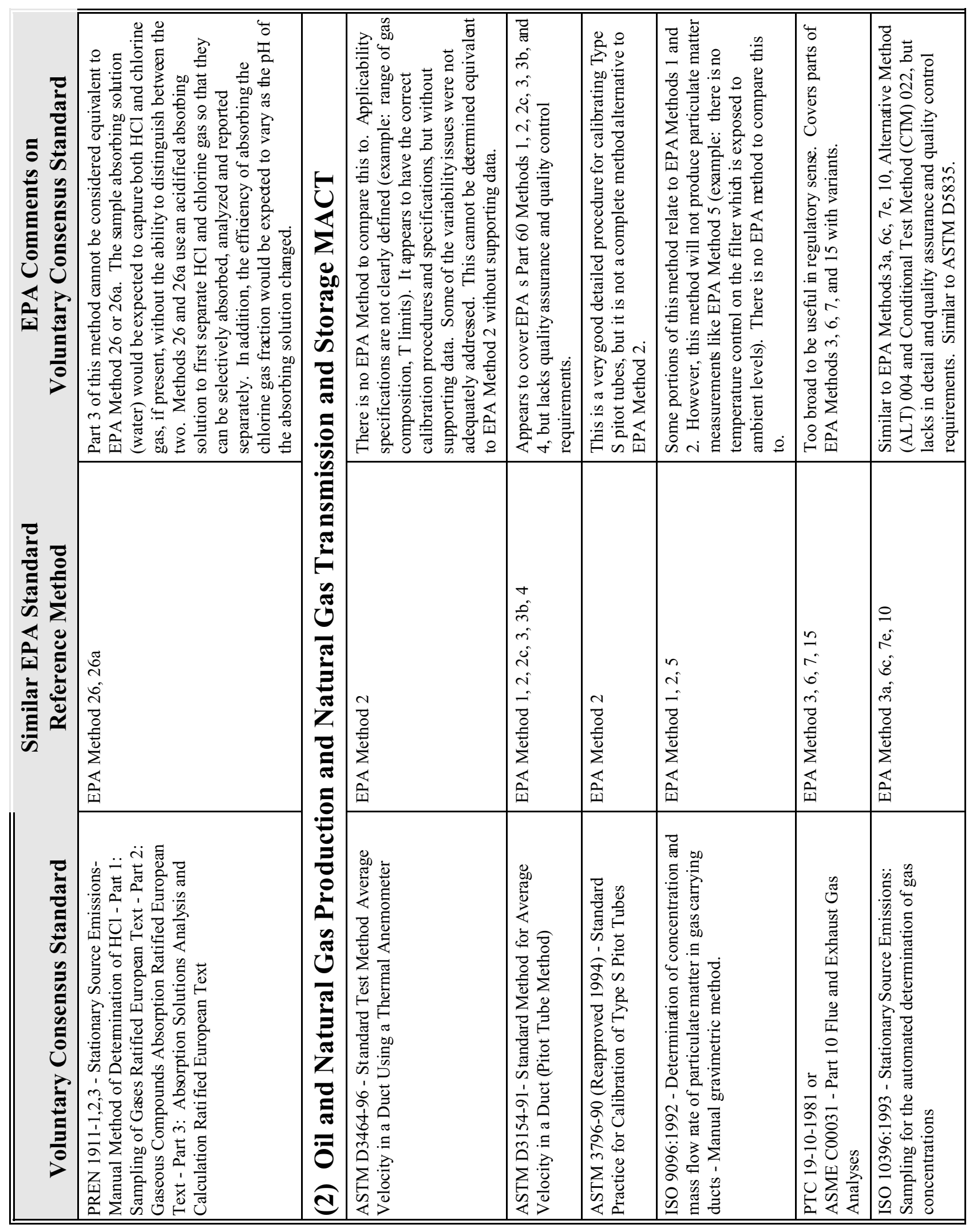




\begin{tabular}{|c|c|c|c|c|c|c|c|c|c|}
\hline 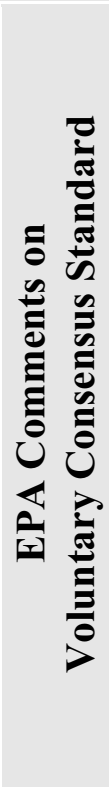 & 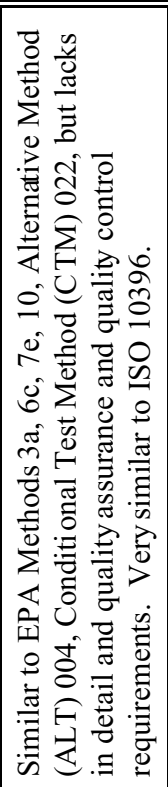 & 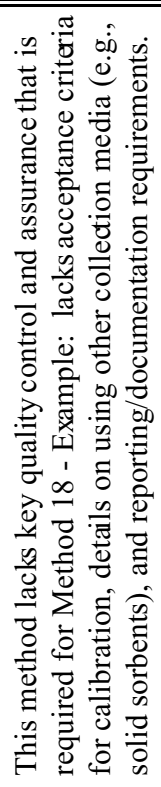 & & 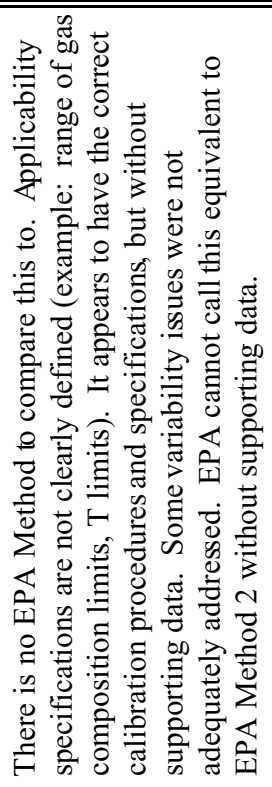 & 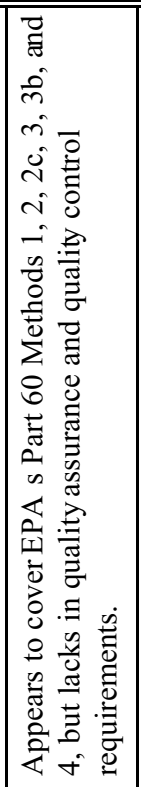 & 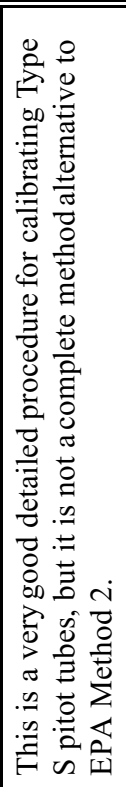 & 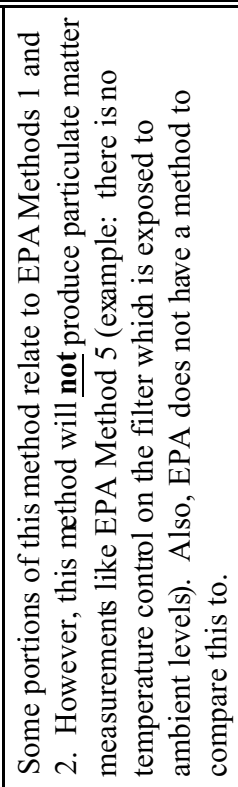 & 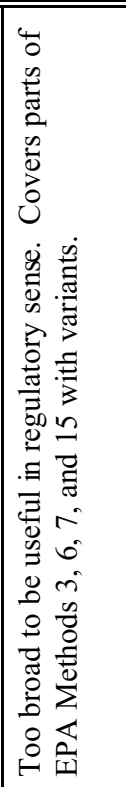 & 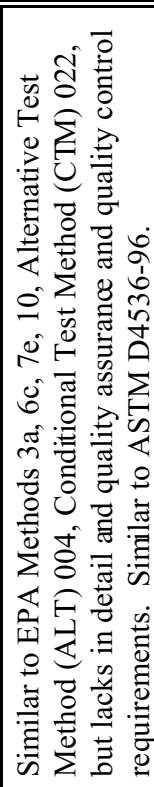 \\
\hline 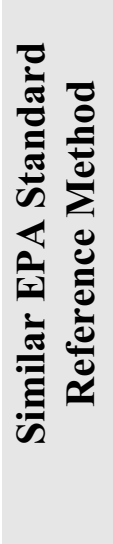 & 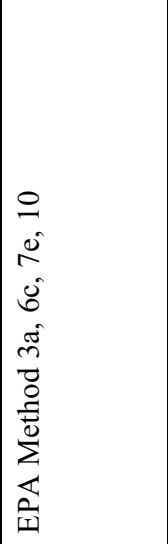 & 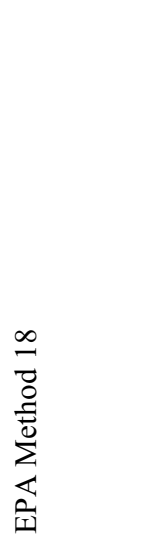 & 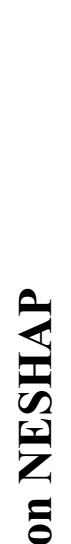 & 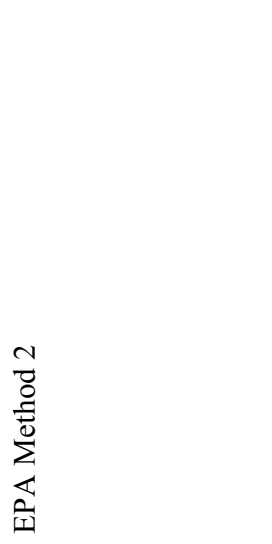 & 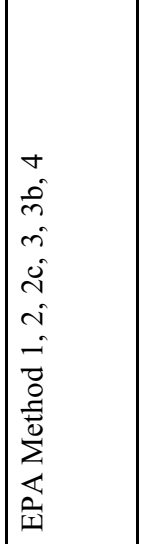 & 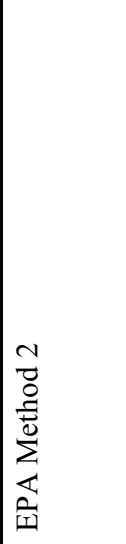 & 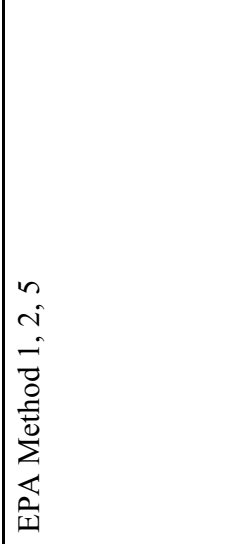 & 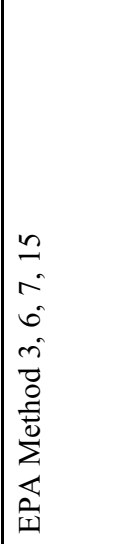 & 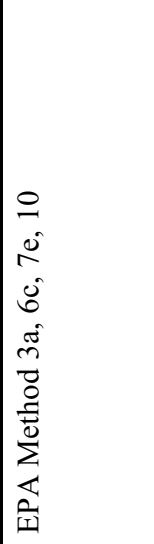 \\
\hline 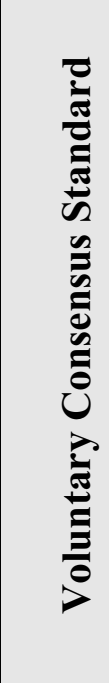 & 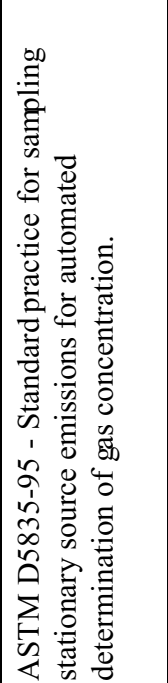 & 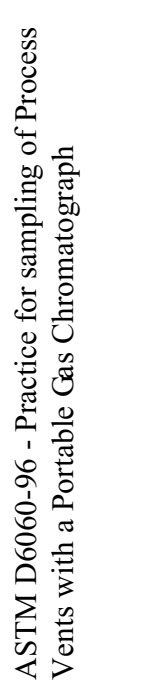 & 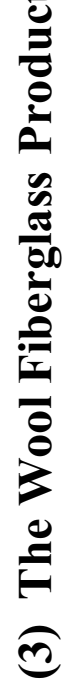 & 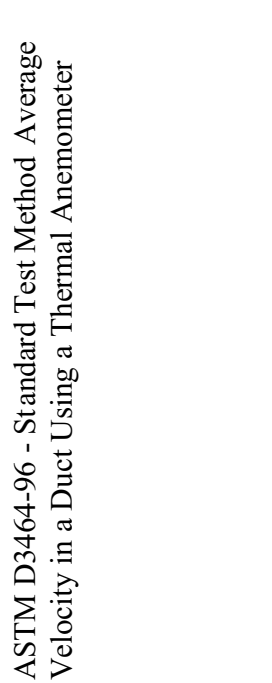 & 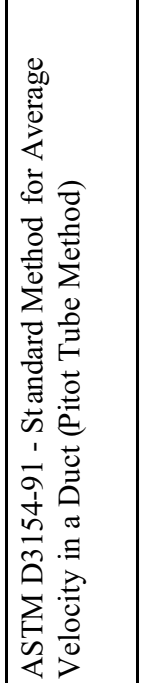 & 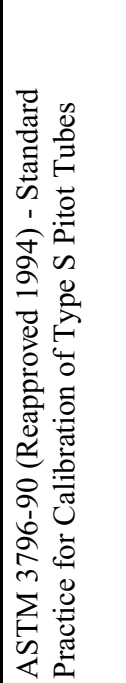 & 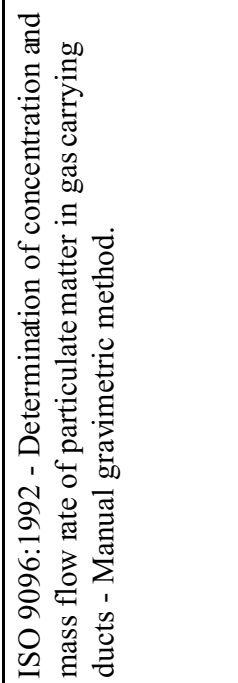 & 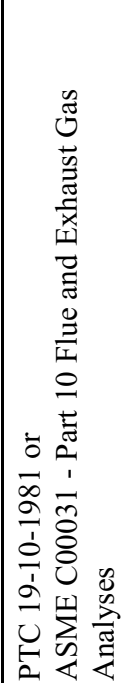 & 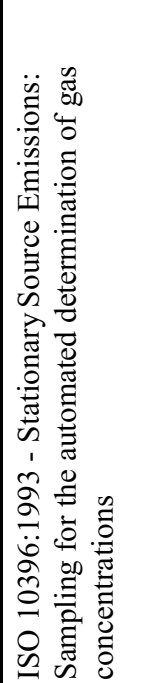 \\
\hline
\end{tabular}




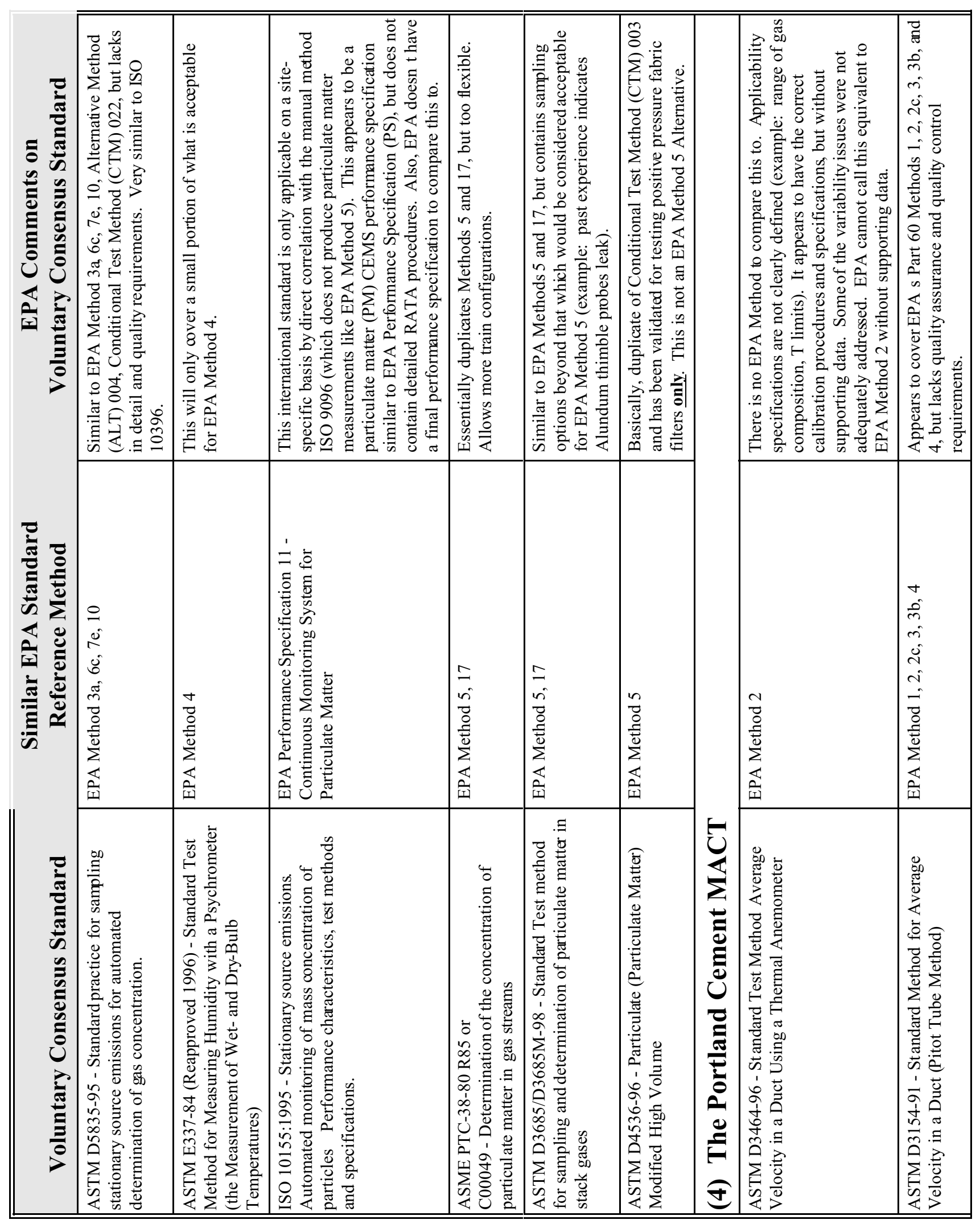




\begin{tabular}{|c|c|c|c|c|c|c|c|c|c|}
\hline 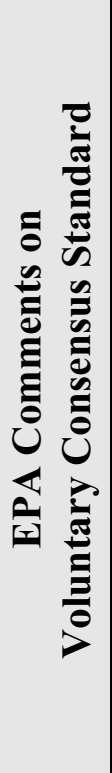 & 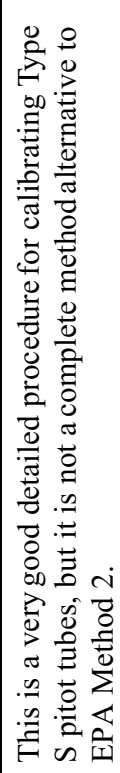 & 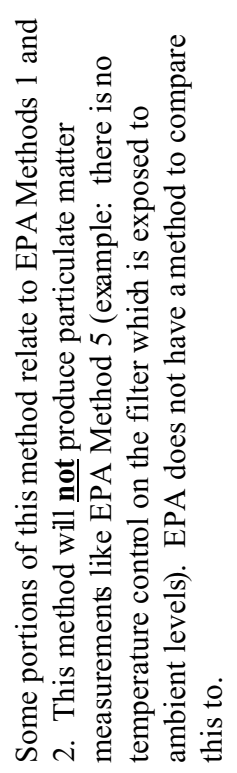 & 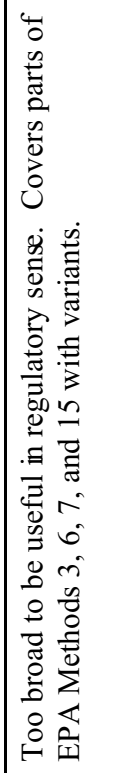 & 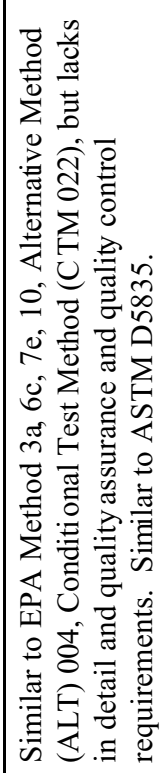 & 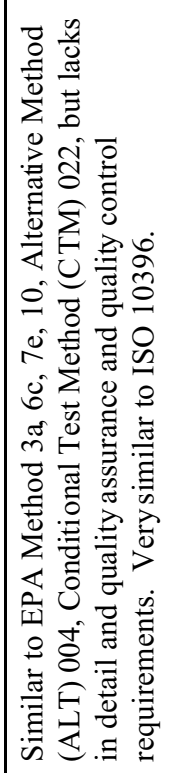 & 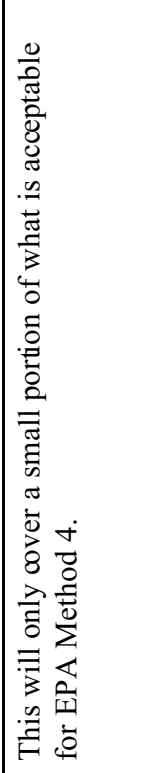 & 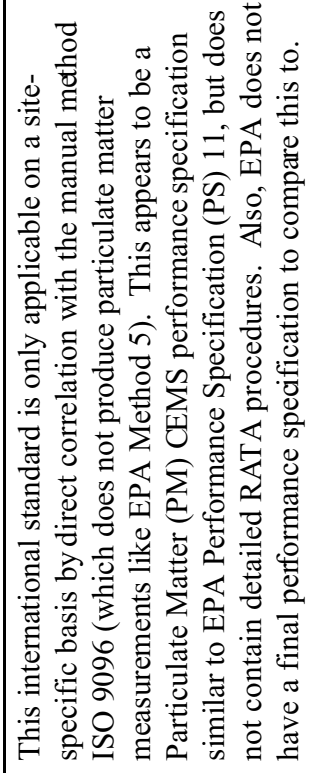 & 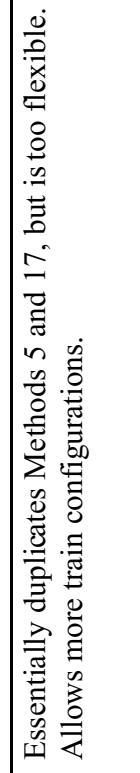 & 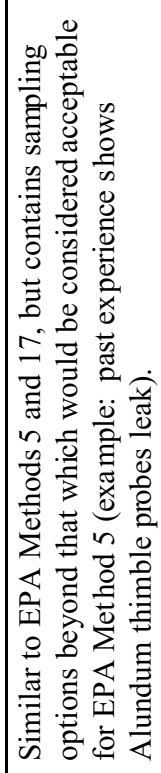 \\
\hline 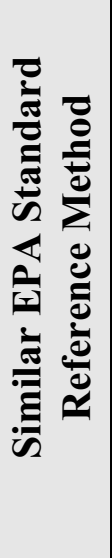 & 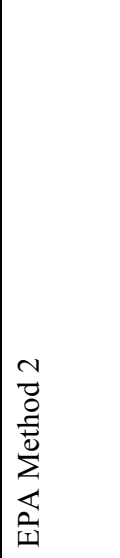 & 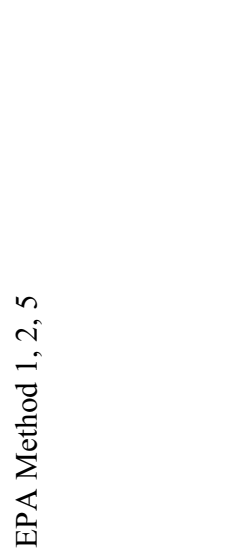 & 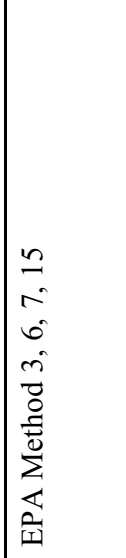 & 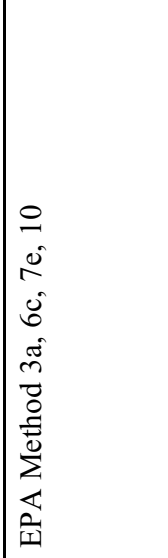 & 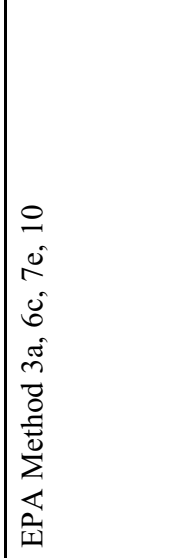 & 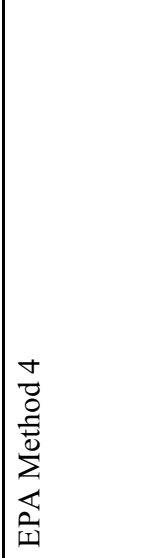 & 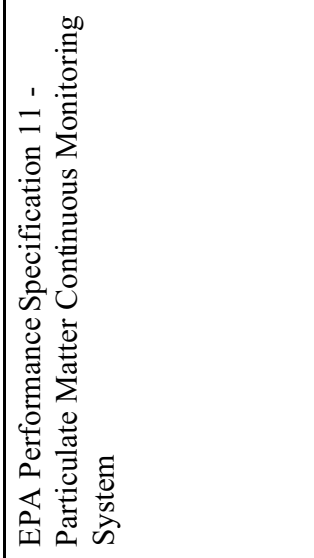 & 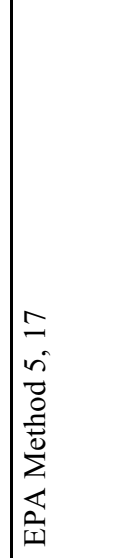 & 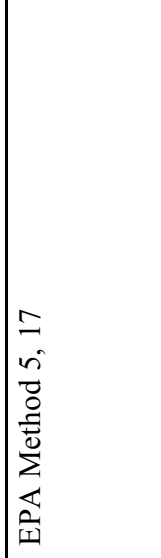 \\
\hline 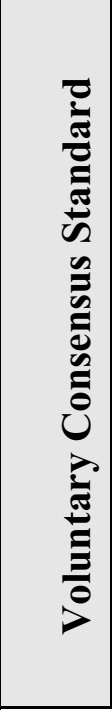 & 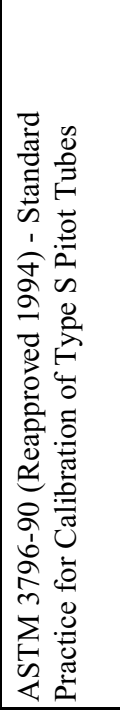 & 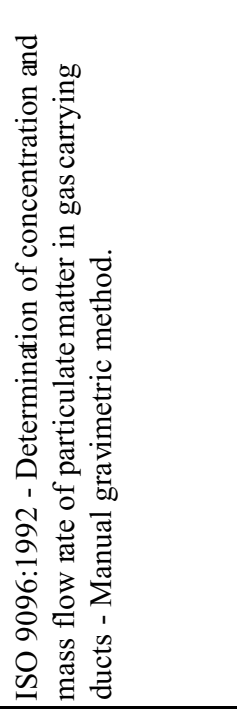 & 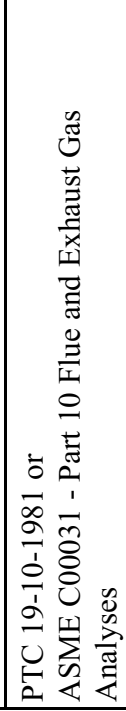 & 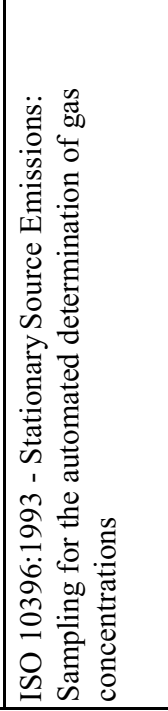 & 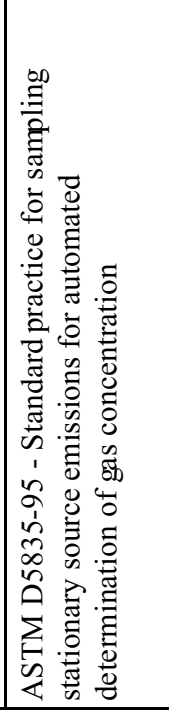 & 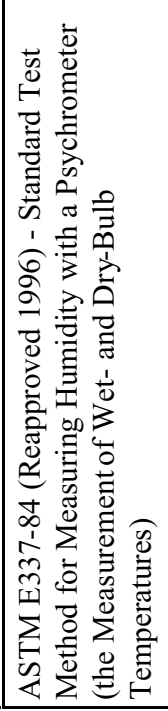 & 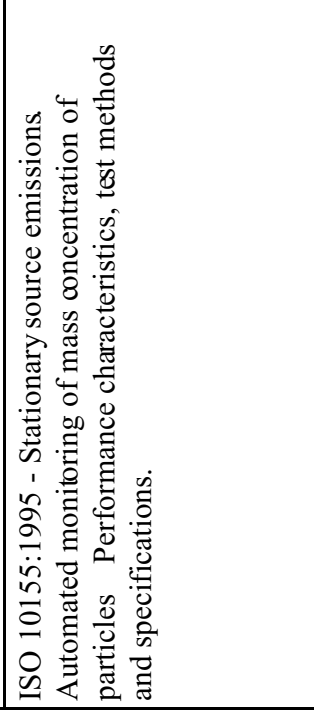 & 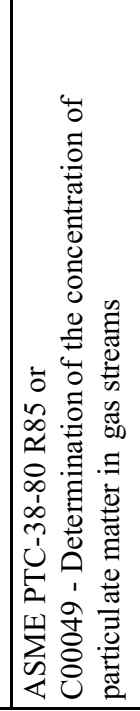 & 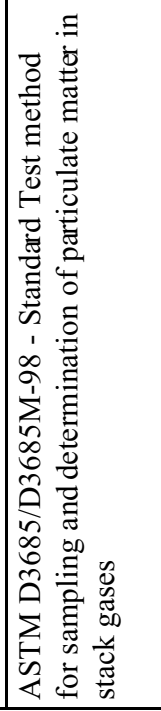 \\
\hline
\end{tabular}




\begin{tabular}{|c|c|c|c|c|c|c|c|c|c|c|}
\hline 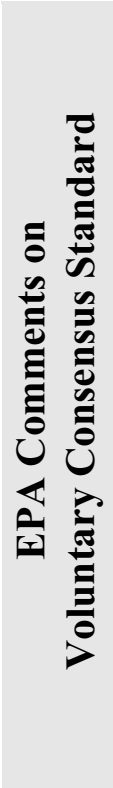 & 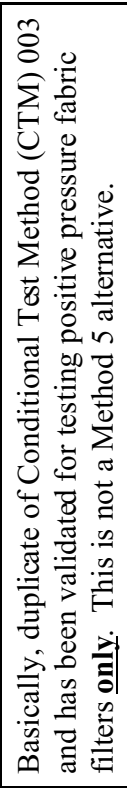 & 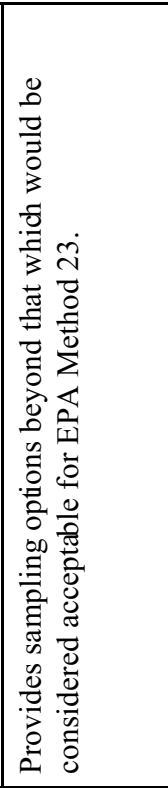 & 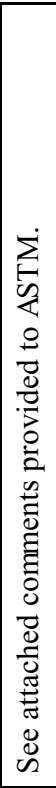 & & 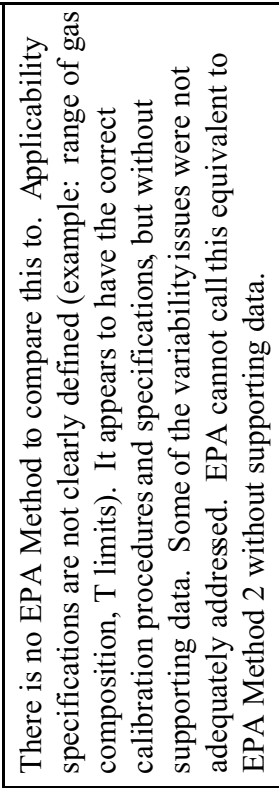 & 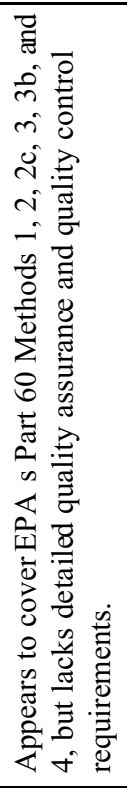 & 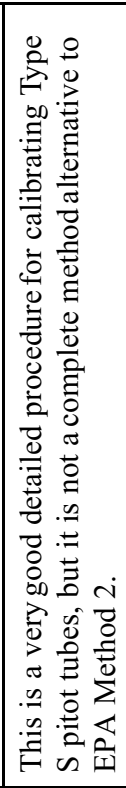 & 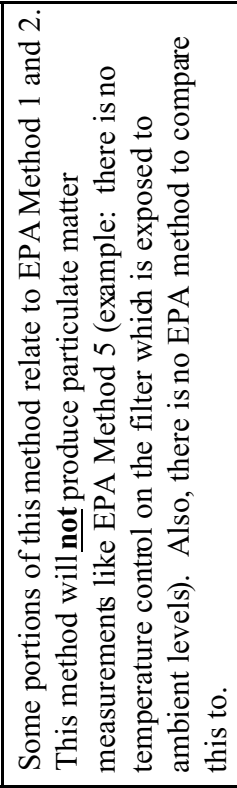 & 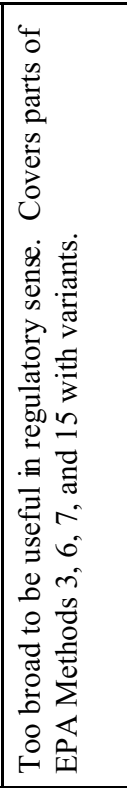 & 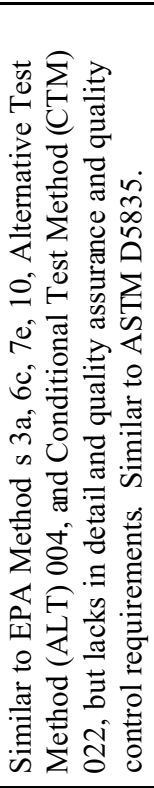 \\
\hline 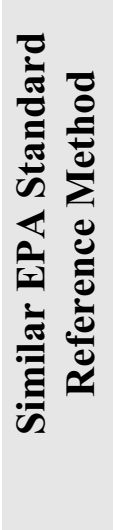 & 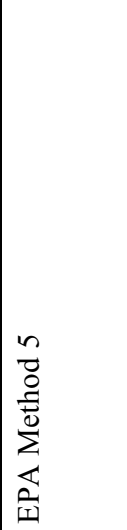 & 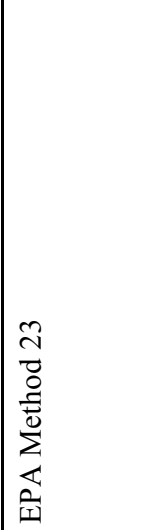 & 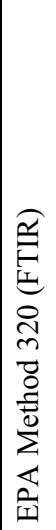 & 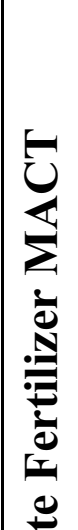 & 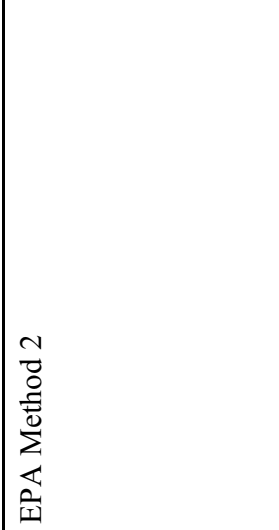 & 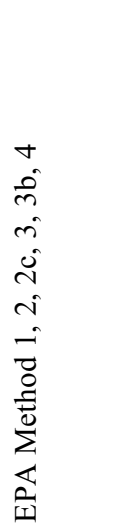 & 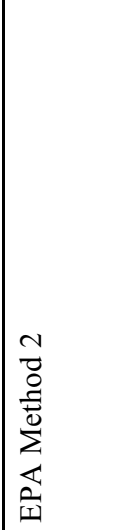 & 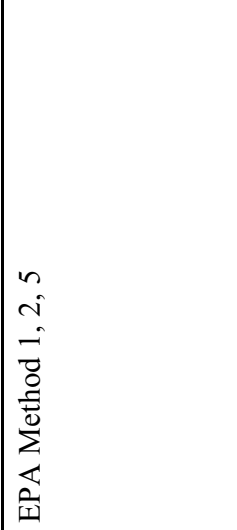 & 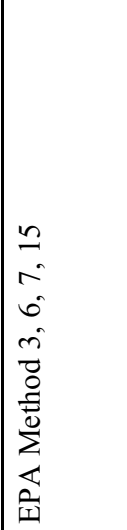 & 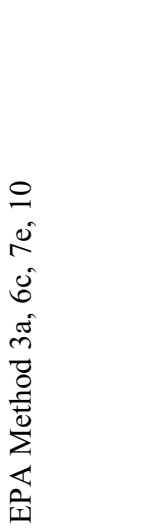 \\
\hline 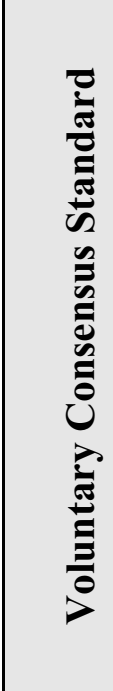 & 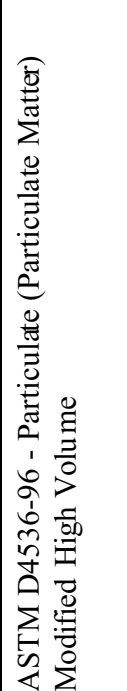 & 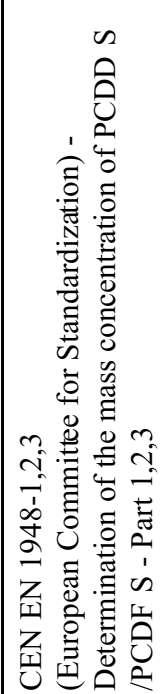 & 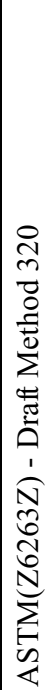 & 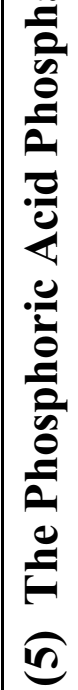 & 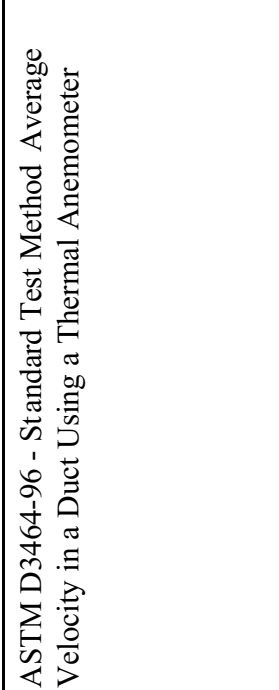 & 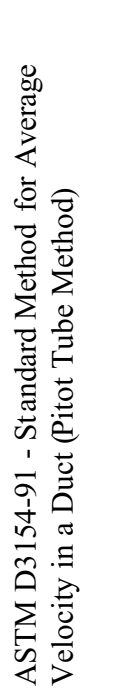 & 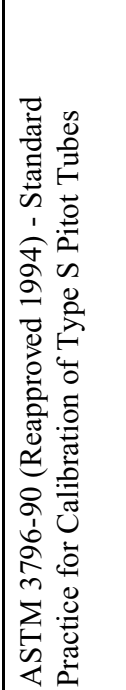 & 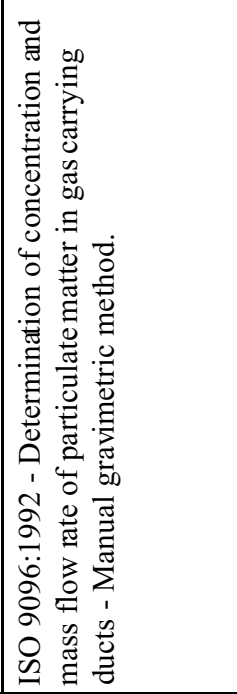 & 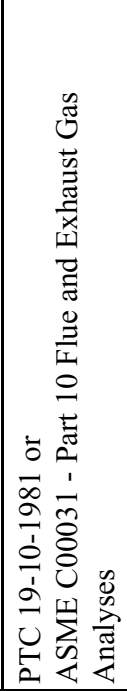 & 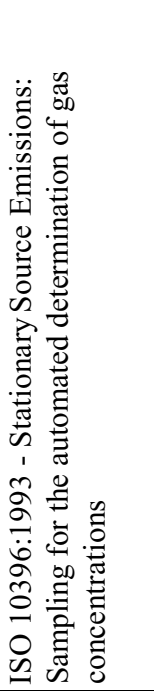 \\
\hline
\end{tabular}




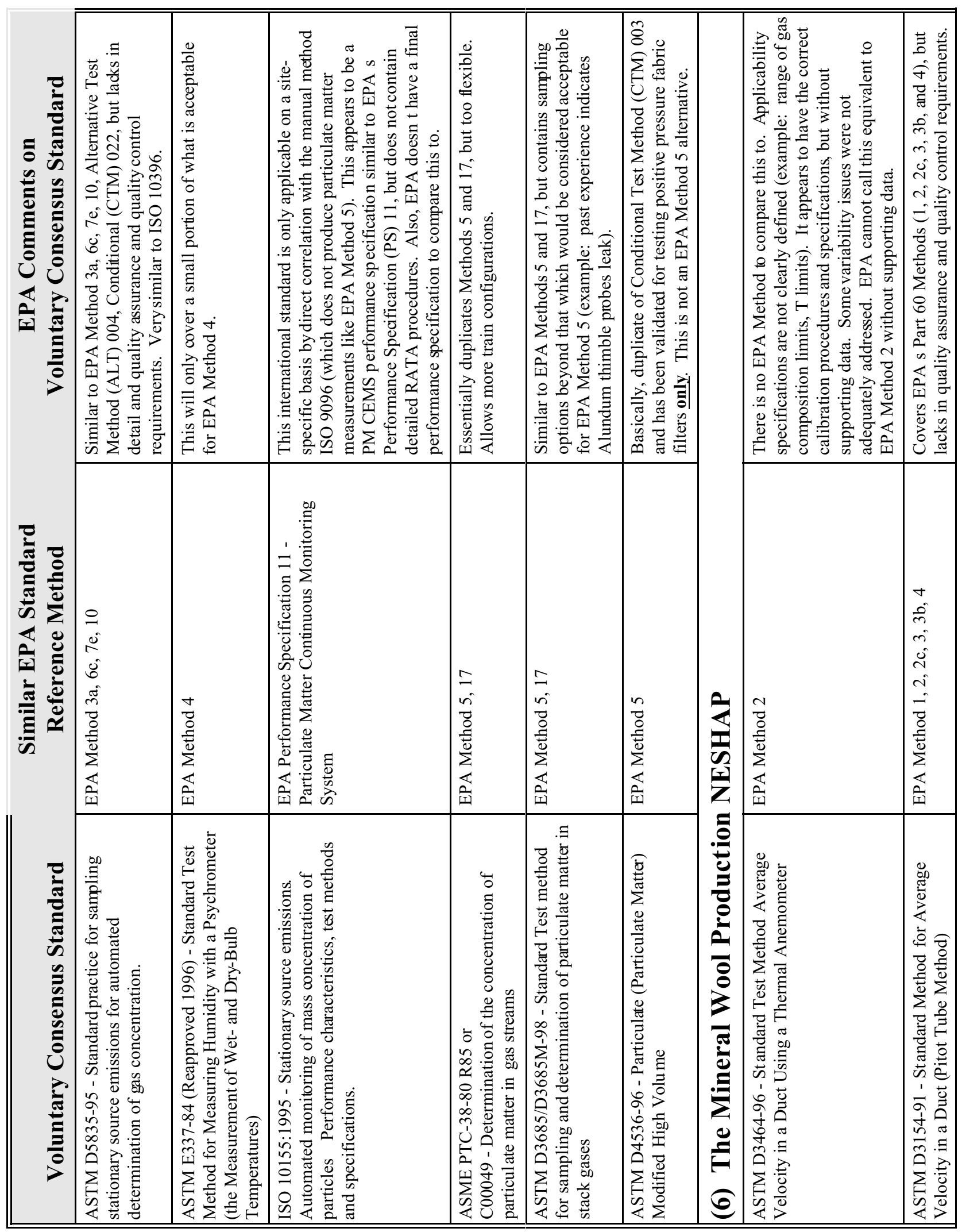




\begin{tabular}{|c|c|c|c|c|c|c|c|c|c|}
\hline 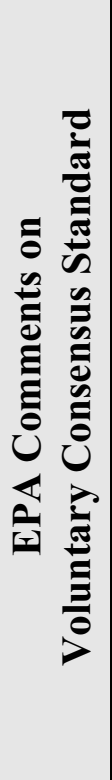 & 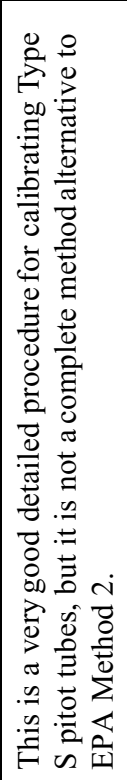 & 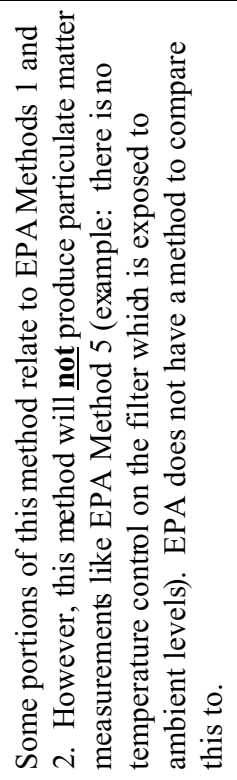 & 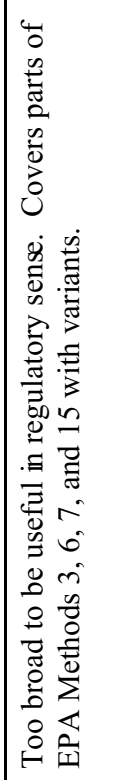 & 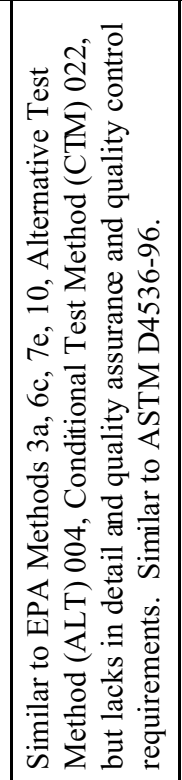 & 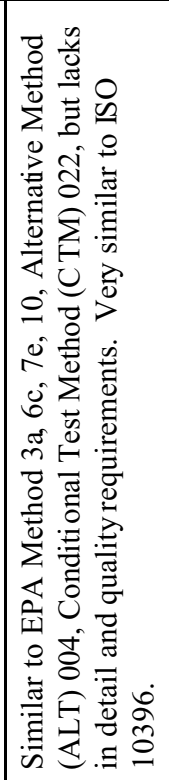 & 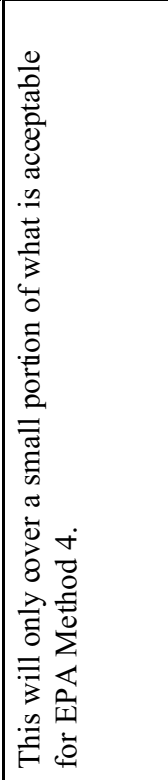 & 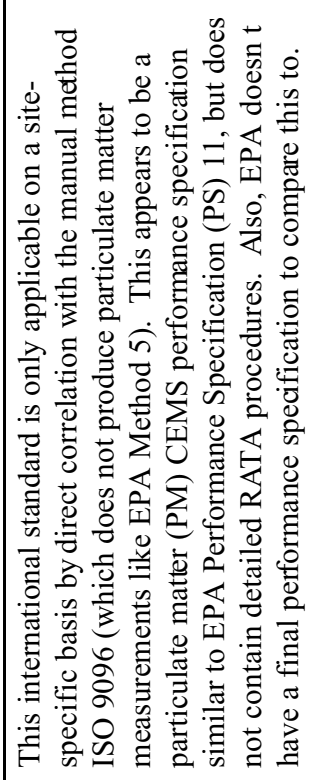 & 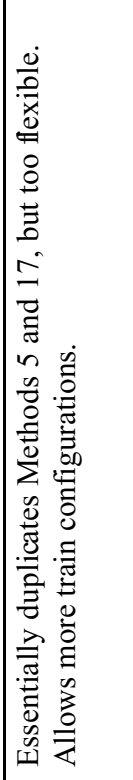 & 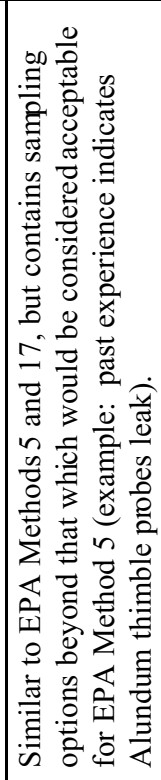 \\
\hline 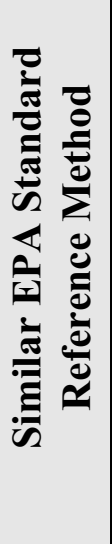 & 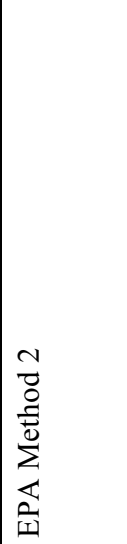 & 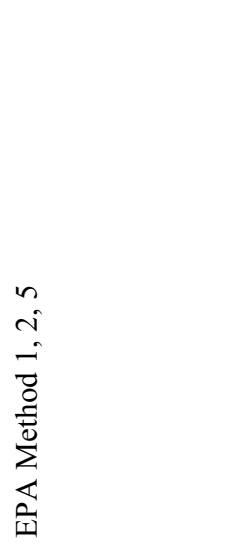 & 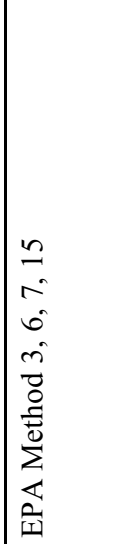 & 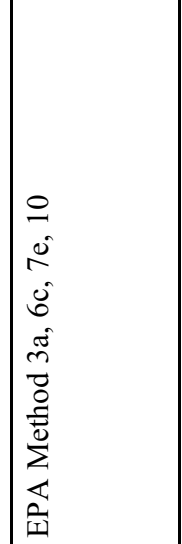 & 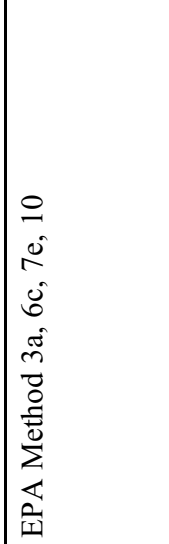 & & 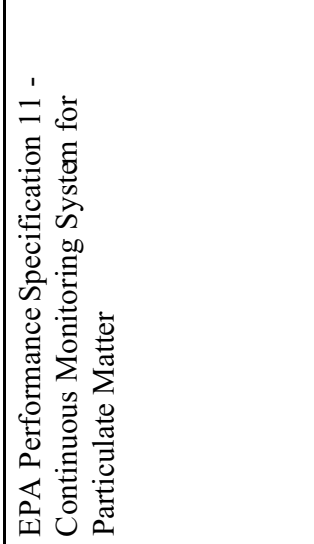 & 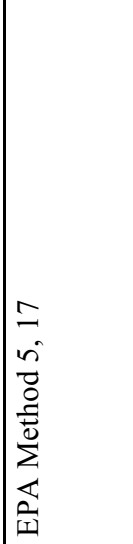 & 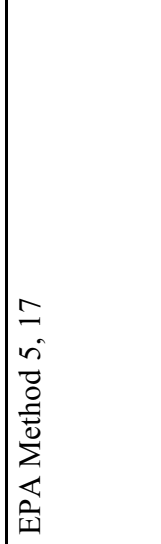 \\
\hline 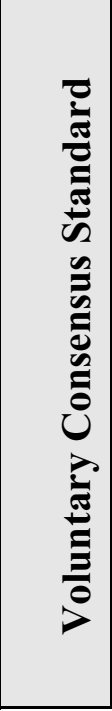 & 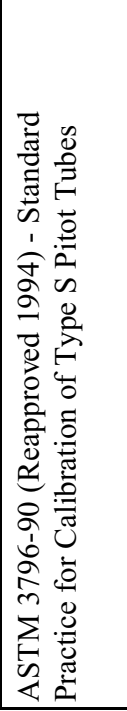 & 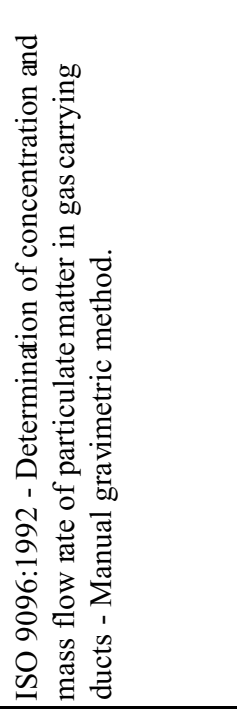 & 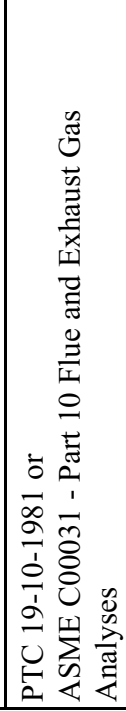 & 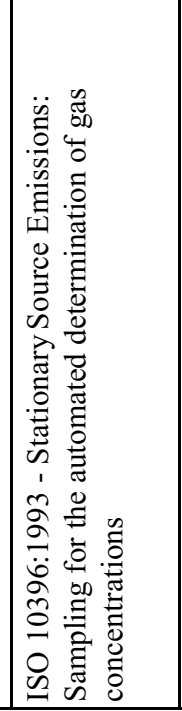 & 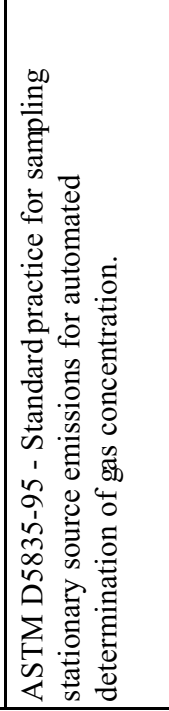 & 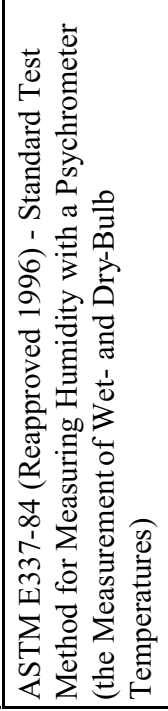 & 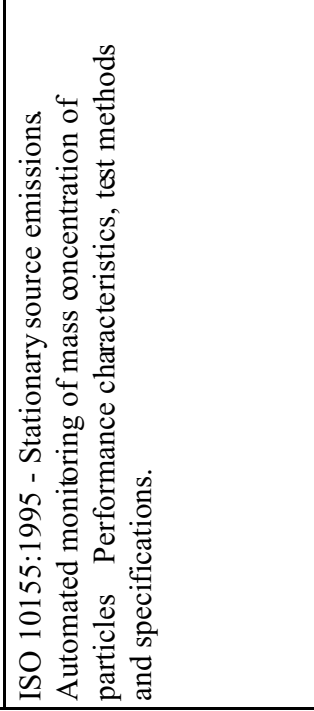 & 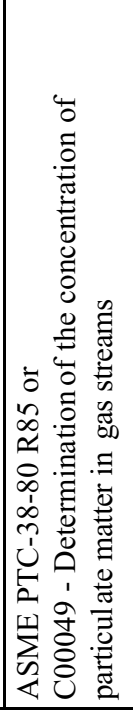 & 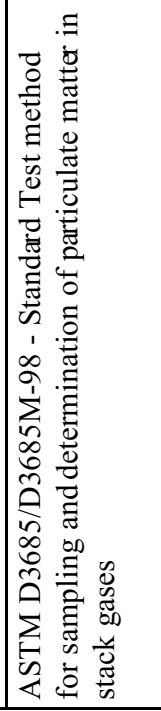 \\
\hline
\end{tabular}




\begin{tabular}{|c|c|c|c|c|c|c|c|c|c|c|}
\hline 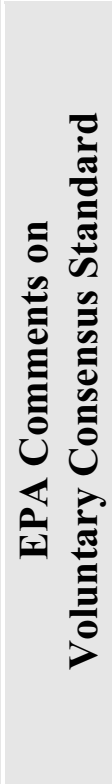 & 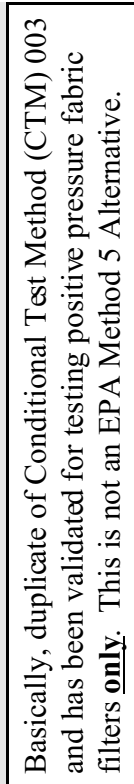 & & 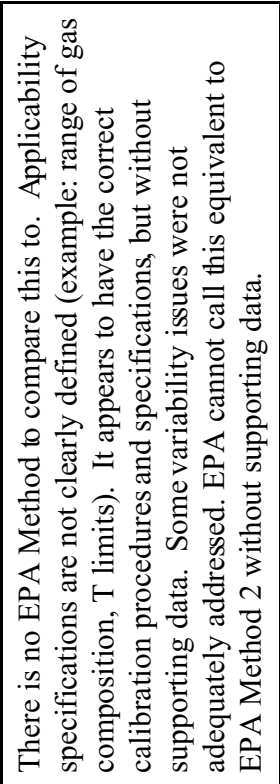 & 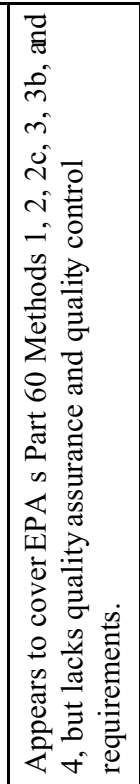 & 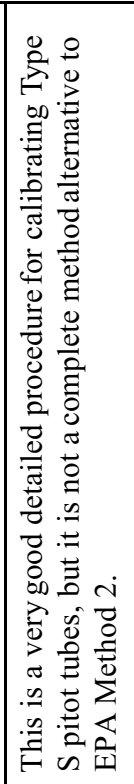 & 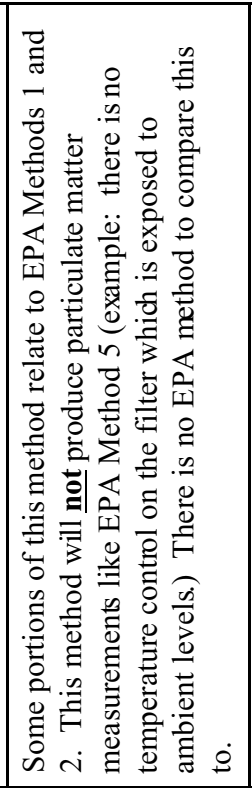 & 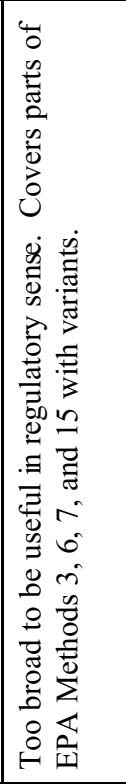 & 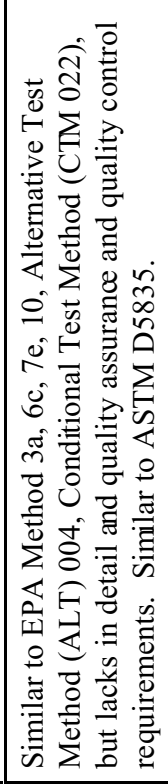 & 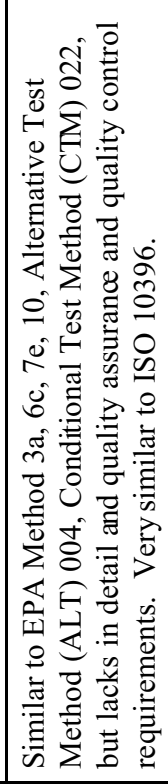 & 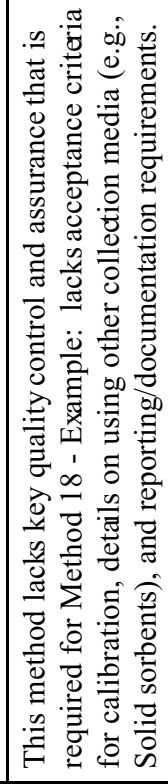 \\
\hline 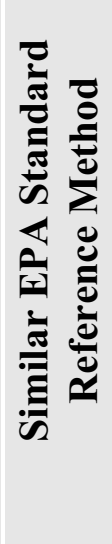 & 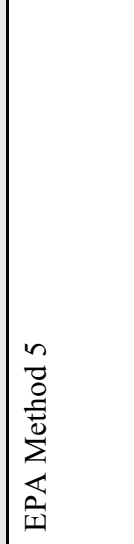 & $\underset{\pi}{\stackrel{2}{Z}}$ & 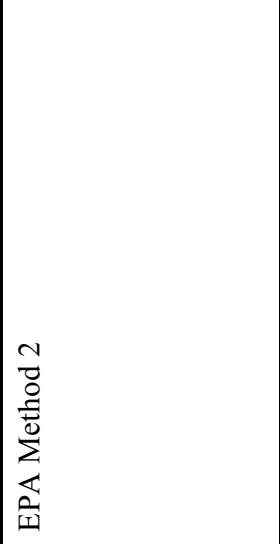 & 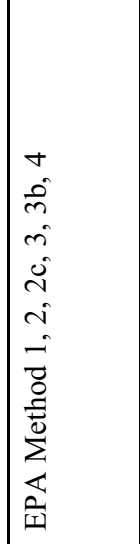 & 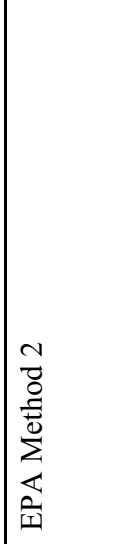 & 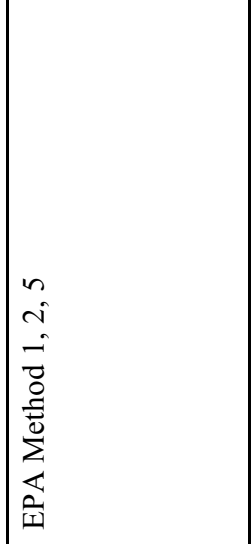 & 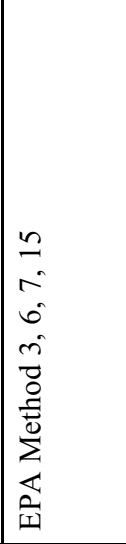 & 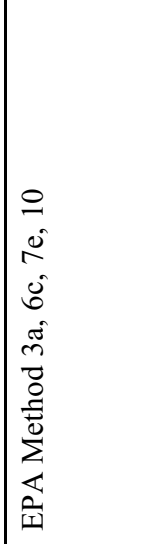 & 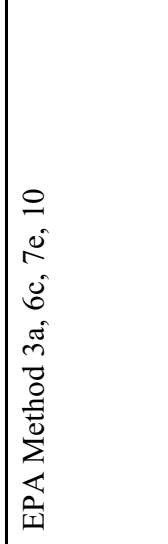 & 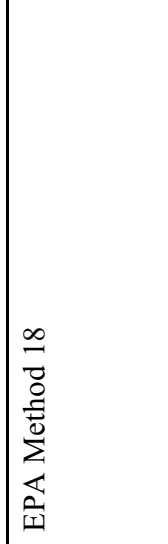 \\
\hline 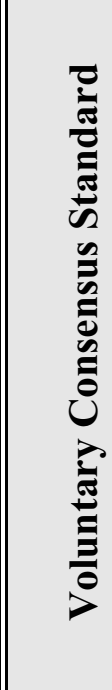 & 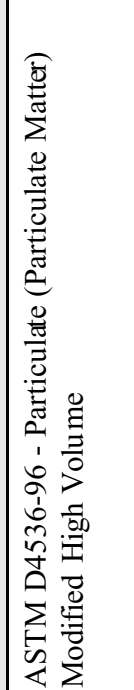 & 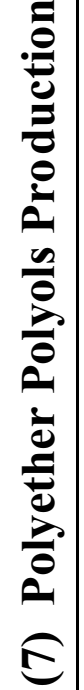 & 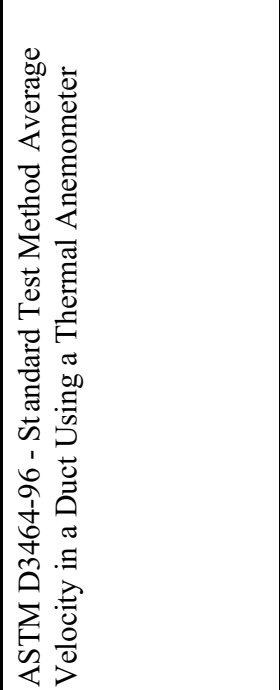 & 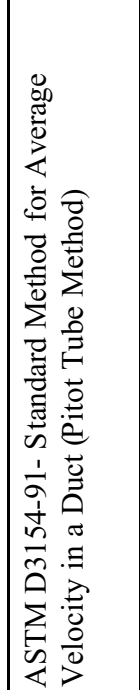 & 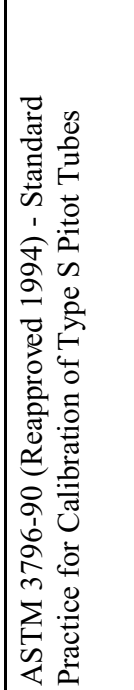 & 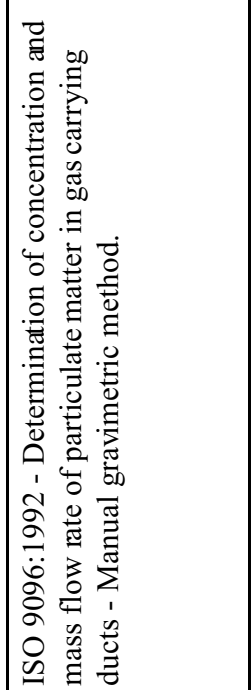 & 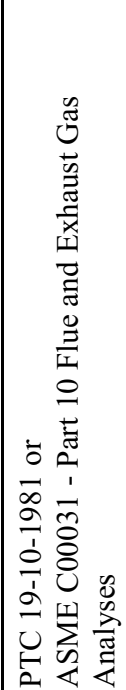 & 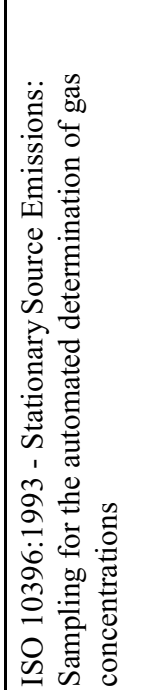 & 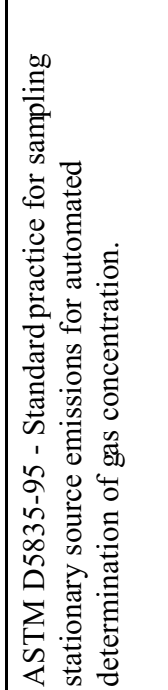 & 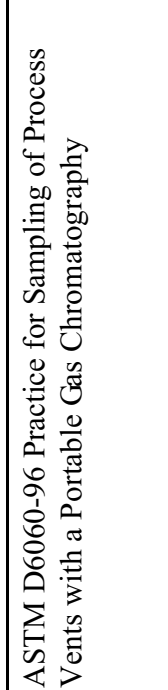 \\
\hline
\end{tabular}




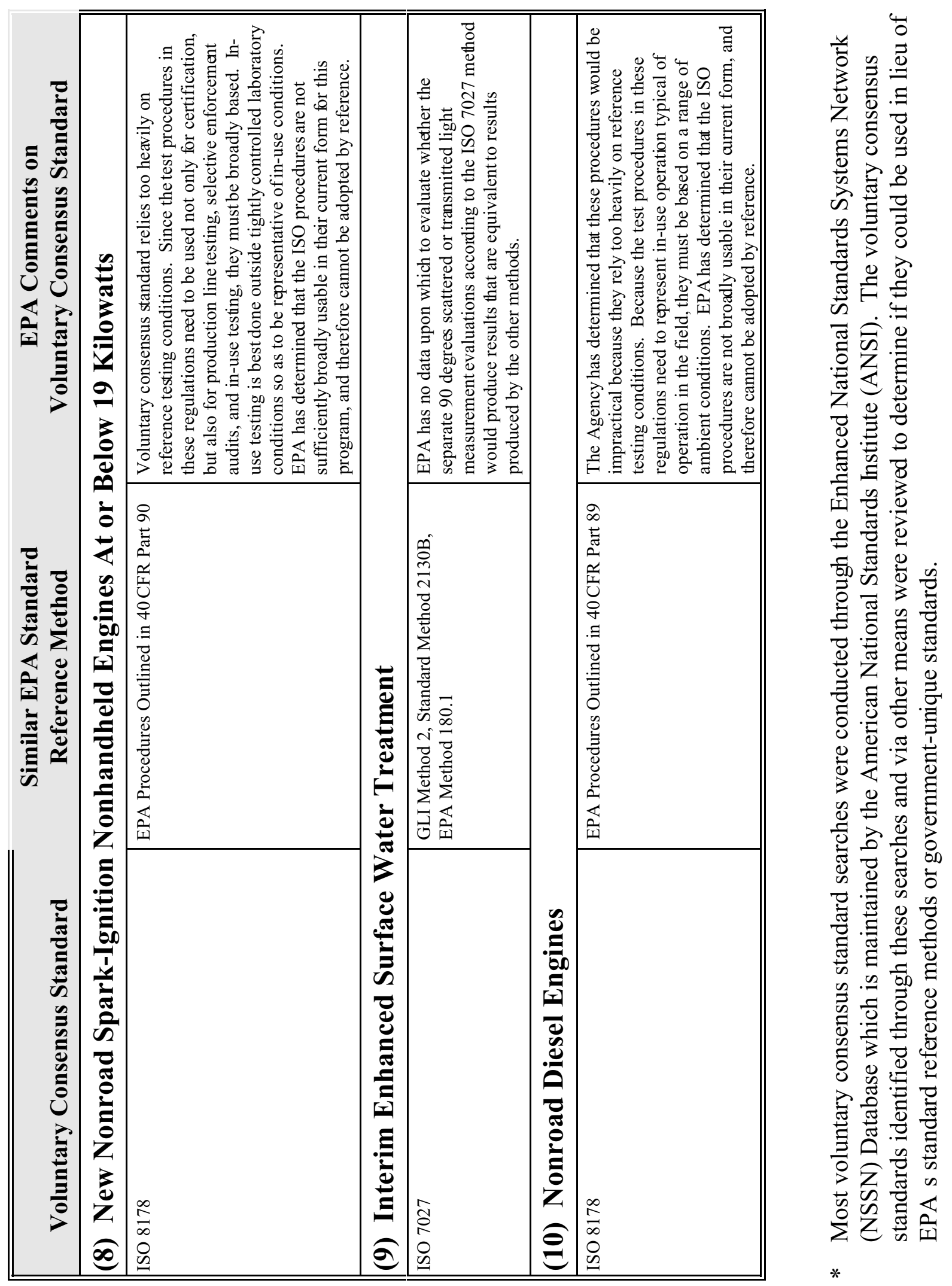





\section{FEDERAL COMMUNICATIONS COMMISSION (FCC)}

The Commission has not used or adopted any government-unique standards in lieu of voluntary consensus standards since October 1, 1998.

The Commission has not used or adopted any voluntary consensus standards since October 1, 1998.

No voluntary consensus standards have replaced government-unique standards as a result of Agency review of existing standards since October 1, 1998.

FCC participates in a variety of organizations that develop telecommunications standards. The actual level of participation with each organization varies depending on the need for Commission involvement and importance of the work relative to our objectives. The Commission presently has approximately 50 employees involved in more than 24 standards bodies and approximately 100 subgroups within these bodies. The Commission uses voluntary standards in several different ways:

- to satisfy industry and user requirements where it appears that mandatory standards are unnecessary. Examples include telephone industry standards for network protocols and interfaces, International Special Committee on Radio Interference standards to control radio emission from automobiles, Telecommunications Industry Association (TIA) standards for digital cellular radio protocols, and TIA/T1 standards for protocols in the personal communications service.

- to correct problems that might otherwise require regulation. For example, the Commission has strongly encouraged compliance with Electronics Industry Association (EIA) standards on television susceptibility to interference rather than moving swiftly to mandatory regulations. It has worked with the industry and local governments to develop measurement standards for testing the signal quality of cable systems, and is working with TIA to encourage development and voluntary implementation of a standard for telephone immunity to interference.

- as the basis for mandatory requirements, either by incorporating voluntary standards by reference, or including the normative portion of the standard in the FCC rules. Examples include American National Standards Institute (ANSI) measurement procedures for radio noise emitted by digital devices; ANSI/EIA standards on AM broadcast transmission specifications; EIA standards for telephone compatibility with hearing aids; International Telecommunications Union Radiocommunications Standardization Sector recommendations on digital selective equipment for use in ship and cost stations; EIA 
task force recommendations on standards for displaying closed-captioning information on television receivers, and an EIA/TIA standard for protection of microwave systems from interference from personal communications systems.

The Commission continues to increase its use of voluntary standards. In many instances, the Commission has chosen not to implement regulations (or more detailed regulations) because adequate voluntary industry standards already exist or are under development. For example, the regulations for Personal Communications Service do not include transmission protocol standards because industry has voluntarily developed these standards. In other instances where the adoption of a standard is, or may be, in the public interest, the Commission has attempted to use voluntary standards whenever possible. For example, the Commission is allowing the industry to establish a spectrum etiquette policy for devices operating at millimeter wavelengths and are working with and looking to industry to develop standards for the transmission of digital radio. In addition, the Commission regularly works close with industry through the negotiated rulemaking process to resolve technical compatibility issues.

The Commission recognizes the benefits of using voluntary consensus standards when applicable and endeavors to comply with the guidance provided in Office of Management and Budget Circular A-119 and the mandates of Public Law 104-113. The Commission s current standards Executive is:

Dale N. Hatfield

Chief, Office of Engineering and Technology

Federal Communications Commission

$44512^{\text {th }}$ Street, S.W.

Washington, D.C. 20554

Telephone (202) 418-2470 


\section{FEDERAL EMERGENCY MANAGEMENT ASSOCIATION (FEMA)}

As required by Public Law (P.L.) 104-113, identification of all instances when the agency used government-unique standards in lieu of voluntary consensus standards:

FEMA continues to use Military Standard (MIL-STD) 188.141B for HF radio, although the agency is working on a voluntary standard for transmitting e-mail via HF radio if landlines are not available.

Developers of the National Emergency Management Information System used and continue to use MIL-STD 498, Software Development and Documentation; MIL-STD 490A, Specification Practices; MIL-STD 1521B, Technical Reviews and Audits for Systems, Equipment and Computer Programs; and MIL-STD 2168, Defense System Software Quality Program, et al. The Agency used these standards as part of a large project started in 1995. At that time, the Agency wanted to use standards with which contractors were familiar. A solid, proven standard that worked and would keep costs in line.

Number of voluntary consensus standards the agency has used since October 1, 1998, based on the procedures set forth in sections 11 and 12 of the Circular:

All desktop computers are configured with the TCP/IP and the IPX and SPX protocols.

FEMA makes extensive use of Institute of Electrical and Electronics Engineers standards.

Real audio player is used for voice messages.

Norton anti-virus and other generally available standards are used ex tensively.

Asynchronous transfer mode is being implemented as part of the upgrade for the FEMA Switched Network.

Digital Line Graph Level 3 as the standard data model for the distribution and storage of digital flood insurance rate map products.

Hypertext Markup Language (HTML) as the standard for FEMA s Web site; discussion is underway to replace HTML with Extensible Markup Language.

Multi-purpose Internet Mail Extension is used to encode e-mail attachments. FEMA uses standard protocols to run the e-mail operations.

Portable Document Format is used to retrieve and post formatted documents between differing computing environments. 
Visio is the Agency s standard for automated visual graphics.

Identification of voluntary standards that have been substituted for government-unique standards as a result of an agency review under section $15 b(7)$ of the Circular:

Voluntary standards are preferred, but because FEMA is a small agency, no formal review has been imposed on the program directors.

The number of voluntary consensus standards bodies in which there is agency participation, as well as the number of agency employees participating:

FEMA participates in the HF industry association working group to resolve HF standards problems, as well as the HF e-mail working group.

An evaluation of the effectiveness of Circular A-119 policy and recommendations for any changes:

The use of consensus standards is official FEMA policy and the mainstay of the information technology architecture. 


\section{GENERAL SERVICES ADMINISTRATION (GSA)}

GSA has 49 employees participating in 79 voluntary consensus standards bodies. The number of employees increased slightly over the previous year, while the number of standards bodies decreased as the Agency became more selective in its participation. GSA continues to expand its emphasis on the procurement of commercial off-the-shelf products and services.

As a result of the review of existing standards, the following voluntary standards have been substituted for government-unique standards. Acronyms are spelled out following this list.

$\underline{\text { Voluntary Standard }}$

ANSI B212.15

ANSI Z87.1

ANSI Z89.1

ANSI Z89.2

ASME A112.18.1M

ASTM D98

ASTM D458

ASTM D632

CGA Std. G-6.2

FMR 6031

FMVSS No. 125

GPA Std. 2140

NFPA Std.

\section{Government Standard *}

GGG-D-650

A-A-1110, A-A-1770 and A-A-1813

A-A-2269 and A-A-2270

A-A-2271

A-A-240

A-A-169

A-A-41

A-A-1545

A-A-2869

A-A-2079

A-A-2128

A-A-2897

A-A-2156

* Includes Federal specifications, standards, and commercial item descriptions.

\section{$\underline{\text { Acronyms }}$}

ANSI American National Standards Institute

ASME American Society of Mechanical Engineers

ASTM American Society for Testing and Materials

CGS Compressed Gas Association

FMR Factory Mutual Research

FMVSS Federal Motor Vehicle Safety Standards (National Highway Traffic Safety Association)

GPA Gas Processors Association

NFPA National Fire Protection Association 
The Agency has no comments or recommendations for changes concerning Office of Management and Budget Circular A-119.

No government-unique standards are being used in lieu of existing voluntary standards. 


\section{GOVERNMENT PRINTING OFFICE (GPO)}

The GPO utilizes the following internally-developed standards on a regular basis for the preparation and development of printing and microform contracts. The information contained in these standards is unique to GPO and cannot be found in any other voluntary consensus standards.

Quality Assurance Through Attributes Program for Printing and Binding, GPO Publication 310.1, Effective May 1979 (Revised April 1996)

Quality Assurance Through Attributes Program for Microforms, GPO Publication 310.3, Effective August 31, 1988

Quality Assurance Through Attributes Program for Composition, GPO Publication 310.4, December 1985

GPO Guidelines for Specifying Quality and Determining Compliance of MICR, OCR, and OMR, Quality Assurance Through Attributes Program, GPO Publication 310.5, January 1993

GPO has used 469 voluntary consensus standards since October 1, 1998.

GPO has not substituted any voluntary consensus standards for government-unique standards as a result of an agency review.

The number of standards bodies in which GPO participates:

American National Standards Institute - one employee

Association for Information and Image Management - two employees

Office of Management and Budget Circular A-119 is effective in that it advocates use of existing resources rather than inefficiently re-inventing the wheel. No recommendations for changes. 


\section{NATIONAL AERONAUTICS AND SPACE ADMINISTRATION (NASA)}

NASA policy for technical standards is documented in NASA Policy Directive (NPD) 8070.6 (Revised 1998). It reflects the requirements of Public Law (P.L.) 104-113 and Office of Management and Budget (OMB) Circular A-119. NPD 8070.6 specifically cites the preference for use of voluntary consensus standards, encourages participation in voluntary consensus standards development to meet NASA needs, establishes responsibilities for standards management in NASA, and references OMB Circular A-119 for detailed requirements.

The NASA Chief Engineer is the NASA Standards Executive. Policy level issues are coordinated through NASA s Engineering Management Council (EMC), an Agency-wide group of senior management officials from NASA s Engineering and Safety and Mission Assurance (S\&MA) functions. The Chief Engineer has overall responsibility for administration of the NASA Technical Standards Program. Implementation and management responsibility for the NASA Technical Standards Program has been assigned to the Marshall Space Flight Center, which chairs an Agency-wide Engineering Standards Steering Council responsible for procedures, coordination of internal document development, and adoption of voluntary consensus standards.

NASA $\mathrm{s}$ use of technical standards is for internal engineering and procurement purposes. The Agency has no regulatory responsibilities and therefore has chosen a categorical or standards management system approach for reporting, which is an option provided in OMB Circular A-119. The NASA Technical Standards Management System currently contains listings of NASA Preferred Technical Standards, lists of NASA participants in voluntary consensus standards activities, and extensive links to other sources of technical standards. The home page for the NASA Technical Standards Management System can be found on the Internet at $<$ http://standards.msfc.nasa.gov $>$.

As required by P.L.104-113, identification of all instances when the Agency used government-unique standards in lieu of voluntary consensus standards (for each instance include Agency rationale for such use, as well as the specific government-unique standard used):

Because NASA uses the categorical method of reporting, use of governmentunique standards is reported in terms of additions to the NASA Technical Management System, as opposed to tracking use in individual procurement transactions. During 1999, NASA has developed 11 internal standards, all of which were either unique to NASA needs or were internal procedures for program management or for the implementation of standards. 
The number of voluntary consensus standards the Agency has used since October 1, 1998, based on the procedures set forth in sections 11 and 12 of the Circular:

In 1998, NASA began an intensive effort to identify voluntary consensus standards currently being used on NASA programs and to review them as candidates for formal adoption. Since October 1, 1998, NASA has identified an additional 430 voluntary consensus standards products based on current use by one or more NASA installations. These are now in the final stages of the review process for formal adoption by NASA. This will bring the total number of voluntary consensus standards the Agency has adopted to 1,032. Approximately 74 percent of the voluntary consensus standards adopted are in the area of materials and processes specifications. The adoptions were based on staff recommendations, concurrence of the NASA Engineering Standards Steering Council, and formal approval by the NASA EMC and the NASA Standards Executive. There are 201 voluntary consensus standards identified by the Office of Safety and Mission Assurance called out in existing S\&MA documents previously approved through the S\&MA process. This list of standards products is being reviewed for inclusion as NASA Preferred Technical Standards.

Identification of voluntary consensus standards that have been substituted for government-unique standards as a result of an Agency review under section 15b(7) of the Circular:

There is a two-phase effort underway for identification and substitution of government-unique standards. The first phase involved an extensive review of Government standards currently in use, including both NASA internal technical standards and standards of other Government agencies, such as the Department of Defense. The objective of this review is to identify all Government standards used across the Agency for inclusion in the NASA Technical Standards Management System on an interim basis. So far, 190 military specifications and standards have been identified and are now in the final stages of the review process for NASA adoption. The second phase is to identify which government-unique technical standards in the system can be eliminated or replaced with voluntary consensus standards. There were eight data communications standards that were converted in 1999 from international intergovernmental standards to International Organization for Standardization standards. The Agency will continue to identify and screen its internal standards. Completion of this review is a major objective for the Technical NASA Standards Program during fiscal year (FY) 2000. 
The number of voluntary consensus standards bodies in which there is Agency participation, as well as the number of Agency employees participating:

In FY 1999, NASA had 145 employees participating in 45 voluntary consensus standards developing bodies, both domestic and international. This is approximately 2 percent less than reported in FY 1998, largely due to corrections that deleted the names of employees who were members of professional societies but not directly involved in the development of standards. The relative constancy of the number of participants was remarkable given that the total turnover of participants in the past year was approximately 43 percent.

An evaluation of the effectiveness of Circular A-119 policy and recommendations for any changes:

OMB Circular A-119 continues to provide stimulus for NASA's effort to improve its technical standards management system, enhance the use of voluntary consensus standards products, and challenge the need for NASA-unique technical standards requirements. It is an integral part of the NASA Technical Standards Program. It is an effective guideline to implement the law and NASA has no recommendations for any changes. 


\section{NATIONAL ARCHIVES AND RECORDS ADMINISTRATION (NARA)}

The NARA continues to be active in the area of voluntary standards. Based on the reporting requirements of Office of Management and Budget (OMB) Circular A-119, NARA submits the following report:

As required by Public Law (P.L.) 104-113, identification of all instances when the agency used government-unique standards in lieu of voluntary consensus standards:

While NARA has adopted many voluntary standards, we are using a governmentunique standard from the U.S. Marshal Service because there is no suitable voluntary consensus standard to classify and secure government facilities. The U.S. Marshal Service security guidelines are from the 1995 Vulnerability Assessment of Federal Facilities and related Interagency Security Committee implementation guidance.

During the reporting period, NARA endorsed the Department of Defense Standard 5015.2, Design Criteria for Electronic Records Management Software Applications, for use across the Federal Government as one possible approach to managing electronic records. There are currently no voluntary consensus standards in place that address this issue.

The number of voluntary consensus standards the agency has used since October 1, 1998, based on the procedures set forth in sections 11 and 12 of the Circular:

During fiscal year 1999, the agency published a proposed rule relating to the operation of records centers. In this regulation, NARA incorporates, by reference, 22 voluntary consensus standards. This regulation was published as a final rule on December 2, 1999.

Identification of voluntary consensus standards that have been substituted for government-unique standards as a result of an agency review under section $15 b(7)$ of the Circular:

No new voluntary consensus standards were adopted for use during the reporting period. 
The number of voluntary consensus standards bodies in which there is agency participation, as well as the number of agency employees participating:

There are a total of eight NARA employees actively involved in a variety of voluntary consensus standards organizations, committees, and subcommittees, either as official NARA representatives or alternates. They serve on the following entities:

American Society of Testing and Materials

American National Standards Institute

Association for Information and Image Management

National Fire Protection Association

National Information Standards Organization

Photographic and Imaging Manufacturers Association

Audio Engineering Society

Society of Motion Picture and Television Engineers

An evaluation of the effectiveness of Circular A-119 policy and recommendations for any changes:

NARA supports the policy of OMB Circular A-119 and will continue to adopt voluntary consensus standards in our policies and regulations. 


\section{NATIONAL SCIENCE FOUNDATION (NSF)}

The required information as outlined in Office of Management and Budget Circular A-119 follows:

NSF has not used any government-unique standards in lieu of voluntary consensus standards during this reporting period.

The number of voluntary consensus standards the agency has used since October 1, 1998 is zero.

No voluntary consensus standards that have been substituted for government-unique standards as a result of agency review under section 15b(7) of the Circular.

There are three voluntary consensus standards bodies in which there is agency participation, with three employees participating.

An evaluation of the effectiveness of the guidelines in section 7 of the proposed revision of the Circular and recommendations for any changes.

The proposed guidelines allow appropriate agency participation in standards activities. No changes are recommended. 


\section{NUCLEAR REGULATORY COMMISSION (NRC)}

The NRC has been an active participant in the development and use of consensus standards since its establishment in 1975. The Commission s Strategic Assessment and Rebaselining Initiative in 1996 further increased NRC s focus on the use of standards. For nuclear reactor and nuclear materials safety, the strategy is to increase the involvement of licensees and others in the NRC regulatory process consistent with Public Law (P.L.) 104-113, National Technology Transfer and Advancement Act of 1995. To do this, NRC will continue to encourage industry to develop codes, standards, and guides that NRC can endorse and the industry can carry out.

In fiscal year (FY) 1999, NRC took several actions to increase the effectiveness and efficiency of our process for implementing P.L. 104-113 and Office of Management and Budget (OMB) Circular A-119, Federal Participation in the Development and Use of Voluntary Consensus Standards and in Conformity Assessment Activities. The NRC staff used information gained from the stakeholder meeting it held in Chicago in September 1998, to prepare a

Recommendation ${ }^{7}$ to the Commission to develop guidance for staff use when participating in the development and utilization of consensus standards. The Commission supported the staff Recommendation. ${ }^{8}$ In May 1999, the NRC held a follow-up to the Chicago meeting to focus on communications with standards developing organizations (SDOs). This meeting demonstrated the value of bringing representatives from different SDOs and the NRC staff together to discuss the current needs, priorities, and constraints of each organization. Based on the success of this meeting, future meetings will be held periodically. The next meeting is scheduled for January 2000 .

During the period for this annual report, the NRC staff prepared a management directive ${ }^{9}$ to provide direction for staff to support the NRC standards strategy. The management directive defines NRC organizational responsibilities for standards activities and provides direction for staff participation in the development and use of consensus standards. Specifically, the management directive provides direction for identifying and prioritizing needed new and revised technical standards, selecting and nominating staff as authorized agency representatives on SDO committees, and coordinating standards activities with SDOs and other stakeholders. It provides direction for identifying and prioritizing standards for timely endorsement, annual reporting,

${ }^{7}$ SECY-99-029, NRC Participation in the Development and Use of Consensus Standards, January 28, 1999.

${ }^{8}$ Staff Requirements, SECY-99-029, February 17, 1999.

${ }^{9}$ Management Directive 6.5, NRC Participation in the Development and Use of Consensus Standards, issued November 1999. 
taking exception to using a consensus standard, and monitoring and assessing the NRC standards program. The management directive requires periodic training of staff involved with standards activities to provide updates on Federal requirements for standards development and to discuss lessons learned.

The NRC response to the reporting provisions of OMB Circular A-119 is as follows:

Identification of all instances when the agency used government-unique standards in lieu of voluntary consensus standards (for each instance include agency rationale for such use, as well as the specific government-unique standard used):

No government-unique standards were used by NRC in lieu of existing voluntary consensus standards.

The number of voluntary standards the agency has used since October 1, 1998, based on the procedures set forth in sections 11 and 12 of the Circular:

During this reporting period, seven consensus standards were incorporated by reference into NRC regulations. Six American Society of Mechanical Engineers (ASME) standards were incorporated by reference into 10 CFR 50.55a, Codes and Standards (see table below for a list of the standards). During proposed rulemaking, the proposed uses of the ASME standards were identified and, in some instances, NRC defined exceptions or supplemental requirements. The public comment period provided the opportunity for stakeholders to comment, which resulted in a revision to some of the NRC defined exceptions and supplemental requirements. In all instances, the six consensus standards provide the basis for the NRC regulation. In addition, one Institute of Electrical and Electronics Engineers standard was incorporated by reference into 10 CFR 50.55a(h), Protection Systems, to supplement the existing reference (see table).

The NRC also endorsed 30 standards in three final regulatory guides ${ }^{10}$ and eight standards in one final NUREG ${ }^{11}$ (see table for identification of these standards with the specific method of endorsement).

Final direction ${ }^{12}$ to address rulemaking (section 11 of the Circular) and procurement (section 12) activities was developed during this reporting period. Proposed regulations.

${ }^{11}$ NUREG-1556, which provides consolidated guidance for material licensees.

${ }^{12}$ See Footnote 10. 
rulemakings that have incorporated previous interim guidance to implement section 11 procedures have not completed final rulemaking.

Identification of voluntary consensus standards that have been substituted for government-unique standards as a result of an agency review under section 15(b)(7) of the Circular:

Generic Letter 90-05, Guidance for Performing Temporary Non-Code Repair of ASME Code Class 1, 2, and 3 Piping, December 1994, provides guidance that NRC staff consider in evaluating relief requests submitted by licensees for temporary non-Code repairs of Code Class 1, 2, and 3 piping. ASME Section XI Code Cases N-513, Evaluation Criteria for Temporary Acceptance of Flaws in Class 3 Piping, and N-523-1, Mechanical Clamping Devises for Class 2 and 3 Piping, have been incorporated by reference into 10 CFR 50.55a to allow licensees to substitute applicable related provisions for temporary non-Code repairs in these Code cases for the guidance in Generic Letter 90-05.

The number of voluntary consensus standards bodies in which there is agency participation, as well as the number of agency employees participating.:

During FY 1999, 141 NRC staff participated on 18 SDOs on a total of 267 standards writing, consensus, and board-level committees.

An evaluation of the effectiveness of Circular A-119 policy and recommendations for any changes:

The policy guidelines provided in OMB Circular A-119 for participating in voluntary consensus standards bodies and using voluntary consensus standards are generally consistent with longstanding NRC practices. The staff believes that these guidelines provide appropriate direction and encouragement for Federal agencies to develop internal agency-wide guidelines to implement P.L. 104-113 and OMB

Circular A-119. These guidelines also provide sufficient and reasonable flexibility for each agency to make an independent case-by-case determination as to the usability of a particular standard within that agency s scope and responsibility. 


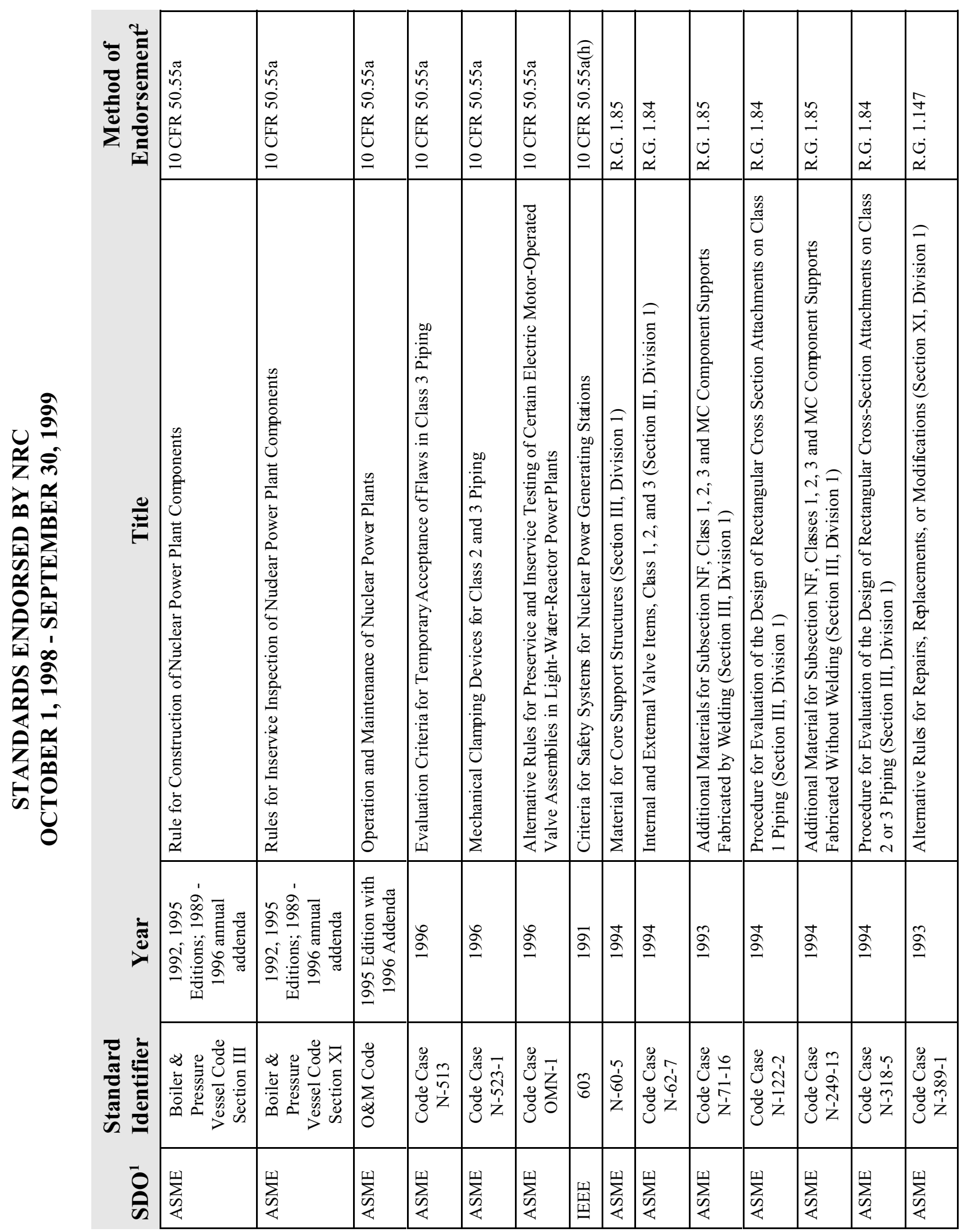




\begin{tabular}{|c|c|c|c|c|c|c|c|c|c|c|c|c|c|c|c|c|c|c|c|}
\hline 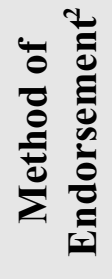 & 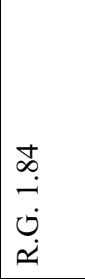 & $\begin{array}{l}\tilde{y} \\
\Xi \\
\dot{\Xi} \\
\check{4}\end{array}$ & 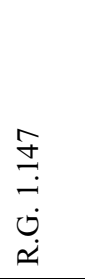 & $\begin{array}{l}\hat{\Xi} \\
\Xi \\
\dot{\Xi} \\
\check{\simeq}\end{array}$ & $\begin{array}{l}\infty \\
\stackrel{\infty}{-} \\
\dot{\sim} \\
\end{array}$ & 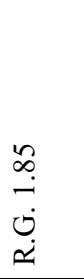 & 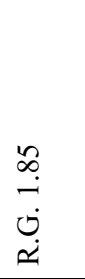 & 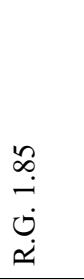 & 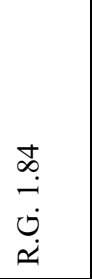 & 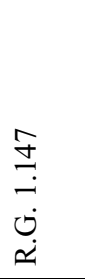 & 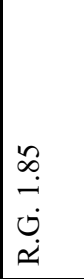 & 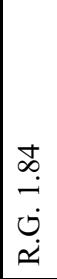 & 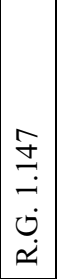 & $\begin{array}{l}\mathcal{J} \\
\beth \\
\dot{\Xi} \\
\check{\sim}\end{array}$ & 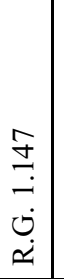 & 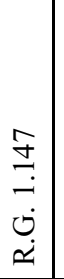 & 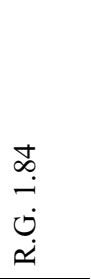 & 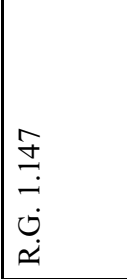 & 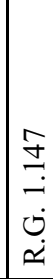 \\
\hline 車 & 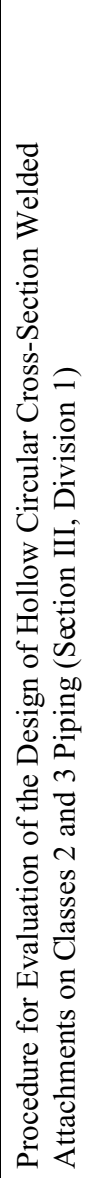 & 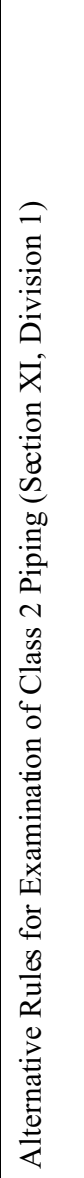 & 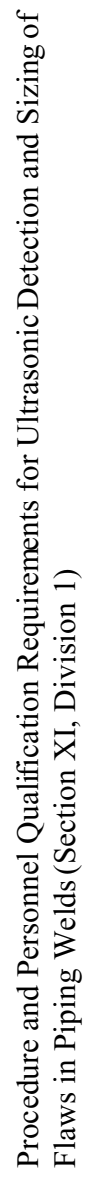 & 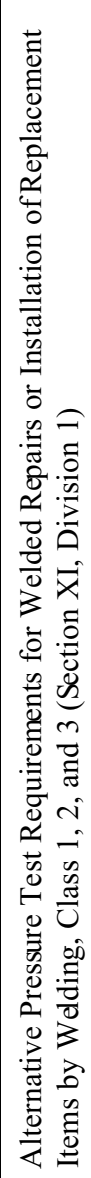 & 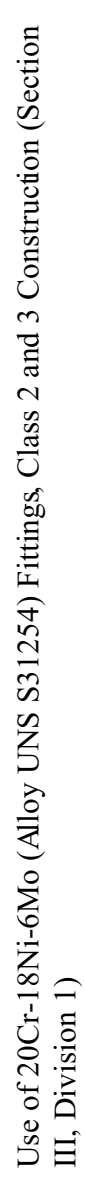 & 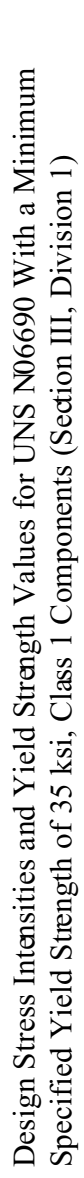 & 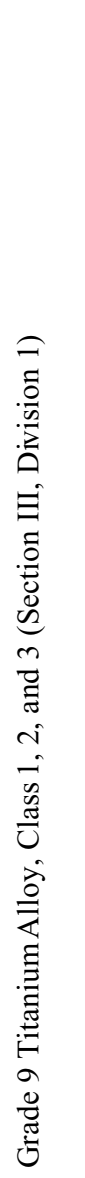 & 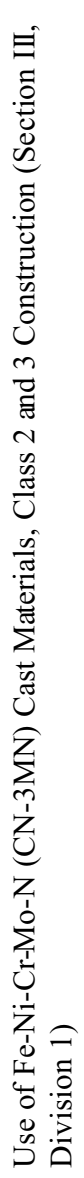 & 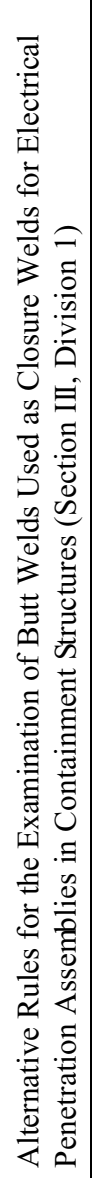 & 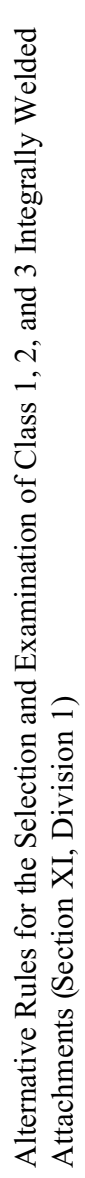 & 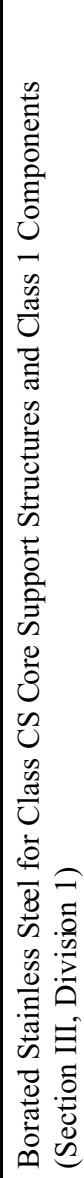 & 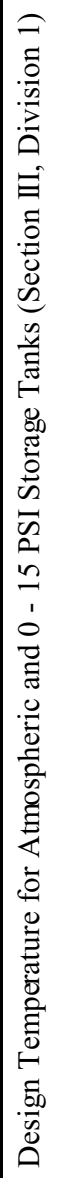 & 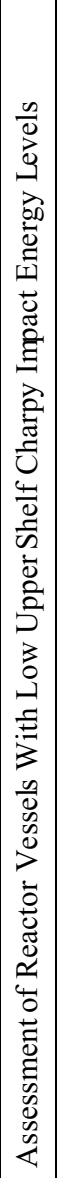 & 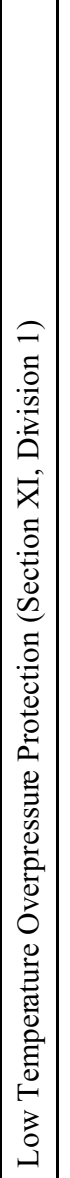 & 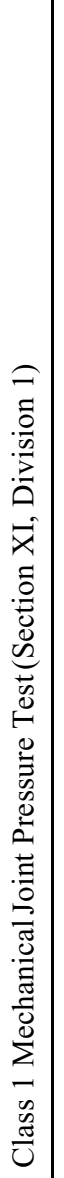 & 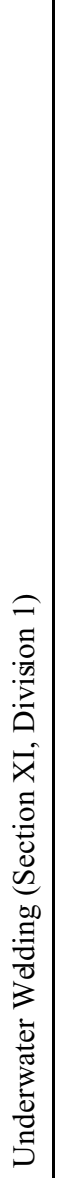 & 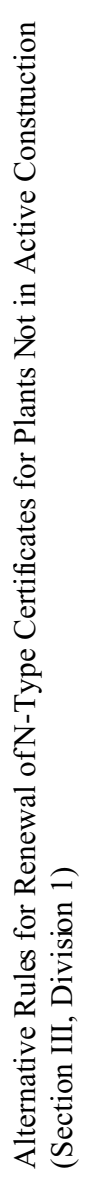 & 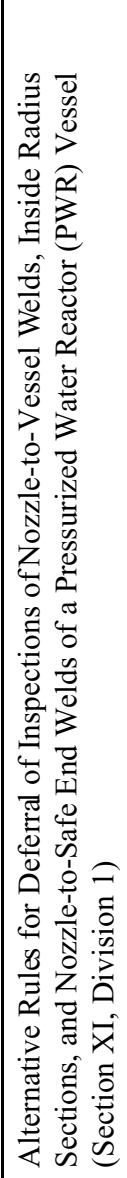 & 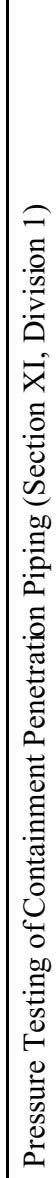 \\
\hline 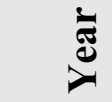 & کू & $\hat{\Omega}$ & $\hat{\sigma}$ & な & ऽ̆ & ळे & な & $\tilde{\sigma}$ & ऽ̆ & کे & & $\stackrel{2}{\Omega}$ & & $\stackrel{\check{\sigma}}{\sigma}$ & 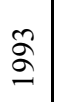 & $\stackrel{\text { }}{\sigma}$ & $\hat{\sigma}$ & $\hat{\sigma}$ & $\tilde{\sigma}$ \\
\hline 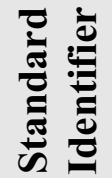 & 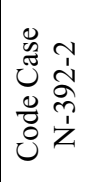 & 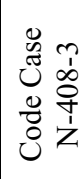 & 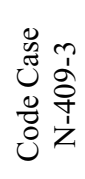 & 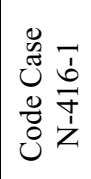 & 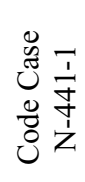 & 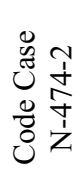 & 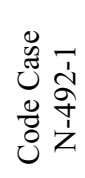 & 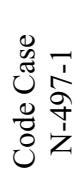 & $\begin{array}{l}n \\
0 \\
n \\
z\end{array}$ & $\begin{array}{l}\text { Oे } \\
\text { ż }\end{array}$ & $\begin{array}{l}0 \\
\stackrel{0}{n} \\
z \\
z\end{array}$ & $\begin{array}{l}\bar{n} \\
z \\
z\end{array}$ & $\begin{array}{l}\frac{v}{n} \\
z\end{array}$ & $\begin{array}{l}\frac{\partial}{n} \\
\tilde{z} \\
z\end{array}$ & $\begin{array}{l}n \\
\frac{n}{n} \\
z\end{array}$ & $\begin{array}{l}0 \\
\vdots \\
i \\
z\end{array}$ & $\begin{array}{l}\text { त } \\
\tilde{1} \\
z\end{array}$ & 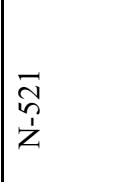 & $\begin{array}{l}\tilde{N} \\
i \\
z\end{array}$ \\
\hline อ̊ & 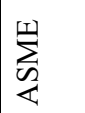 & $\sum_{\infty}^{\infty}$ & $\sum_{\infty}^{\infty}$ & 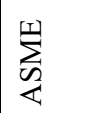 & $\sum_{\substack{\infty\\
}}^{1}$ & $\sum_{\substack{\alpha \\
<}}^{n}$ & 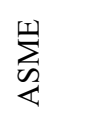 & 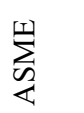 & $\sum_{\substack{\infty \\
\text { In }}}^{1}$ & 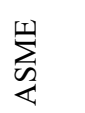 & 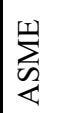 & 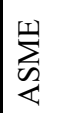 & $\sum_{i=1}^{n}$ & $\sum_{\infty}^{\infty}$ & 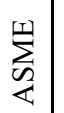 & 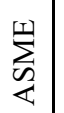 & $\sum_{\substack{\infty \\
\mid}}^{m}$ & 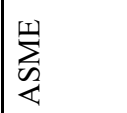 & 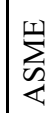 \\
\hline
\end{tabular}




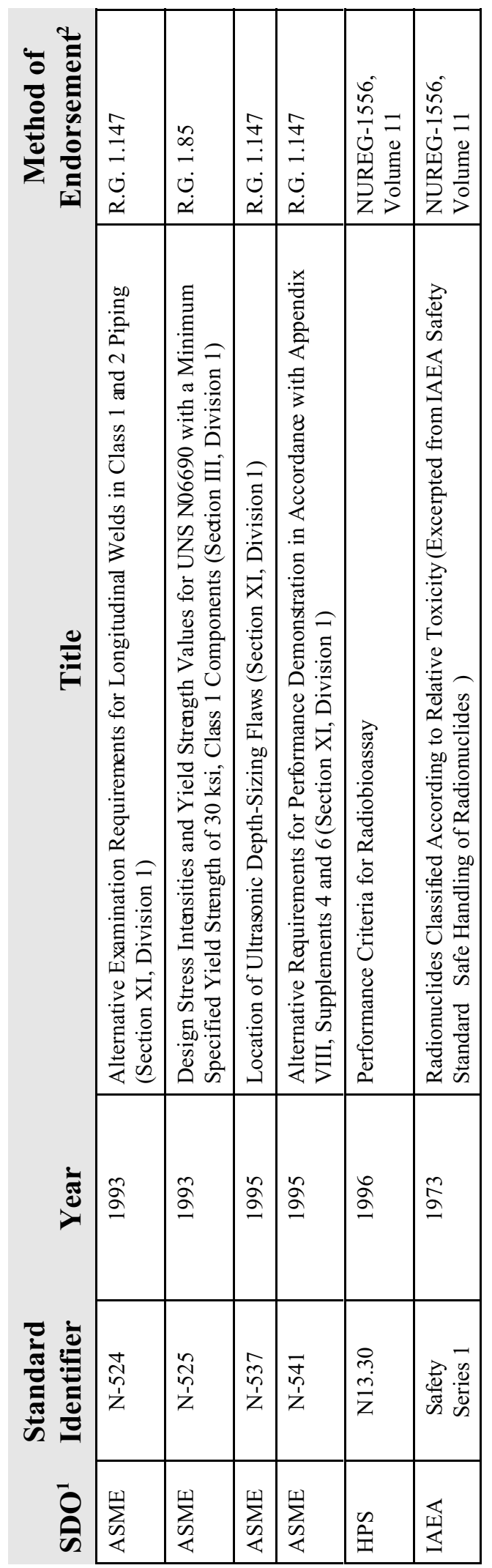

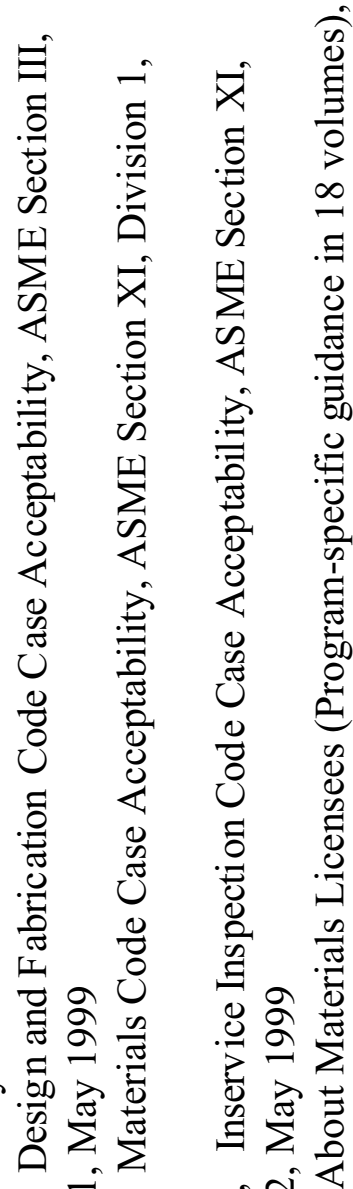

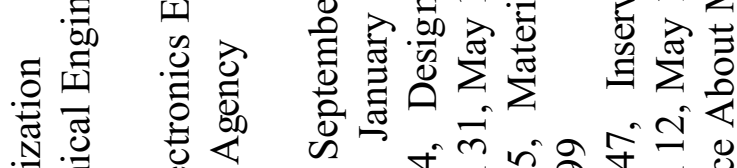

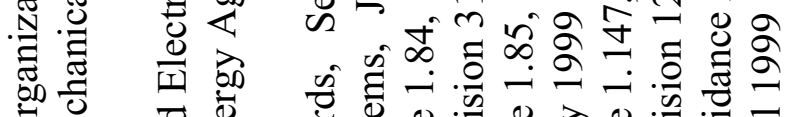

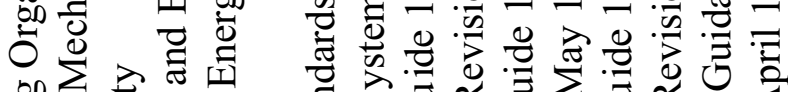

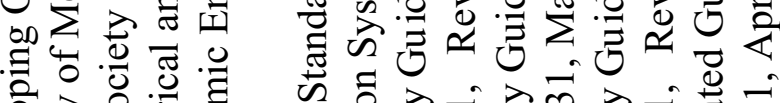

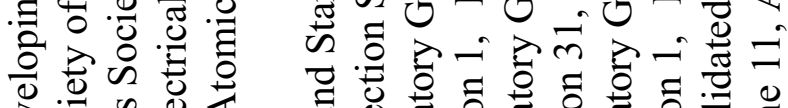
D.

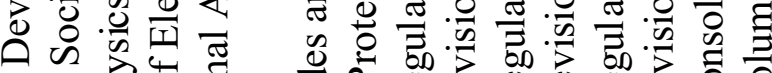

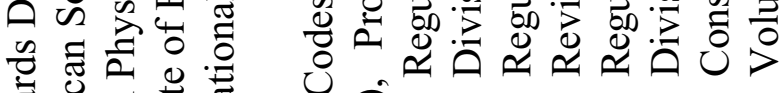

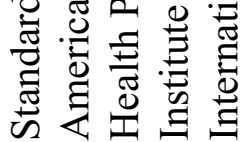

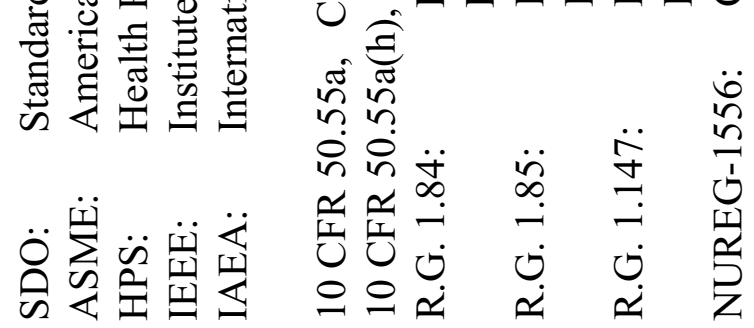





\title{
Appendix C:
}

\author{
Charter of the \\ Interagency Committee \\ on \\ Standards Policy (ICSP)
}




\section{DEPARTMENT OF COMMERCE}

\section{CHARTER \\ OF THE \\ INTERAGENCY COMMITTEE ON STANDARDS POLICY}

\section{$\underline{\text { Establishment }}$}

1. The Interagency Committee on Standards Policy (herein after referred to as the Committee) is established to advise the Secretary of Commerce and the heads of other Federal agencies in matters relating to standards policy.

2. The Committee fulfills the mandates set out in paragraph 8.a.2 of the Office of Management and Budget (OMB) Circular No. A-119, "Federal Participation in the Development and Use of Voluntary Standards," in its revision of October 20, 1993.

3. The Committee reports to the Secretary of Commerce through the Director of the National Institute of Standards and Technology.

\section{$\underline{\text { Purpose }}$}

The purpose of the Committee is to ensure effective participation by the Federal Government in domestic and international standards activities and to promote the adherence to uniform policies by Federal agencies in the development and use of standards. Well-considered Federal policies reflecting the public interest can expedite the development and adoption of standards that stimulate competition, promote innovation, and protect the public safety and welfare. The establishment and application of appropriate standards for the characteristics or performance of goods, processes, and services can contribute significantly to national and international prosperity, economic growth, and public health and safety. The establishment of such standards can also further national goals for environmentally sound and energy efficient materials, products, systems, services, or practices. Heightened national and international awareness of the importance of standards activities, as reflected by enactment of the National Technology Transfer and Advancement Act of 1995 (P.L. 104-113, signed into law March 7, 1996), and recommendations presented in the National Research Council s report "Standards, Conformity Assessment, and Trade into the 21st Century" (National Academy Press, 1995) call for the Committee to intensify its efforts to identify the broad roles and appropriate interactions of agencies in exercising the Government's authority. 


\section{Objective}

The objective of the Committee shall be to promote effective and consistent standards policies in furtherance of U.S. domestic and foreign goals and, to this end, to foster cooperative participation by the Federal Government and U.S. industry and other private organizations in standards activities, including the related activities of product testing, quality system registration, certification, and accreditation programs.

\section{Functions}

1. As appropriate, the Committee shall gather, analyze, and maintain current information about standards, product testing, quality system registration, accreditation and certification, and related regulations, rules, policies, and activities:
a. conducted within or established by Federal agencies;
b. conducted by private domestic and foreign national standards bodies and by regional and international private and intergovernmental organizations engaged in such programs; and
c. pertaining to the relationships among agencies of the Federal Government with industry and the various national, regional, and international organizations engaged in such programs.

2. On the basis of such information and when appropriate with respect to the activities named in paragraph 1 above, the Committee shall make recommendations to the Secretary of Commerce to:

a. strengthen coordination of the standards-related policies and activities among the Federal agencies;

b. improve the efficiency within the Federal Government of standardization efforts with the U.S. private sector, as well as with regional and international organizations, both private and governmental;

c. promote standards-related policies, including directory of personnel participating in standards activities, within the Federal Government consistent with statutory obligations in regard to interactions with non-Federal Government organizations;

d. ensure effective representation of the Federal Government at significant regional and international standards-related meetings and conferences;

e. promote the use of internationally acceptable standards and related activities with a view to increasing trade and economic integration and development;

f. monitor U.S. technical obligations as a signatory to the World Trade Organization, the U.S.-Canada Free Trade Agreement, the North American Free Trade Agreement, and other treaties encompassing standards-related trade issues;

g. encourage the development of agency strategic plans for managing and monitoring use of voluntary standards and participation in standards-related activities; 
h. promote the use of standards that serve national goals related to increased use of the metric system of measurement and environmentally sound and energy efficient materials, products, systems, services, and practices; and

i. assess and improve the adequacy of such agency plans and activities.

\section{Membership}

1. Together with the Department of Commerce, the following agencies constitute the membership of the Committee:

Department of Agriculture

Department of Defense

Department of Education

Department of Energy

Department of Health and Human Services

Department of Housing and Urban Development

Department of the Interior

Department of Justice

Department of Labor

Department of State

Department of Transportation

Department of the Treasury

Department of Veterans Affairs

Office of Consumer Affairs

Consumer Product Safety Commission

Environmental Protection Agency

Federal Communications Commission

Federal Emergency Management Agency

Federal Trade Commission

General Services Administration

International Trade Commission

Office of Management and Budget

National Aeronautics and Space Administration

National Archives and Records Administration

National Communications Systems (Dept. of Defense) - (nonvoting member)

National Science Foundation

Nuclear Regulatory Commission

U.S. Agency for International Development

U.S. Government Printing Office - (legislative liaison - nonvoting member)

U.S. Postal Service

Office of the U.S. Trade Representative 
The head of each member agency shall ensure representation by a responsible high level policy official (Senior Executive Service or higher) who serves as the agency representative on the Committee. Such agency representative shall also serve as the "Standards Executive" as defined in section 8.b.2 of OMB Circular No. A-119. Appointments to the Committee shall be for an indefinite term.

2. Agency representatives may designate alternates of equivalent senior status to serve in their absence.

3. Experts from organizations within the member agency may be designated by agency representatives to serve on task groups established by the Committee.

4. Other Federal agencies may become members of the Committee upon application to or invitation by the Secretary of Commerce.

\section{$\underline{\text { Administrative Provisions }}$}

1. The Director of the National Institute of Standards and Technology (NIST) or the Director's designee shall chair the Committee.

2. NIST shall provide administrative arrangements for the Committee including secretarial services, calling of meetings, arranging for a meeting place, and preparation of an agenda, discussion material, and reports.

3. The Committee shall meet at least three times each year. Other meetings may be called at the discretion of the Chair or at the written request of five (5) members of the Committee.

4. The Committee may establish task groups as appropriate.

5. Attendance at Committee meetings by at least one-half of the designated members of the Committee shall constitute a quorum. Decisions internal to the Committee's operations, such as formation of a task group, shall be made by a majority of those present and voting. Voting on Committee business and proposals shall be limited to designated agency members. Decisions concerning Committee recommendations to the Secretary of Commerce on governmental policy or other matters set out in paragraph two of the section entitled "Functions" shall require ratification by two-thirds of the members present and voting. Dissenting positions of the decision may be made a matter of record. The Chair shall not vote except in the case of a tie vote.

6. The annual cost of operating the Committee is estimated at $\$ 31,000$ (with overhead) which includes 0.20 staff year for staff support. 
7. The Committee shall submit an annual report to the Secretary of Commerce so that the Secretary may satisfy the reporting requirements set forth in OMB Circular No. A-119, as applicable to the Secretary, and in P.L. 104-113, as applicable to the head of each agency. Each such report shall also summarize the Committee's activity during the period covered and shall include a listing of all recommendations formulated by the Committee during that period.

\title{
$\underline{\text { Duration }}$
}

The need and mission of the Committee shall be reexamined three years after the date of this Charter to determine the need for the Committee's continuation.

\author{
/signed/ \\ Secretary of Commerce
}

Dated: October 29, 1997 


\section{Appendix D:}

\section{Membership of the \\ Interagency Committee on Standards Policy (ICSP) \\ Fiscal Year 1999}




\section{AGENCY MEMBER}

$\underline{\text { Agency for International Development, U.S. (USAID) }}$

$\underline{\text { Agriculture, Department of (USDA) }}$

Commerce, Department of (DOC)

$\underline{\text { Consumer Product Safety Commission (CPSC) }}$

Alternate:

Defense, Department of (DOD)

Alternate:

\section{REPRESENTATIVE}

Ms. Kathleen O'Hara

Acting Deputy Director, Office of Procurement

U. S. Agency for International Development

Ronald Reagan Building

Washington, DC 20523-7804

Phone: 202-712-5040

Fax: 202-216-3136

Email: kohara@usaid.gov

Mr. Joseph Leo*

Chief Information Officer

Department of Agriculture

Room 416-W

Jamie L. Whitten Federal Building

1400 Independence Avenue, SW

Washington, DC 20250-7603

Phone: 202-720-8833

Fax: 202-720-1031

Email: joe.leo@usda.gov

*for the FY 1999 reporting period--Anne F. Thomson Reed

Dr. Belinda L. Collins

Director, Office of Standards Services

Department of Commerce

National Institu te of Standards and Technology

100 Bureau Drive, Stop 2100

Gaithersburg, MD 20899-2100

Phone: 301-975-4000

Fax: 301-963-2871

Email: belinda.collins@nist.gov

Mr. Colin B. Church

Voluntary Stnds \& Int 1 Activities Coordinator

Consumer Product Safety Commission

4340 East-West Highway

Room 604-C

Bethesda, MD 20207

Phone: 301-504-0554, x-2229

Fax: 301-504-0407

Email: cchurch@cpsc.gov

Ms. Jacquie Elder

Deputy Assistant Executive Director

Consumer Product Safety Commission

4340 East-West Highway

Room 702

Bethesda, MD 20207

Phone: 301-504-0554, x-2254

Fax: 301-504-0407

Email: jelder@cpsc.gov

Mr. Gregory E. Saunders

Director, Defense Standardization Program Office

Department of Defense

ATTN: DLSC-LM

8725 John J. Kingman Road, Suite 4235

Fort Belvoir, VA 22060-6221

Phone: 703-767-6880

Fax: 703-767-6876

Email: gregory_saunders@hq.dla.mil

Ms. Trudie Williams

Defense Standardization Program Office 
Department of Defense

ATTN: DLSC-LM

8725 John J. Kingman Road, Suite 4235

Fort Belvoir, VA 22060-6221

Phone: 703-767-6875

Fax: 703-767-6876

Email: trudie_williams@hq.dla.mil

Education, Department of (DOEd)

Energy, Department of (DOE)

Alternate:

$\underline{\text { Environmental Pro tection Agency (EPA) }}$

Alternate:
Mr. Gerald Malitz

National Center for Education Statistics

Department of Education

555 New Jersey Avenue, NW

Washington, DC 20208

Phone: 202-219-1364

Fax: 202-219-1728

Email: gerald_malitz@Ed.gov

Mr. Richard L. Black

Director, Office of Nuclear Safety Policy and Standards (EH-31)

Department of Energy

Room A-430, GTN

Washington, DC 20854

Phone: 301-903-3465

Fax: 301-903-6172

Email: richard.black@eh.doe.gov

Mr. Richard Serbu Manager, DOE Technical Standards Program (EH-31) Department of Energy 19901 Germantown Road

Germantown, MD 20874-1290

Phone: 301-903-2856

Fax: 301-903-6172

Email: richard.serbu@eh.doe.gov

Ms. Mary McKiel

Director, EPA Standards Program

Environmental Protection Agency

Office of Prevention, Pesticides \& Toxic Substances

401 M Street, SW, MC 7101

Washington, DC 20460

Phone: 202-260-3584

Fax: 202-260-6906

Email: mckiel.mary@epa.gov

Mr. Craig Annear

Office of General Counsel (232A)

Environmental Protection Agency

401 M Street, SW

Washington, DC 20460

Phone: 202-564-5538

Fax: 202-564-5541

Email: annear.craig@epa.gov 
Federal Communications Commission (FCC)

$\underline{\text { Federal Emergency Manag ement Agency (FEMA) }}$

$\underline{\text { Federal Trade Commission (FTC) }}$

$\underline{\text { General Services Admini stration (GSA) }}$

Alternate:

Government Printing Office, U.S. (GPO)
Mr. Julius P. Knapp

Chief, Office of Engineering and Technology

Federal Communications Commission

1919 M Street, NW

Mail Stop Code 1300

Washington, DC 20554

Phone: 202-418-2468

Fax: 202-418-1944

Email: jknapp@fcc.gov

Dr. Edward Kernan*

Director, Management Division

Information Technology Services Directorate

Federal Emergency Management Agency

500 C Street SW, Room 251 FCP

Washington, DC 20472

Phone: 202-646-2986

Fax: 202-646-3074

Email: edward.kernan@fema.gov

*for the FY 1999 reporting period--Rosetta Bowsky

Mr. Alain Sheer

Director of Marketing Practices

Federal Trade Commission

Bureau of Consumer Protection

6th and Pennsylvania Avenue, NW

Room 4200

Washington, DC 20580

Phone: 202-326-3321

Fax: 202-326-3392

Email: asheer@ftc.gov

Mr. William N. Gormley

Assistant Commissioner

Office of Acquisition, Federal Supply Service (FC)

General Services Administration

1941 Jefferson Davis Highway

Room 710

Arlington, VA 22202

Phone: 703-305-7901

Fax: 703-305-6851

Email: william.gormley@gsa.gov

Mr. Charles P. Gallagher

Director, Environmental \& Engineering Policy (FCOE)

General Services Administration

1941 Jefferson Davis Highway

Room 703

Arlington, VA 22202

Phone: 703-305-6930

Fax: 703-305-6731

Email: charles.gallagher@gsa.gov

Mr. Robert H. Thomas

Manager, Quality Control and Technical Department

U. S. Government Printing Office

North Capital \& H Street

Washington, DC 20401

Phone: 202-512-0766

Fax: 202-512-0015

Email: rthomas@gpo.gov 
$\underline{\text { Health and Human Services, Department of (HHS) }}$

Alternate:

$\underline{\text { Housing and Urban Development, Department of (HUD) }}$

Alternate:

$\underline{\text { Interior, Department of the (DOI) }}$

$\underline{\text { International Trade Commission (ITC) }}$
Ms. Janet J. Showalter*

Director, International Scientific Activities and Standards Staff

Department of Health and Human Services

Food and Drug Administration, HHS

5600 Fishers Lane, Room 15-22, HFY-20

Rockville, MD 20857

Phone: 301-827-0865

Fax: 301-443-0232

Email: jshowalt@oc.fda.gov

*for the FY 1999 reporting period--Linda R. Horton

Dr. John P. Lucas*

Associate Director for Standards

Office of Internation al Programs

Department of Health and Human Services

Food and Drug Administration, HHS

5600 Fishers Lane, Room 15A16, HFG-1

Rockville, MD 20857

Phone: 301-827-0917

Fax: 301-443-0235

Email: jlucas@oc.fda.gov

*for the FY 1999 reporting period--Kathleen Hastings

Ms. Ayse Can Talen*

Deputy Assistant Secretary for Research,

Evaluation, and Monitoring

Office of Policy Development \& Research

Department of Housing and Urban Development

451 7th Street, SW, Suite 8146

Washington, DC 20410

Phone: 202-708-4230, x-3666

Fax: 202-708-3141

Email: Ayse Can Talen@hud.gov

*for the FY 1999 reporting period--Xavier de Souza Briggs

Mr. Roy Mullinax*

Departmental Policy \& Oversight Support

Department of Housing and Urban Development

451 7th Street, SW, Suite 3182

Washington, DC 20410-3600

Phone: 202-708-0614, x-6075

Fax: 202-708-1559

Email: Roy_P._Mullinax@hud.gov

*for the FY 1999 reporting period--Warren Friedman

Mr. David Shearer

Chief, IRM Program Policy Review, and

Standards Division

Department of the Interior

1849 C Street, NW, Mail Stop-5312

Washington, DC 20240

Phone: 202-208-4281

Fax: 202-501-2360

Email: david_shearer@ios.doi.gov

Mr. Stephen A. McLaughlin

Director, Office of Administration

International Trade Commission

Room 414

500 E Street, SW

Washington, DC 20436

Phone: 202-205-3131

Fax: 202-205-2034 
$\underline{\text { Justice, Department of (DOJ) }}$

$\underline{\text { Labor, Department of (DOL) }}$

$\underline{\text { National Aeronautics and Space Administra tion (NASA) }}$

Alternate:

$\underline{\text { National Archives and Records Administration (NARA) }}$

$\underline{\text { National Communications System (NCS) }}$
Dr. M. Wayne Shiveley

Information Management and Security Staff

Department of Justice

1001 G Street, NW, Suite 850

Washington, DC 20530

Phone: 202-305-4107

Fax: 202-616-5455

Email: wayne.m.shiveley@usdoj.gov

Mr. Roland G. Droitsch

Deputy Assistant Secretary for Policy

Department of Labor

Room S 2312

200 Constitution Avenue, NW

Washington, DC 20210

Phone: 202-219-9058

Fax: 202-219-9216

Email: droitsch_roland@dol.gov

Mr. W. Brian Keegan*

National Aeronautics and Space Administration

Mail Code AE

NASA Headquarters

300 E Street, SW

Washington, DC 20546-0001

Phone: 202-358-1823

Fax: 202-358-3296

Email: brian.keegan@hq.nasa.gov

*for the FY 1999 reporting period--Daniel R. Mulville

Mr. Richard H. Weinstein

National Aeronautics and Space Administration

Mail Code AE

NASA Headquarters

300 E Street, SW

Washington, DC 20546-0001

Phone: 202-358-0538

Fax: 202-358-3296

Email: richard.weinstein@hq.nasa.gov

Ms. Mary Ann Hadyka

National Archives and Records Administration

Policy and Communication Staff

Suite 4100

8601 Adelphi Road

College Park, MD 20740-6001

Phone: 301-713-7360, x-222

Fax: 301-713-7270

Email: maryann.hadyka@arch2.nara.gov

Mr. Dale Barr

Chief, Technology and Standards Division

National Communications System

Office of the Manager

701 South Court House Road

Arlington, VA 22204-2198

Phone: 703-607-6200

Fax: 703-607-4830

Email: barrd@ncs.gov 
National Science Foundation (NSF)

$\underline{\text { Nuclear Regulatory Commission (NRC) }}$

Office of Management and Budget (OMB) Liaison

\section{$\underline{\text { Postal Service, U.S. (USPS) }}$}

Alternate:

$\underline{\text { State, Department of (STATE) }}$
Dr. William S. Butcher Senior Engineering Advisor

Engineering Education and Centers Division

National Science Foundation

4201 Wilson Boulevard, Suite 585

Arlington, VA 22230

Phone: 703-306-1380

Fax: 703-306-0289

Email: wbutcher@nsf.gov

Mr. Michael E. Mayfield*

Acting Director, Engineering Technology

Nuclear Regulatory Commission

Office of Nuclear Regulatory Research

Mail Stop T-10D20

Washington, DC 20555-0001

Phone: 301-415-5678

Fax: 301-415-5074

Email: mem2@nrc.gov

*for the FY 1999 reporting period--John W. Craig \& Alternate: Gilbert C. Millman

Mr. Ed Springer*

Office of Management and Budget

Office of Information and Regulatory Affairs

NEOB, Room 10236

Washington, DC 20503

Phone: 202-395-3562

Fax: 202-395-5167

Email: edward_springer@omb.eop.gov

*for the FY 1999 reporting period--Virginia A. Huth

Mr. Charles W. Newman*

Manager, Configuration Management

U.S. Postal Service

Engineering Research and Development

Merrifield, VA 22082-8149

Phone: 703-280-7649

Fax: 703-280-8414

Email: cnewman@email.usps.gov

*for the FY 1999 reporting period--Myles A. Jackson

Mr. Bill Griggs*

Acting Manager, Configuration Management

U.S. Postal Service

Engineering Research and Development

Merrifield, VA 22082-8149

Phone: 703-280-7276

Fax: 703-280-8414

Email: wgriggs@email.usps.gov

*no Alternate for the FY 1999 reporting period

Ms. Marian Gordon

Director for Telecommunications and

Information Standards

Department of State

2201 C Street, NW, Room 2529

Washington, DC 20520

Phone: 202-647-0197

Fax: 202-647-7407

Email: gordonmr@state.gov 
Mr. Julian Minard*

Department of State

$\mathrm{EB} / \mathrm{CIP} / \mathrm{MA}$

2201 C Street, NW, Room 2529

Washington, DC 20520

Phone: 202-647-0965

Fax: 202-647-7407

Email: minardje@state.gov

*no Alternate for the FY 1999 reporting period

$\underline{\text { Transportation, Department of (DOT) }}$

Alternate:

$\underline{\text { Treasury, Department of (Treasury) }}$

Meeting Correspondence to:

$\underline{\text { U.S. Trade Representative (USTR) }}$
Ms. Kate Hallahan*

Office of the Deputy Secretary

Department of Transportation 400 Seventh Street, SW

Suite 10200

Washington, DC 20590

Phone: 202-366-2222

Fax: 202-366-7202

Email: kate.hallahan@ost.dot.gov

*for the FY 1999 reporting period--Julie Abraham

Ms. Julie Abraham

Director of International Harmonization

National Highway Traffic Safety Administration Department of Transportation

400 Seventh Street, SW

Suite 5208

Washington, DC 20590

Phone: 202-366-2114

Fax: 202-366-2559

Email: jabraham@nhtsa.dot.gov

Mr. James J. Flyzik

Deputy Assistant Secretary (Information

Systems) \& Chief Information Officer

Department of Treasury

1500 Pennsylvania Avenue, NW

Room 2464

Washington, DC 20220

Phone: 202-622-1200

Fax: 202-622-2224

Email: jim.flyzik@cio.treas.gov

Mrs. Helen W. Whatley

Office of Information Resources Management

Department of Treasury

1425 New York Avenue, NW

Washington, DC 20220

Phone: 202-622-1541

Fax: 202-622-1595

Email: helen.whatley@cio.treas.gov

Ms. Suzanne Troje

Director, Technical Trade Barriers

U.S. Trade Representative

600 17th Street, N.W.

Washington, DC 20508

Phone: 202-395-9444

Fax: 202-395-5674

Email: stroje@ustr.gov 
Veterans Affairs, Department of (VA)

Alternate:

$\underline{\text { National Institu te of Standards and Technology (NIST) }}$

$\underline{\text { National Institu te of Standards and Technology (NIST) }}$

National Institu te of Standards and Technology (NIST)

$\underline{\text { National Institu te of Standards and Technology (NIST) }}$

$\underline{\text { National Institu te of Standards and Technology (NIST) }}$
Mr. Gary J. Krump

Deputy Assistant Secretary for Acquisition \&

Material Management (90)

Department of Veterans Affairs

810 Vermont Avenue, NW

Washington, DC 20420

Phone: 202-273-6029

Fax: 202-273-6163

Email: krugar@mail.va.gov

Mr. Pierre Lundy

Department of Veterans Affairs

810 Vermont Avenue, NW

Washington, DC 20420

Phone: 202-273-6102

Fax: 202-273-6236

Email: pierre.lundy@mail.va.gov

Ms. Maureen Breitenberg

National Institu te of Standards and Technology

100 Bureau Drive, Stop 2100

Gaithersburg, MD 20899-2100

Phone: 301-975-4031

Fax: 301-963-2871

Email: maureen.breitenberg@nist.gov

Mr. David Alderman

National Institu te of Standards and Technology

100 Bureau Drive, Stop 2140

Gaithersburg, MD 20899-2140

Phone: 301-975-4171

Fax: 301-926-2884

Email: david.alderman@nist.gov

Mr. Patrick Cooke

National Institu te of Standards and Technology 100 Bureau Drive, Stop 2150

Gaithersburg, MD 20899-2150

Phone: 301-975-4033

Fax: 301-926-1559

Email: patrick.cooke@nist.gov

Ms. Krista Johnsen-Leuteritz National Institu te of Standards and Technology 100 Bureau Drive, Stop 2100

Gaithersburg, MD 20899-2100

Phone: 301-975-5104

Fax: 301-963-2871

Email: krista.leuteritz@nist.gov

Ms. JoAnne Overman

National Institu te of Standards and Technology 100 Bureau Drive, Stop 2150

Gaithersburg, MD 20899-2150

Phone: 301-975-4037

Fax: 301-926-1559

Email: joanne.overman@nist.gov 



\section{APPENDIX E:}

\section{LIST OF NIST PUBLICATIONS RELATED TO P. L. 104-113}




\title{
STANDARDS AND CONFORMITY ASSESSMENT RELATED PUBLICATIONS
}

\author{
Office of Standards Services \\ National Institute of Standards and Technology \\ Gaithersburg, Maryland 20899-2100
}

\section{NTTAA PUBLICATIONS:}

The National Technology Transfer and Advancement Act - Plan for Implementation (NISTIR 5967)

Toward a National Standards Strategy - Conference Report (NISTIR 6290)

Toward A National Standards Strategy: Conference Summary Report (NISTIR 6259) by

Walter G. Leight and Krista J. Johnsen Leuteritz, published September 23, 1998

Towards Strategic Management of Standards Activities at NIST (NISTIR 6292)

Conference on Using Voluntary Standards in the Federal Government - September 8, 1997

Using Voluntary Standards in the Federal Government (NISTIR 6086)

1998 Federal Standards Workshop: Standards Management - A World of Change and Opportunities Conference Handbook -- A joint DOE, NIST, EPA, NASA, Partnership in RMS, FDA publication

1998 Federal Technical Standards Workshop Proceedings (CONF-980822) A joint DOE, NIST, EPA, NASA, Partnership in RMS, FDA publication

\section{INTRODUCTORY PUBLICATIONS ON STANDARDS AND CONFORMITY} ASSESSMENT ACTIVITIES:

The ABC's of Standards-Related Activities in the United States (NBSIR 87-3576)

The ABC's of Certification Activities in the United States (NBSIR 88-3821)

The ABC's of the U.S. Conformity Assessment System (NISTIR 6014)

Laboratory Accreditation Activities in the United States (NISTIR 4576)

Questions and Answers on Quality, the ISO 9000 Standard Series, Quality System Registration, and Related Issues (NISTIR 4721) 
More Questions and Answers on the ISO 9000 Standard Series and Related Issues (NISTIR 5122)

The U.S. Certification System from a Governmental Perspective (NISTIR 6077)

ISO Environmental Management Standardization Efforts (NISTIR 5638-1)

\section{NACLA PUBLICATIONS:}

Report on the Open Forum on Establishment of the National Council for Laboratory Accreditation (NAC LA) at the National Institute of Standards and Technology, January 7, 1997 (NISTIR 6008)

Examination of Laboratory Accreditation Programs in the United States and the Potential Role for a National Laboratory Accreditation System (NIST GCR 97-714)

Proceedings of the Open Forum on Laboratory Accreditation at the National Institute of Standards and Technology, October 13, 1995 (NIST SP 902)

\section{DIRECTORIES:}

Directory of International and Regional Organizations Conducting Standards-Related Activities (NIST SP 767)

Directory of European Regional Standards-Related Organizations (NIST SP 795)

Standards Activities of Organizations in the United States (NIST SP 806, 1996 Edition)

Directory of Federal Government Certification and Related Programs (NIST SP 739, 1999 Edition)

Directory of U.S. Private Sector Product Certification Programs (NIST SP 903)

Directory of Federal Government Laboratory Accreditation/Designation Programs (NIST SP 808)

Directory of State and Local Government Laboratory Accreditation/Designation Programs (NIST SP 815)

Directory of Professional/Trade Organization Laboratory Accreditation/Designation Programs (NIST SP 831)

Standards Setting in the European Union - Standards Organizations and Officials in EU Standards Activities (NIST SP 891, 1997 Edition) 
Profiles of National Standards-Related Activities (NIST SP 912)

An Overview of the Development of Technical Infrastructure in the Asia-Pacific Region: The Work of the Asia-Pacific Economic Cooperation (APEC) Sub-committee on Standards and Conformance (SCSC) and the Specialist Regional Bodies (SRBs) (NISTIR 6325)

Free Trade Area of the Americas (FTAA) Conformity Assessment Infrastructure (NIST SP 941)

Semi-Annual Listing of North American Quality System Registration Organizations (NAQSRO) Annual Directory of DOC Memberships on Outside Standards Committees

\section{NVLAP PUBLICATIONS:}

NIST Handbook 150: NVLAP Procedures and General Requirements

Directory of Accredited Laboratories

NVLAP Program-Specific Handbooks

NVLAP Policy Guides:

PG-1-1998: NVLAP Traceability Policy (March 1998)

PG-2-1998: Accreditation Documents for Laboratories Whose Accreditation Has Been Suspended, Revoked, or Otherwise Terminated (May 1998)

PG-3-1999: Delegation of Authority from the Director of NIST to the Chief of NVLAP

(November 1999)

NVLAP NEWS:

Summer/Fall 1999

Winter 1999

Summer/Fall 1998

Winter/Spring 1998

Summer/Fall 1997 


\section{MISCELLANEOUS PUBLICATIONS:}

TBT Agreement Activities of the National Institute of Standards and Technology

Environmental Management Systems Voluntary Project Evaluation Guidance (NISTIR 6120)

A Selective Review of Testing Laboratory Accreditation Movements in the United States (NIST GCR 98-740)

Survey on the Implementation of ISO/IEC Guide 25 by National Laboratory Accreditation Programs (NISTIR 5473)

Government s Role in Standards-Related Activities: Analysis of Comments (NISTIR 4367)

\section{MAGAZINE ARTICLES:}

Leight, W.G., Collins, B.L., Setting the Standards. Mechanical Engineering, 122, No. 2, February 2000, pp. 46-52.

Collins, B.L., A Standards Infrastructure for the Future. Enjeuex, 200, January 2000, pp. 63-74.

Collins, B.L., Federal Government Coordination on Standards - The Role of NIST and the Interagency Committee on Standards Policy. The Standards Forum, $\underline{7}$, No. 3 , December 1999, pp. 1, 15-16.

Collins, B.L., Standards and Government Regulations in the United States. Warnings and Risk Communications, Chapter 12. Taylor and Francis Ltd., 1999.

Collins, B.L., Federal Government Coordination on Standards - The Role of NIST and the Interagency Committee on Standards Policy. ASTM Standardization News, 27, May 1999, pp. 20-21.

Collins, B.L., Update on the activities of the National Cooperation for Laboratory Accreditation. Accreditation and Quality Assurance: Journal for Quality, Comparability and Reliability in Chemical Measurement, $\underline{3}$, September 1998, pp. 351-355.

Collins, B.L., National Cooperation of Laboratory Accreditation, Radioactivity \&

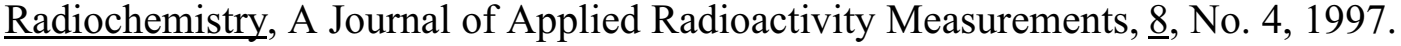

Collins, B.L., NIST to Lead in NTTAA Implementation. ANSI Reporter, April 1997, p. 3.

Collins, B.L., The National Technology Transfer and Advancement Act - Plan for Implementation. NISTIR 5967, January 1997. 
Collins, B.L., National Cooperation of Laboratory Accreditation. CIRMS Annual Meeting Abstracts, Radioactivity \& Radiochemistry, $\underline{8}$, 1997, pp. 16-17.

Collins, B.L., Laboratory Accreditation: The Need for a National Infrastructure. $\underline{\text { Cal Lab, }}$ November-December 1996, pp. 18-22.

Collins. B.L., Helping Reduce Technical Barriers to Trade. Proceedings of CPSC Conference on Bringing Standards Together: An International Framework. July 18, 1996, pp. 48-53.

Collins, B.L., The Consensus Process in Standards Development. Proceedings of the Joint Conference on Standard Setting in Large-Scale Assessments. 1995, pp. 203-219.

Breitenberg, M., Conformity Assessment: An Important Policy Issue, ASTM Standardization News, November 1997, pp. 20-23.

Johnsen Leuteritz, K., Toward Strategic Management of Standards Activities at NIST, ASTM Standardization News, December 1999, cover article. Reprinted in DOE s "The Standards Forum," March 2000.

Leight, W. G., Preserving the Miracle, Partnership in RMS Standards: A Newsletter for Professionals, January 2000, pp. 1-6. 